\title{
NOTHINGNESS
}

\section{AN EXPLORATION OF DISSOLVING ARCHITECTURE}

\author{
Jessica Stanford
}

A design research thesis presented to Ryerson University in partial fulfillment of the requirements for the degree of Master of Architecture in the Program of The Department of Architectural Science Toronto, Ontario, Canada, 2013

(C) Jessica Stanford 2013 

I hereby declare that I am the sole author of this thesis. This is a true copy of the thesis, including any required final revisions, as accepted by my examiners.

I authorize Ryerson University to lend this thesis to other institutions or individuals for the purpose of scholarly research.

I further authorize Ryerson University to reproduce this thesis by photocopying or by other means, in total or in part, at the request of other institutions or individuals for the purpose of scholarly research.

I understand that my thesis may be made electronically available to the public. 



\title{
Nothingness An Exploration of Dissolving Architecture
}

\author{
Jessica Stanford \\ Master of Architecture | 2013 \\ Department of Architectural Science
}

Ryerson University

\section{abstract}

This thesis explores the idea of nothingness from a variety of perspectives in order to better understand how this notion might manifest in architecture. Taking the critiques of objectification and architectural worthlessness by Dejan Sudjic and James Howard Kunstler as points of departure, the research involved an examination of spiritual and philosophical traditions dealing with nothingness, including the traditional ideas of Buddhism and the phenomenological and existential perspectives that developed in the twentieth century. Research into artistic and architectural manifestations of these perspectives provided important examples of how the abstract idea of nothingness could be translated from a purely analytical to a projective practice. Through a series of experiments on nothingness and space, a technique was developed to produce architecture in a thoughtful and meaningful manner rather than to produce the architectural garbage, the unconscious architecture, the visible entropy that Kuntsler and others refer to. Ultimately, however, nothingness can act as an architectural device that distills an idea - it is the pause in the chaotic life of consumption, the still point in a turning world. 



\section{acknowledgements}

To my supervisor, Marco Polo: Thank you for unlocking these ideas out of my mind, for encourging me to pursue them, for helping me transform them into a written document, and for giving me the motivation to not let them go.

To Cheryl Atkinson and John Cirka: you have both greatly helped in shaping this thesis and any ideas associated with it. Your support and encourgement has made my graduate education a fantastic experience and I cannot thank you enough.

To all professors who have given me words of encourgement or indulged in a debate or dicussion with me - thank you for helping me define and pursue my ideas. You have all made a lasting impact.

To my friends, from both home and away, thank you for your support and patience.

Lastly, this thesis could not have been completed without the full time support of my family. To my father, mother, and sister: thank you for providing me with undeniable love and support, not just through the undertaking of this thesis, but for the entirety of my academic career. My successes are yours, always. 

For Poppy.

ix 



\section{table of contents}

unconscious architecture

the lost avant-garde

the experience of meaning

how, then, can architecture

be made to disappear?

ideas on nothingness

experiments

conclusions

bibliography
V

xiii

1

7

19

27

35

47

53

85

155

161 



\section{list of figures}

1. Banksy - The Joy of Not Being Sold Anything, 2012

(http://www.brandnewmedia.co.uk/2012/02/29/the-joy-of-not-being-sold-any

thing/)

2. Barbara Kruger - I shop therefore I am, 1987.

(http://www.maryboonegallery.com/artist_info/pages/kruger/detail1.html)

3. The real Venice (author's photo) \& the Fake Venice (http://purpleroofs.com/gay-travelblog/2010/09/purple-roofs-travels-three-nights-in-gay-las-vegas.html)

4. Unconscious Architecture.

5. Superstudio, The Continuous Monument, 1969.

(http://www.megastructure-reloaded.org/superstudio/)

6. Superstudio, Twelve Ideal Cities, 1972

(http://designmuseum.org/_entry/4279?style=design_image_popup)

7. Mies van der Rohe, The Resor House,1937-38

(http://www.etsavega.net/dibex/Mies_Resor-e.htm)

8. Mies van der Rohe, The Barcelona Pavilion,1937-38

(http://noonjes.wordpress.com/tag/barcelona-pavilion/)

9. SANAA, Serpentine Pavilion, 2009.

(http://www.archdaily.com/28672/the-2009-serpentine-gallery-pavilion-sanaa/)

10. SANAA, Louvre, Lens, 2012.

(http://archrecord.construction.com/news/2012/11/121128-SANAA-Louvre-Lens. asp)

11. Junya Ishigami, Architecture as Air, 2010.

(http://www.domusweb.it/en/architecture/2011/08/03/architecture-as-air-chateaula-coste.html) 
12. Gijs Van Vaerenbergh, Reading Between the Lines, 2011.

(http://www.archdaily.com/298693/reading-between-the-lines-gijs-van-vaeren bergh/)

13. Yves Klein, Le Vide (The Void), 1958.

(http://monstermadeofeyes.tumblr.com/post/2407047940/ataleofafewcities-yvesklein-in-the-void)

14. Yves Klein, Le Saut dans le Vide (Leap into the Void), 1960.

(http://www.retronaut.com/2013/03/yves-kleins-leap-into-the-void/)

15. John Cage, Score for 4'33", 1952.

(http://www.forbes.com/sites/jonathonkeats/2013/01/14/did-john-cage-inventsilence/)

16. Zion + Breen, Paley Park, NYC, 1967.

(http://www.flickr.com/photos/88017382@N00/7799724746/)

17. DGT, Luce Tempo Luogo, 2011.

(http://www.dgtarchitects.com/project/detail/it05/en\#8)

18. DGT, Luce Tempo Luogo, 2011.

(http://www.dgtarchitects.com/project/detail/it05/en\#4)

19. Mary Miss, Perimeters, Pavilions, Decoys, 1978.

(http://clconleyarhs4973.wordpress.com/2013/02/09/the-nature-of-art-objectsmaterials-and-processes/)

20. Diller Scofidio + Renfro, Blur Building, 2002.

(http://www.dsrny.com)

21. Diller Scofidio + Renfro, Blur Building Interior, 2002.

(http://www.dsrny.com)

22. Transsolar + Tetsuo Kondo, Cloudscapes, 2010.

(http://www.tumblr.com/tagged/transsolar?language=ja_JP) 
23. Transsolar + Tetsuo Kondo, Cloudscapes, 2010.

(http://www.designboom.com/architecture/transsolar-tetsuo-kondo-architectscloudscapes-at-venice-biennale/)

24. Map of installation, Architecture Building, Ryerson University.

25. On Nothingness, installation, 2012.

26. Times Square, New York City.

27. Dundas Square, Toronto.

28. Piccadilly Circus, London.

29. Interior view of observatory at night.

30. Section through potential observatory space.

31. Window looking to the north.

32. List of terms.

33. Context map - City of Toronto, downtown.

34. Site map.

35. Intervention diagram.

36. Context of Queen Street W. (from John to Spadina) - South (above), North (below).

37. View of existing site looking North.

38. View of existing from above looking North.

39. View of existing site looking East.

40. View of existing site looking South.

41. Site Plan

42. Looking North to Queen Street West.

43. Looking East along Queen Street West.

44. Transverse section looking North.

45. Light detail.

46. Bench detail. 
47. Water detail.

48. Looking South through the site.

49. Looking North through alleyway to Richmond Street West.

50. Looking East through site.

51. Looking up.

52. Sectional view looking West: summer.

53. Sectional view looking West: winter.

54. Daylight study with model.

55. 1:50 scale model of site and intervention.

56. 1:50 scale model - view looking South.

57. 1:50 scale model - views through the site.

58. 1:100 scale massing model

59. 1:1 scale model - detail of lattice pattern. 


There is a shock more profound than any action, when nothing is a consequence of a provocation.

Gustav Metzger, artist/political activist 



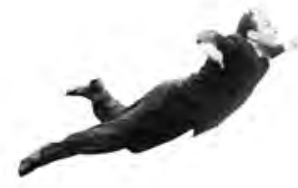



a leap into the void 

If design is merely an inducement to consume, then we must reject design; if architecture is merely the codifying of the bourgeois models of ownership and society, then we must reject architecture; if architecture and town planning is merely the formalization of present unjust social divisions, then we must reject town planning and its cities - until all design activities are aimed towards meeting primary needs.

Until then design must disappear. We can live without architecture.

Adolfo Natatlini of Superstudio - Lang \& Menking, 2003

Living, as we do, in a world overwhelmed by objects run by a society in a continuous state of consumption and ultimately, as a result, producing architecture that directly reflects these sort of conditions - perhaps we should reconsider Natalini's suggestion, even though it's forty years out of context. Rather than inject more banal objects into the world, rather than unconsciously design buildings as thoughtless creations produced at a bare minimum, architecture today should instead dissolve into nothingness. It should attempt to reject its object-ness, attempt to distill itself down to almost nothing, and eventually form a new relationship with its surroundings to become an architecture that is thoughtful and meaningful by nature. This isn't necessarily anti-architecture nor is it 
necessarily a nihilistic approach but rather the idea is to use nothingness as an expression of resistance, as a pause in a chaotic world, and as a method of creating meaning without becoming yet another banal object for the world to ultimately consume. An exploration of nothingness through architecture attempts to do just that - to slow the chaos of the world and distill it in slow motion to reveal a pause; a still point in a turning world brought into the realm of experience through the careful, edited, and restrained work of the architect as mediator.

Nothingness is not nothing. It is this fact that makes nothingness so alluring, so interesting, and, most importantly, so meaningful. The writer and art critic Lucy Lippard once wrote that if nothingness was "the absence of presence... it has become clear that [it] can assume a resonant presence if properly manipulated....in a zen sort of way, [it] ends up by coming full circle into everything... [it] is a form of utopia" (Lippard, 2009, p. 228). Only once nothingness is understood and experienced can it become far more than it seems to entail. In the 1960s, Yves Klein gave himself completely over to the 'other,' leaping fearlessly from the rooftop of a house in the Parisian suburb of Fontenay-auxRoses in his piece Leap into the Void (Figure 14). Though this work was seamlessly edited, the photo represents an act against the norm and an acceptance of nothingness; it is a leap into the 'other.' Perhaps, like Klein's final work, it is time for architecture to leap into the void, into a realm of nothingness. 


notes on the object 

We've never had as many possessions as we do now. Our homes are filled with designer sofas we never sit on, top of the line ovens that we never bake in, beautiful books that we never read, and endless forms of technology that we consistently replace (Sudjic, 2008). Deyan Sudjic, director of the Design Museum in London, claims that we are a world drowning in our objects - a world where these 'things' are the "consolations for the incessant pressures on us to have the means to buy them" and, as Sudjic comments, "they infantilize us in our pursuit of them" whether or not these objects are beautiful, witty, ingenious, sophisticated, or crude and banal (Sudjic, 2008, p.5). We consume them because they have an altruistic appeal. We often feel like we are doing something good when we buy them - convincing ourselves that the next purchase is an investment or that purchasing yet another winter coat will keep us warmer than our last. We buy as a means to feel better, we buy to achieve social status, as a habit, and sometimes out of necessity. In this way, there's no end to our constant consumption: "like geese force fed grain until their livers explode, to make foie gras, we are a generation born to consume" though unlike the geese panicking at the sight of the metal funnel, we welcome it and fight the others for our turn at the trough that "provides us with the never-ending deluge of objects that constitutes our world" (Sudjic, 2008, p. 6). No matter how much we have it seems that we always want something more, something better, 


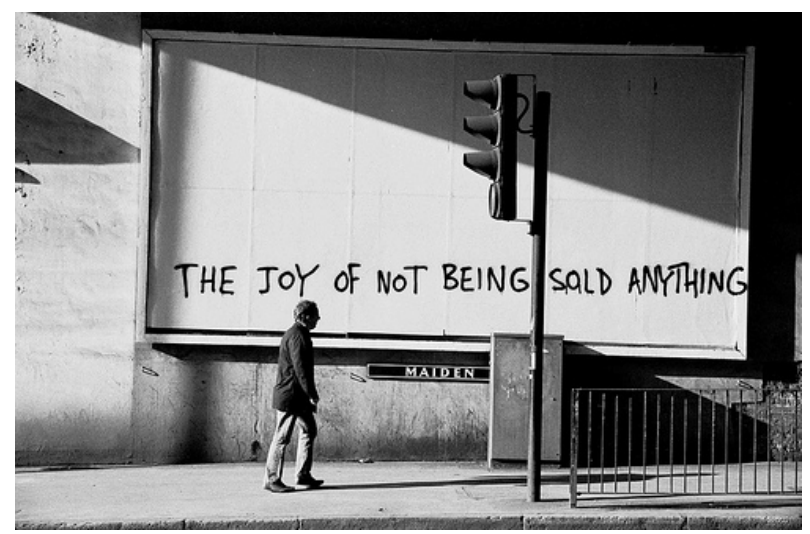

1. Banksy - The Joy of Not Being Sold Anything, 2012.

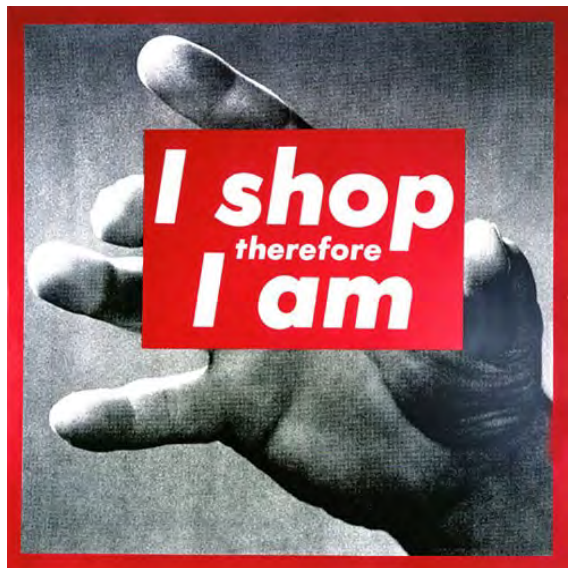

2. Barbara Kruger - I shop therefore I am, 1987. 
something faster and those responsible for selling us these objects certainty don't hold back from trying to lure more objects into our lives. Beyond physically attaining more objects, we also want more out of them. We have cell phones that can do much more than place a call, refrigerators that are also televisions that are also grocery lists that can also access the Internet. Our relationship with our objects is total - our reality deeply involves the objects which we consume combined with our un-ending desire for more, for better, or for faster, and that is equally fueled by an unending and ever-growing cycle of objects delivered/ advertised/promoted to us by the many companies that keep this consumer culture in motion. In fact, in nearly every aspect of our lives something is being advertised to us - pop-up ads on the internet, ads filling every second page in magazines and newspapers, billboards and signs on streets, ads plastered on public transit - everywhere and anywhere companies will take advantage of space to attempt to sell you something you likely don't want, paying nearly any price demanded by those who will host them. Artists have long taken on this subject in their work. One may think of Duchamp's urinal or Warhol's soup cans as art associated with the culture of consumption. A more recent example is the work of the graffiti artist Banksy who, in an act of guerilla art, spraypainted the phrase "the joy of not being sold anything" over an empty billboard in Bankside, London as a demonstration of the overwhelming effect that these ads have upon us (Figure 1). Likewise, Barbara Kruger created an untitled piece by collaging a hand holding a sign with the 
phrase "I shop therefore I am" reflecting upon the power and status that we ascribe to the objects we consume (Figure 2). It is clearly evident that we are not only suffocating from the deluge of objects brought upon ourselves but also from the deluge of propaganda forced upon us to increase our consumption and ensure our suffocation does not fail.

As a result, we are, as lan Bogost claims, "living in a tiny prison of our own devising, one in which all that concerns us are the fleshy beings that are our kindred and the stuffs with which we stuff ourselves" (Bogost, 2012, p. 3). Yet, this idea goes well beyond Bogost's prison since it seems that within the state of current affairs there is not much hope (or any conceived thought of such) to escape. In reality, to the majority of our society this is no prison at all but an Eden filled with all the apparent joys of life. There seems to be no despair over the endless toys we own but just more excitement when something new is released; we will stand, and even camp out, in lines for days in order to be the first to get the newest piece of technology even though the one we currently own works just fine. We can create innumerable objects so that if one were ever to break or be lost, we can find another - anywhere in the world and likely within a few hours - to replace it. We are drowning in a world of 'aluminum atrocities,' cheap re-creations, and illusion-induced indulgences coupled with a complete immersion of advertisements convincing us to buy them again and again (Frampton, 1982). We seem to completely and unquestioningly accept this reality. Have we become 
a society where we are more obsessed with the things we can create than the things which exist outside of our own creation? Are we a culture lost in the fetishism of the object?

In Travels in Hyperreality, Umberto Eco expands on this idea claiming that "Disneyland tells us that technology can give us more reality than nature can" - if things exist, they do so only for us (Eco, 1990, p. 44). As a society, we no longer want the real, we no longer value it - we disregard real experiences and prefer fabricated ones that mimic it, simulacra: hyperreality versus reality. In this world it is possible to go to Venice without actually going to Venice because a significant portion of it is replicated at the Venetian Hotel in Las Vegas, except there it's even better than the real Venice since it is all so well controlled (or designed) for your viewing and using pleasure - the canals are cleaner, the buildings look newer, and it is all under a perpetually sunny ceiling (Figure 3). As Ada Louis Huxtable points out, "the outrageously fake fake has developed its own indigenous style and lifestyle to become a real place" and the people who make these fakes "have perfected the spirit of informed ludicrousness and outer-edge spectacle that mark the best of these undertakings" (Huxtable, 1997, p. 75). Eco agrees, claiming that "the 'completely real' becomes identified with the 'completely fake' [where] absolute unreality is offered as real presence" (Eco, 1990, p. 7). "With reality voided and illusion preferred, almost anything can have uncritical acceptance" where "escalating 

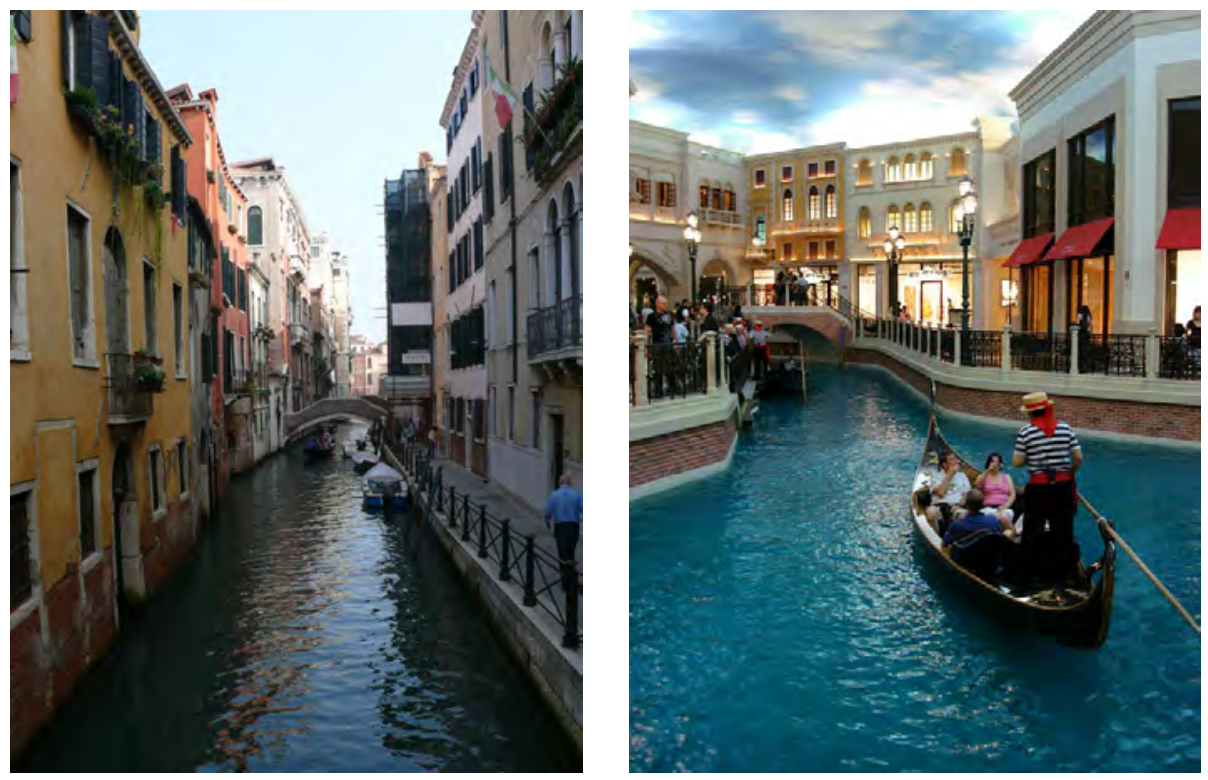

3. The real Venice (left) and the 'fake' Venice at Las Vegas (right). 
sensation supplants intellectual and aesthetic response ... [and] above all, one must be able to buy sensation and status; the experience and the products must be for sale" (Huxtable, 1997, p. 88). Each object, each product is calculatingly designed to evoke a particular emotion, sensibility or atmosphere - and architecture does not escape this. As a result of our consumerist and hyperrealist behavior, we've lost our sense of value - we are a society that seems to be stuck in a continual cycle of the bare minimum, of the minimum quality in exchange for an excess of quantity, where neither the designer nor the public demands anything better.

As a result, society is, at present, a consumer society. We live within a machine of consumption where nothing escapes and everything exists in a continual cycle, where ideas are proposed, created and then consumed, where objects that define who we think we are drown our worries and concerns and where an ever-hungry society is only more than happy to capitulate to a never-ending cycle of indulgence. The art critic Hans Ulrich Obrist refers to this concept as the consensus machine, a machine that he describes as the act of continual acceptance based on a supposed majority lacking the will to escape or think against the norm (Miessen and Basar, 2006). Hannah Arendt also describes this condition claiming that "civilization tends to be increasingly embroiled in a never-ending chain of 'means and ends' [wherein] the 'in order to' has become the content of the 'for the 
sake of": utility established as meaning generates meaninglessness" (Frampton, 1982, p. 79). In Disabling Professions, Ivan Illich further advances Obrist's consensus machine arguing that professionals themselves are holding society captive in a consensus, that "life is paralyzed in permanent intensive care" (Illich, 1977, p. 27). Worse yet, it seems impossible to conceive that this is even happening since "professionalism is a powerful ritual which generates credence in the thing it does," leaving a thoughtless society to entirely accept the decisions being made (Illich, 1977, p. 28). Illich summarizes the effect of this by claiming that "man ceases to be one of his own kind when he can no longer shape his own needs by the more or less competent tools that his culture provides" (Illich, 1977, p. 31). The current state of our society is one that is held captive by the very things that it creates. We are unconsciously stuck in the tangles of a preconditioned society where we lack the ability to even question the society itself, no longer possessing the skill of critique and replacing it with an aptitude for mass consumption.

The profession of architecture, like everything else, has and always has been part of the machine, and it is here that it currently holds itself captive. As citizens of this society, we are ourselves responsible for the consensus in which we are stuck - one where creating massive big box centres, for example, is an acceptable creation of the built form rather than one that must be improved upon. Our society seems to be 
more of a suppressed body of people so self-indulged in consumption that we lack the ability for or are unwilling to assume a critical outlook on the world - an old idea if we remember Socrates' contention that the unexamined life is not worth living (Kraut, 2009). As a society, and as Socrates predicted, we are unwilling to come to terms with the reality of our lives and thus critique it, make improvements upon it, create delight, and, ultimately, attempt to do better. This unwillingness creates an architecture that is mostly unconscious, uncritical, unaware, and thoughtless. 

unconscious architecture 

The term unconscious [adjective] refers to lacking awareness and the capacity for sensory perception; occurring in the absence of conscious awareness or thought; lacking normal awareness of the environment, or insensible (Oxford English Dictionary, 1971). When applied to architecture it refers to the lack of awareness or capacity for thought occurring in the design of buildings, resulting in thoughtless pieces of work - it's architecture as things, as objects to be simply consumed with no consideration for the social, cultural, physical, or environmental impact (or lack thereof) of the design itself (Figure 4). James Howard Kunstler discusses unconscious architecture as part of a lecture delivered at a TED Conference when he claims that the "immersive ugliness of our everyday environments is entropy made visible. We can't overestimate the amount of despair we are generating with places like this. Mostly, I want to persuade you that we have to do better if we're going to continue the project of civilization" (Kunstler, 2004). Going on to claim that these are places that are not worth caring about, Kunstler's argument is not far from the truth. Why do we create and then tolerate these places of worthlessness, of architectural garbage?

Many, but not all, architectural practices are producing work without really thinking beyond that work or considering the consequences in the longer term - the work lacks thought, it lacks any sense of 


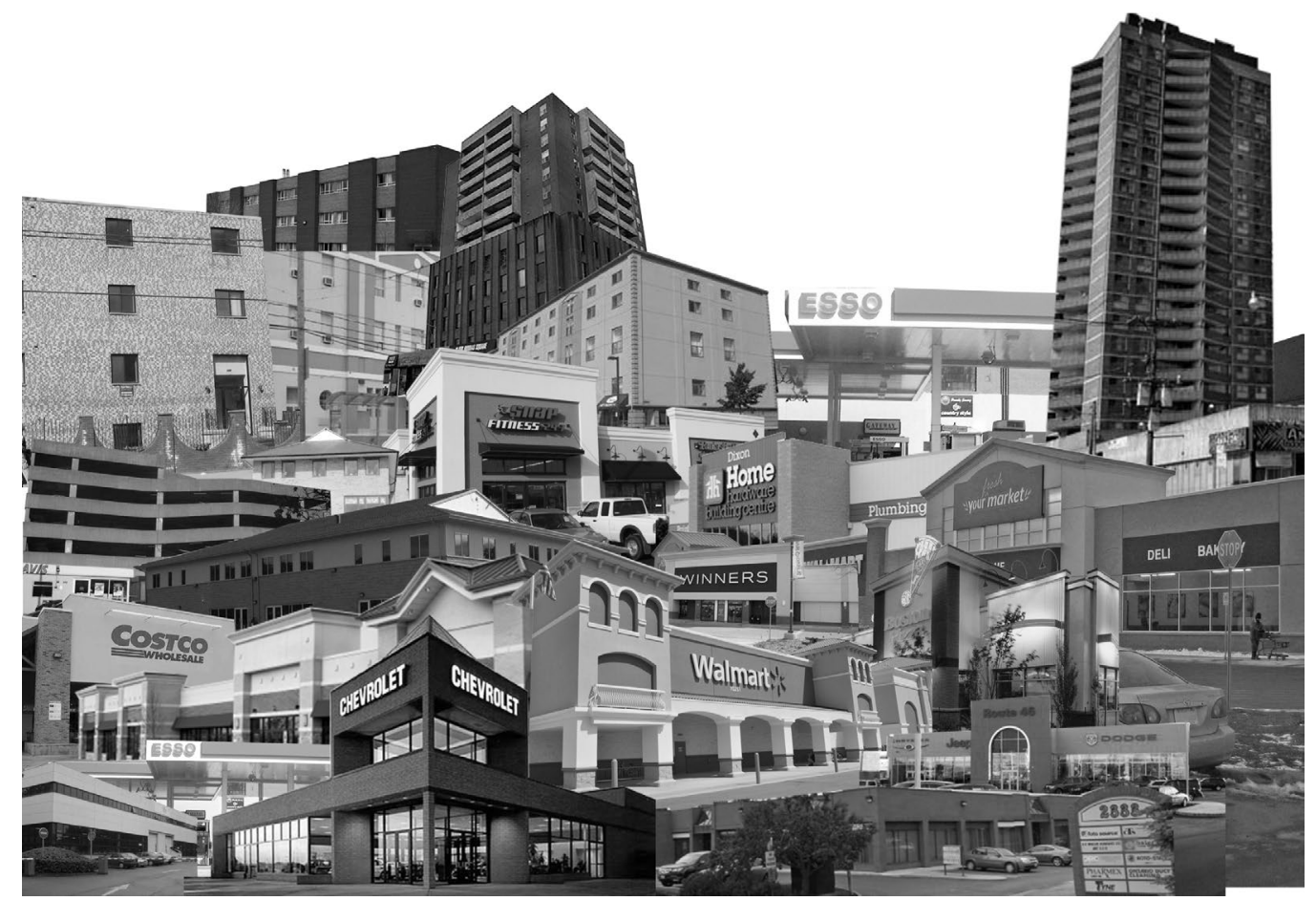

4. Unconscious architecture. 
what something could be other than what it is already - it is often unconsciously designed. It seems that many firms are caught in Obrist's consensus machine - it is this very act that is responsible for creating the unconscious built form. It is a rather unfortunate reality in which "architecture has surrendered its capacity to imagine, to propose, or to construct alternative realities" (Allen, 1999, p. 50). Instead, many architecture firms are practicing architecture under a veil of unconsciousness where decisions are made based upon money, attitude, position or the taste of a supposed majority (Miessen, 2010). However, under this type of system, as Markus Miessen points out, "hardly anyone seems to have the guts to step out of line" and question exactly what's going on (Miessen, 2010, p. 45). These architects are practicing architecture at a bare minimum, doing enough decent work so that, as Alain Badiou describes, it is a non-evil: good enough to not be considered bad but not necessarily better either - it is essentially just enough to get by (Badiou, 2001). What Badiou is referring to is the same as what Illich and Kunstler are describing - that our society (and architecture as a reflection of it) has become quite unconscious. We have accepted mediocrity. With Illich's concept of false professional credence guiding a society astray or lacking the willingness to care about society beyond Kunstler's architectural garbage, our architecture is a reflection of a society that no longer cares. 
The reality is that architecture is dependent. It is a discipline, practice and profession that is almost completely dependent on forces outside of its own control. As Jeremy Till describes in his book Architecture Depends, "architecture is thus shaped more by external conditions than by the internal processes of the architect... [it is] defined by its very contingency, by its very uncertainty in the face of these outside forces" (Till, 2009, p. 1). It's these outside forces that are continually changing as a reflection of the society that we live in and where the role of the architect becomes transcribing this change, with a critical mindset, into built form. Unfortunately, as architects, we are continuing to design, not necessarily for a future of dynamism and flux (or even for the changing context of the now), but for something else entirely - perhaps for present gain, for monetary gain, for personal gain, for status, for novelty, for lifestyle - and the outcome is an architecture of thoughtlessness, a reflection of the unconscious, deluded society that we live within. We are caught up in a mindset where it is acceptable to design something that seems to be just enough for right now rather than accomplishing something that has any real impact or perspective on the future. Yet, this state of unconsciousness is not particular to our era, it is perennial - it has always existed and likely always will. There has always been an unconscious form of design for every century, more or less defined by the context and the people of each era. Resistance against it comes in waves, beginning with an avant-garde, then developing into a mainstream idea, losing its meaning and purpose over time after being 
absorbed into the machine, until ultimately, the avant-garde resists against it once again. The problem here really lies in how to defeat it, in that moment of resistance - a moment that seems to be severely lacking within the current consumerist culture. 

the lost avant-garde 

Kenneth Frampton, in his 1983 essay "Towards a Critical Regionalism," quotes Andreas Huyssen in commenting on what he believes is the disappearance of an avant-garde culture: "The American Postmodernist avant-garde, therefore, is not only the end game of avantgardism. It also represents the fragmentation and decline of critical adversary culture" (Frampton, 1983, p. 80). Despite the fact that Huyssen is referring to an avant-garde culture from thirty years ago, this observation could also not be truer for today's culture - a link, perhaps, to its first decline three decades ago. There has been a serious decline of "critical adversary culture" - there seems to be less opposition to the norm, or if it does indeed exist, it is much less explicit and not obvious to society as a whole. Since the development of the Internet, written criticism has changed its face. The everyday web user is displacing the traditional critic as many newspapers and magazines are ditching the architectural critic and slipping the Architecture section under Art (Wainwright, 2013). Although this new democratic method of opinion may bring with it a greater readership and the potential of a faster advancement of architecture, it also brings a barrage of posts/tweets/ statuses that one must sift through to find anything worthwhile. With the onset of blogs, personal webpages, and online magazines, this critical culture has become a never-ending onslaught of meaningless commentary on anything by anyone where everyone is the critic. This 
results in the possibility of a lost critical community, and with it, a lost critical project. Beyond this, architecture itself has become a very sophisticated form of marketing and, rather unfortunately, designs seem to be driven entirely by capitalist endeavors. Architects have abandoned their imaginary cities and those limitless, boundless spatial ideas all for the sake of gaining a commission that essentially creates a means to an end and lacks, as the late Lebbeus Woods points out, openness for inspiration (Myers, 2004). Architecture now seems to be smoothed over of any substance with younger architects quite eager to build anything at all - their advanced computer skills create seductive renderings that have absolutely no comment on any social truth or, even further, once respected highly theoretical and critical minds are seemingly selling out as 'starchitects' and designing luxury condominiums that are objectified and ready to consume with titles such as Blue by Bernard Tschumi (2004-2007) or 'Sculpture for Living' by Charles Gwathmey (2004-2005) in New York City. As a result, the profession seems to have "lost some of its capacity for self-criticism and one of its most valuable imaginative tools" in those unbuilt critical projects that kept architects constantly questioning the context that surrounds them and in an avant-garde that promoted difference (Ouroussoff, 2008).

In this light, architecture could use a return to criticality - to reinstate an avant-garde and bring back the critical adversary culture to which Frampton and Huyssen both refer. If not, architects may create nothing 
more than worthless potential solutions to space lacking in innovation and architecture can really be more ambitious than to settle for this bare minimum of barely designing (Speaks, 2006). In this regard, architecture may become a static existence, unchanging and unable to provide worthwhile experiences for society - being nothing more than another object, another "plastic or aluminum atrocity" to be in constant exponential consumption by a society that cannot get enough (Frampton, 1982, p. 77). The critical project, and with it experimental design, in Michael Speaks' perspective, is one that does not have to be grand theoretical ideas limited to paper like many of the avant-garde architects that came before us. Instead, it can thrive off of innovation, attempt to find solutions for problems that may not yet exist - constantly critically examining the changing context with intelligence and perspective yet still having a profound impact on society itself (Speaks, 2006). Those who practice in this fashion understand change and allow for it, accepting all the risks, threats and failures that can potentially come with it - this is the avant-garde, the self-sacrificing and full risktaking advance of the front line (Natalini, 2005). By doing so, they engage with the inescapable reality of the world rather than retreat from it and through that engagement, find the "potential for a reformulation of architectural practice that would resist its present marginalization and find new hope" (Till, 2009, p. 2). Furthermore, Woods claims that architects must create an independent idea of both architecture and the world but in a form of resistance. This resistance, to resist the 
consensus machine, to resist the easy way out, or to resist, as William Saunders describes, "the dominant commercial culture" is paramount in ensuring a critical architecture and to inhibit the creation of unconscious form (Saunders, 2005, p. vii). Miessen elaborated on this point in his lecture at the University of Southern California when he stated that the architect must become proactive - someone with a viewpoint on the built environment that is not a product of the client's wishes, influence or money (Miessen, 2011). In their book Future Worlds, Stephen Kieran and James Timberlake also allude to this idea when they say, "without new product, we become the produced rather than the producer" - reminiscent of Arendt's 'in order to' and 'for the sake of' and a yet another way to view the condition of our current society (Kieran \& Timberlake, 2007, p. 84).

As Frampton claims, "avant-gardism can no longer be sustained as a liberative moment, in part because its initial utopian promise has been overrun by the internal rationality of instrumental reason" (Frampton, 1982, p. 81). If today's dominant commercial and consumerist culture is overpowering an avant-garde then, again, as Natalini, of the Italian group Superstudio claimed: "If design is merely an inducement to consume, then we must reject design; if architecture is merely the codifying of the bourgeois models of ownership and society, then we must reject architecture; if architecture and town planning is merely the formalization of present unjust social divisions, then we must reject town 
planning and its cities - until all design activities are aimed towards meeting primary needs. Until then design must disappear. We can live without architecture" (Lang \& Menking, 2003, p. 20). As it seems, we are not practicing architecture anymore but instead practicing a method of false credence. Perhaps, like Superstudio suggests, it is time we let architecture dissolve into nothingness. 

the experience of meaning 

Nothingness is defined as that which is non-existent; as cessation of consciousness or life; that which has no value; as utter insignificance or unimportance, and, lastly, as void or emptiness (Oxford English Dictionary, 1971 \& Merriam-Webster's, 2004). However, most find it rather difficult to define the word in just a few short phrases. Most associate the term with existentialist philosophies although the idea has been deeply discussed by many philosophers including Martin Heidegger, Jean-Paul Sartre, Freidrich Nietzche and Henri Bergson (to name only a few) and has also been alluded to in myths, pop-culture, and literature. The term has been largely associated with the concept of nothing, though really being expanded to include the idea of absences both as a literal absence and as a more emotional or figurative absence, as seen through traditional ideas in Buddhism.

Buddhist monks have long been known to contemplate nothingness. For them, the idea of 'finding God' is essentially finding nothing and understanding that it is nothing that is God. Michel de Certeau spoke with a monk who explained that "to see God is, in the end, to see nothing, to perceive no specific thing. It is to take part in a universal visibility which is no longer made up of the fragmented, multiple, separate, and interchangeable incidents of which our perceptions consists" (Bonardel, 2009, p. 176). This understanding comes from 
the path to nirvana (nibbana - in Sanskrit translates as 'release'), which includes seven stages of 'purification' - by which the monk is purified of the world and retreats deeper and deeper into a realm of nothingness. The stages are: Purification of Virtue (silavisuddhi), Purification of Mind (cittavisuddhi), Purification of View (ditthivisuddhi), Purification by Overcoming Doubt (kankhavitaranavisuddhi), Purification by Knowledge and Vision of What is Path and Not-path (maggamagganandassanavisuddhi), Purification by Knowledge and Vision of the Way (patipadananadassanavisuddhi), and Purification by Knowledge and Vision (nanadassanavisuddhi) (Nanarama). For Buddhists, nothingness (suunyataa) "stands at the center of all forms of Buddhist thought [...] which, to Western minds, frequently suggests an attitude of complete withdrawal or world-denial" (Dallmayr, 1992, p. 38). However, within the Buddhist line of thinking, nothingness does not have a negative connotation, nor is it a vacuum, but rather an "inner core of reality or the other side of being - which carries life-affirming and sustaining implications" (Dallmayr, 1992, p. 38). Thus, Buddhist monks become 'emptied' while seeking a nothingness and succumbing to it to such a degree that their very soul becomes quite nearly annihilated and goes back into being, though forever changed (Bonardel, 2009, p. 179). The soul has thus become enlightened, having contemplated "the sphere of nothingness" while not succumbing to a nihilistic perspective and eliminating the idea of the self as an entity that exists (Bonardel, 2009, p. 180). "It is nothing less than a conversion from the self- 
centered (or man-centered) mode of being, which always asks what use things have for us (or for man), to an attitude that asks for what purpose we ourselves (or Man) exist" (Dallmayr, 1992, p. 38-39). This switch from an object-oriented mode of thinking into a purpose-oriented mode of thinking, gives meaning to not only the surrounding environment but also to the inner soul itself.

Heidegger, in Being and Time, asks a question along the same lines of Buddhist thought: is there an experience or a method by which the world as a whole is revealed to us? Is there a way to consciously become aware of our surroundings and to question them, to understand why we exist? Heidegger reflects on the idea of nothingness through a feeling he identifies as angst. He explores this feeling in the attempt to understand how the world can be revealed to us as a whole; to discover if there is a way to pull back from the world, to be separate from it, in an effort to understand the world as something greater than we, as humans, are. Angst, for Hiedegger, does not necessarily mean anxiety nor does it mean fear. Heidegger explains angst more as a feeling of anxiety that is created from the freedom of the mind - it is anxiety that is felt once the self becomes aware of its own existence. Fear, on the other hand, is associated with something - we fear a thing in particular and can identify it. We fear we may be stabbed by a man carrying a knife, we have a fear of snakes, or of heights - it is always associated with an object and, likely, when that object is removed so too is the fear. Angst 
goes beyond fear to be defined as essentially a very deep anxiety without quite having an explanation for that anxiety - it is an anxious feeling about nothing, an existential crisis of sorts. Angst is the feeling and act where one becomes acutely aware of the banality of the everyday, of the useless and thoughtless words, actions, and moments that make up our lives and begins to question its worth, its purpose, and beyond that, the purpose of the self. This is not necessarily denoted as a terrible thing, in fact, at one point Heidegger even associates it with feelings of calm and peace, similar to Socrates' call to self-examination. (Critchley, 2009).

It is here that, in the feeling of angst, one becomes aware of the self and aware of the "groundless floating," the following along of others, the lack of self-questioning, and realize the immersive banality of the everyday (Critchley, 2009). It is the discovery of meaninglessness in the world and thus having despair over such a realization and becoming quite aware of the distinction between the self and the world within which it exists. This, according to Heidegger, is the self's experience of freedom - the freedom to become one-self, as a separate entity and distinct from the mediocre world that the self inhabits. It is the beginning of being able to think for oneself, it is self-reflection, brought on by the fear and relation of death itself. Heidegger explains angst as, "the question [that] looms in moments of great despair, when things tend to lose all their weight and all meaning becomes obscured ... it is present in moments of rejoicing, when all things around us are transfigured and seem to be there for the first time, 
as if it might be easier to think they are not than to understand that they are and are as are. The question is upon us in boredom, when we are equally removed from despair and joy, and everything about us seems so hopelessly commonplace that we no longer care whether anything is or is not" (Holt, 1994). For Heidegger, we are unable to "grasp Being by looking at Being" (Heidegger, 1996). Instead, it is this consciousness (self-awareness) that leads to the "authenticity of a life created out of nothing" where nothing is simply the "site of Being's withdrawal, abstention, or oblivion: its recession from what presents itself as any present being" (Comay, 1996, p. 184).

This is a Heideggerian nirvana - a state which cannot be achieved until you grasp at the nothingness of everything and come to see, through angst, the everything of nothingness. It is a reversal in a way, a play on the foreground and background that forces the self to think, to be aware and, ultimately, to create better meaning for life. (Critchley, 2009 \& Heidegger, 1996). Similarly, Jean-Paul Sartre described being as existence though it is meaningless and lacking in consciousness or knowledge. When consciousness enters the world, it brings with it nothingness and meaning. However, for Sartre, nothingness is almost always associated with a negation, an absence that is consciously brought to light. For example, Sartre gives the case that if one were to arrange to meet a friend in a café but upon arriving discovered that the friend is not there in his usual place, the feeling brought on by 
this experience is associated with nothingness since it has tied with it a premeditated absence - an absence that the person themselves has tied meaning to. Sartre claims, "the name ... [of] this possibility which human reality has to secrete a nothingness which isolates it - it is freedom ... freedom ... through [which] nothingness comes into the world" (Sartre, 2005, p. 24-25). It is this nothingness, similar to Heidegger's ideas, that brings meaning into the world. Since we naturally associate meaning with absence and since the feeling that overcomes us when we experience an absence is nothingness, Sartre's viewpoint ultimately has the same outcome as Heidegger's - that it is through nothingness that one brings meaning to being.

The British philosopher Alan Watts, best known for his work communicating Eastern philosophies and ideas to a Western-based culture, also discusses the idea of nothingness, not just as an outpost of Buddhist thought but in a manner through which he believed life existed on earth. Watts spoke of nothingness as a non-literal idea, he proposed that "the most real state is the state of nothing" and if the basic reality is nothingness, then everything comes from this concept of nothingness - Watts believed that this is what is meant by Buddhist philosophy in saying "we are all basically nothing" (Watts, 2004). For Watts, this "means that we are intrinsically pure - pure as in clear, as in void" where the mind thus becomes void, developing from a nothingness (Watts, 2004). Watts claimed that nothingness is like the nothingness of space, 
which contains the whole universe, all is contained in the void and everything comes from the void; void, not as emptiness as the Western mind would conceive of it but rather something like "fundamental clarity" which is "void, not because there's nothing there, but because our mind has no idea of it" (Watts, "Zen Bones" \& "Mahayana Buddhism" 1994, p. $155 \& 21$ ). Watts claimed that there should not be a fear of nothingness, because nothingness is essentially the spirit, it is the human condition. The reason why we do not perceive nothingness as the reality of our world is because we are trained to focus on the foreground (the somethingness) - "we are too fascinated by whatever we, at any given moment, have selected to be the foreground" and often as a result neglect the background, "and so, we frequently can't see the forest for the trees or the trees for the forest" (Watts, "What is Reality?," 1994, p. 241). However, the reality is that we would not even know the foreground if it were not for the background, we cannot know something, without first knowing nothing. When we do see the background or nothingness instead of the foreground or somethingness, we fall into Heidegger's angst and become acutely aware of our surroundings. Like Heidegger, Watts believed nothingness is what brings something into focus - it defines everything, both mentally in our minds and physically through space. As Watts claimed "that which is void is precisely form and that which is form is precisely void" (Watts, 1974) 
No different from T.S. Eliot's still point in a turning world, nothingness is "neither from nor towards/... Neither ascent nor decline/... Erhebung without motion, concentration/ Without elimination ... understood/ In the completion of its partial ecstasy/ In the resolution of its partial horror" (Eliot, 2003). If nothingness is, according to Heidegger, the Buddhist tradition, Watts and in some ways the ideas of Sartre, what defines and brings meaning to life then how can architecture use this as a device to bring meaning to its spaces and thus resist the unconscious form? 


how then, can architecture be made to disappear? 

From Sudjic's world drowning in objects to Heidegger's experience of nothingness that brings meaning to being and to existence, how can architecture change so as not to be yet another banal object to be consumed but still remain in a realm of impact, in a realm of meaning? If a vast majority of architecture, as Kunstler suggests, is part of this banality, part of Sudjic's drowning, part of Eco's false realities - how then, can architecture exist? Perhaps it doesn't. The question now becomes, as Kengo Kuma asks, how then, can architecture be made to disappear? Is it possible to make an architecture of nothingness?

In his book Anti-Object, Kuma claims that "making architecture into an object means distinguishing between inside and outside and erecting a mass called 'inside' in the midst of 'outside' (of which nature is only one version)" (Kuma, 2008, p. 77). He believes that this distinction does not necessarily have to exist. His architecture tries to escape the condition of being an object. However, Kuma notes that he "does not deny that all buildings, as points of singularity created by humankind in the environment, are to some extent objects" (Kuma, 2008, Preface). Kuma's call for a disappearance is brought about by his means to criticize architecture that is "self-centered and coercive" as well as his opposition towards an "architecture that [he] has chosen to call objects" (Kuma, 2008, Preface). For Kuma, whether a building is or is not an object is 
not related to its architectural style but rather to its inherent character. He claims that "no particular skill or effort is required to turn something into an object. Preventing a thing from becoming an object is a far more difficult task" (Kuma, 2008, p. 2). His propositions for the anti-object are something he believes to be very possible, though accomplished through his architectural design work that is, with no doubt, quite objectified. Yet Kuma's ideas, and in some respects his work, are precursors to the ideas that generate the nothingness as an architecture that dissolves.

As Jean Baudrillard stated: "an object that is not an object is precisely not nothing. It's an object that doesn't let up obsessing you with its immanence, its empty and immaterial presence. The whole problem is, at the confines of nothingness, to materialize this nothingness - at the confines of emptiness, to trace the after-image of emptiness - at the confines of indifference, to play according to the mysterious rules of indifference" (Baudrillard, 1993). It is this paradox, that Baudrillard so clearly points out, that is the task of seeking a nothingness in architecture. 


ideas on nothingness 

The idea of nothingness has been tackled from numerous perspectives with projects produced in reaction to varying issues. However, each, in the end, is concerned with achieving nothingness, not for the sake of nothingness itself but as a way to understand something else, something beyond the concept of the project. This is no different from Heidegger's angst, nor from the Buddhist seven stages of purification - the nothingness is simply the device through which the artist or architect becomes more aware, more conscious and thus injects more meaning into their projects and, ultimately, into life. This then allows those to experience these projects not as objects for consumption but rather as moments of contemplation, of pause, and of allowing an experience itself, whatever that experience may, in the end, be.

\section{sublime uselessness}

Nothingness often is revealed by focusing on what Rosalind Krauss calls the negative condition. For example, where a sculpture or artwork becomes rather difficult to define Krauss claims that you can only define what the something is based on what it is not; "it was what was on or in front of a building that was not the building ... or what was in the landscape that was not the landscape" - much like Watts' description of the trees and the forest (Krauss, 1979). These projects are difficult to 
define because they evade being read as an object or a thing, which leaves one wondering how to explain them at all. The most literal take on this idea is to make absolute nothing - an entirely nihilistic perspective. In architecture, one of the most extreme examples of this line of thinking is the avant-garde work of Superstudio. Their work involved radical social commentaries that produced designs with critical vehemence, including installations and exhibitions that were, as they described, "alternative model[s] for life on earth" (Superstudio, 2007, p. 196). Projects such as the Continuous Monument and Twelve Ideal Cities were ironic and satirical takes on the world in the late 1960s and early 1970s - they were projects that weren't; they did not exist, except on paper alone, but the ideas associated with them became somewhat immortalized in the process (Figures $5 \& 6$ ). Superstudio was a collective that wanted architecture to quite literally disappear, more in the nihilistic sense than in the realm of nothingness itself, claiming that "when design as an inducement to consume ceases to exist, an empty area is created, in which, slowly, as on the surface of a mirror, such things as the need to act, mold, transform, give, conserve, modify, come to light" (Superstudio, 2007, p. 200). Their wish for "a life without objects" was the basis for their projects and for their search for a purification of design (Superstudio, 2007, p. 196).

Despite Superstudio's radical thoughts regarding architecture (as well as the thoughts of other avant-gardes of the time) their work 


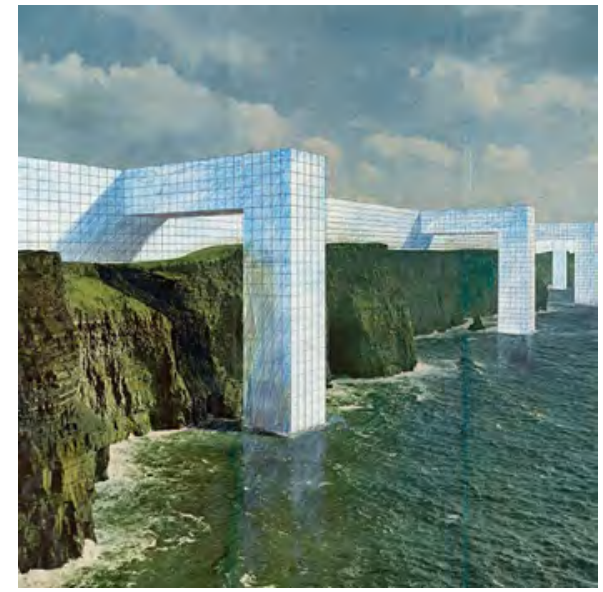

5. Superstudio, The Continuous Monument, 1969.

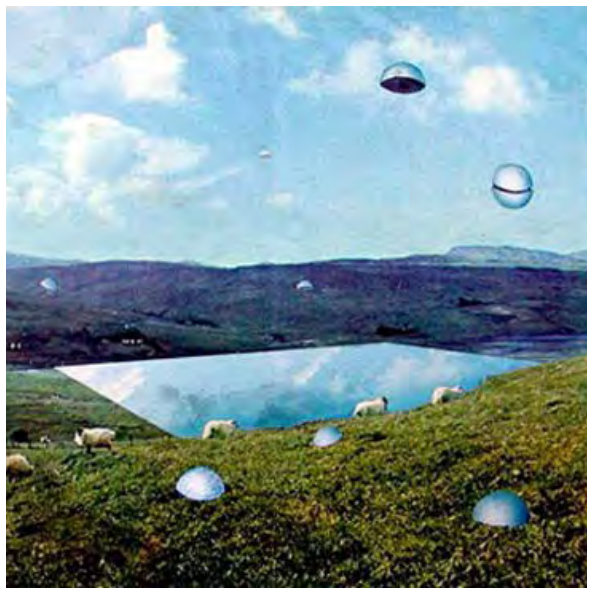

6. Superstudio, Twelve Ideal Cities, 1972 
mostly remained on paper or other similar media and as such became only truly impactful in the realm of academia. Even further, later work that attempted to escape, as Natalini suggests 'an inducement to consume,' just pulled them farther away from the world and into a realm of autotelic impact only really having any effect within the world of architecture alone - an architecture for architecture's sake mode of thinking and acting. As K. Michael Hays suggests, "to the extent that architecture can function in a capitalist society, it inevitably reproduces the structure of that society in its own immanent logics and forms [...] When architecture resists, capitalism withdraws it from service - takes it off-line - so that demonstrations by architects of the critical distance of their practice from degraded life become redundant and trivialized in advance" (Hays, 2010, p. 3-4). Here Hays is specifically referring to the work of the so-called late avant-garde - an avant-garde that became self-sustaining and caught up in an autotelic architectural critique that of the late 1970 s and 80 s specifically. Manfredo Tafuri also refers to this concept when he claims that "the drama of architecture today [is that] architecture is obliged to return to pure architecture. To form without utopia; in the best cases to sublime uselessness" and he further goes on to say that "those who attempt to give architecture an ideological dress ... [are] pathetic in [their] anachronism" (Tafuri, 1976, p. ix). Though the work the avant-garde produced during that time was critical and radical, it nevertheless was nihilistic - it erased architecture from impact in that sense. Hays, in writing the afterword 
for the publication documenting a conference entitled The Presence of Mies, describes that architecture cannot eliminate appearance entirely, nor can it become nothing without completely destroying itself - having no impact and ultimately displaying the mediocre reality that it initially wishes to change (Hays, 1996). If the idea of nothingness were to push this a little further than Hays and Tafuri are suggesting, beyond creating redundancy and trivialized work, beyond sublime uselessness, can architecture be something more, something beyond its own limitations while at the same time, be something less than the object itself? Can an architecture exist that can escape consumption, that can escape from capitalism withdrawing it from service and become an architecture of meaning, of impact? As Baudrillard states, "We can't begin with nothing because, logically, nothingness is the culmination of something" nihilism alone is not the answer to this question (Baudrillard, 1993).

\section{concealing the object: dematerialization}

Before Superstudio took the extreme nihilistic route, Mies van der Rohe explored the idea of nothingness primarily though materiality in his somewhat objectified modernist style. His 1938 design for the Resor House in Jackson Hole, Wyoming was an attempt to dissolve a work of architecture into a landscape by making the materials blend into the surroundings. Similar to his work for the 1929 Barcelona Pavilion, Mies' consideration into dematerializing space aided in reading that space as transparent, blurred, and evading being understood as an object. 
Mies himself coined the term 'almost nothing' in an effort to describe the level of transparency he was trying to achieve and although this seems highly suggestive of a Heideggerian influence, there seems to be no link between the two men at the time (Comay, 1996). Fritz Neumeyer on his visit to the TD Tower in Toronto said, "that in the case of Mies himself, the works actually appear to have the ability to gather significance from their surroundings and to project that significance back at you in a shockingly powerful way"; however, as Krauss claims, they still seem to possess a 'resistance to the spectator's grasp" (Baird, 1996 \& Krauss, 1996). Hays argues that Mies' concern was tipping too far to either side - on the one hand becoming too 'architectural' and thus too aestheticized and commodified or, on the other end, too plain, unformed, and completely nothing (Hays, 1996). Yet in this manner, Mies' work was "inside and outside, unformed and overformed, nothing and appearances" (Hays, 1996). The focus on the other, indeed on framing the other, has the "effect of both facilitating and encouraging a view of a world beyond the immediately inhabited one" (Baird, 1996, p. 169). Despite this ability, Mies' buildings still possessed a 'thingliness' - "a condition of authentic presence in the world" (Baird, 1996, p. 165). In one way Mies' work was very much a product of what Kuma would refer to as the 'disease of objectification' of the modernist era he belonged to but it was also very much a play on what is considered the background and the foreground, a shifting of focus onto what may not necessarily be focused upon, which can be seen clearly through his representation of both the Resor House 


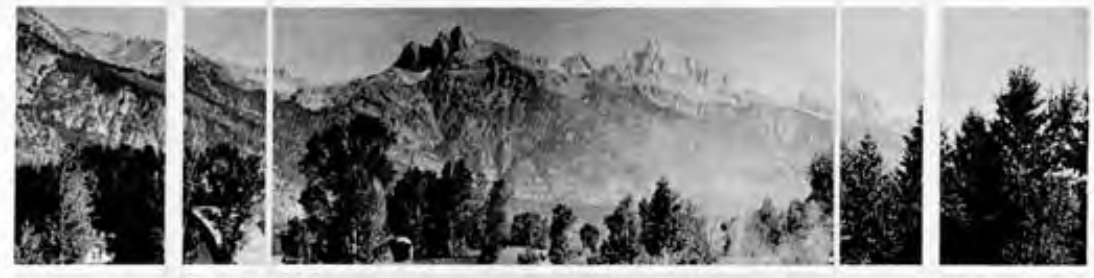

7. Mies van der Rohe, The Resor House,1937-38 


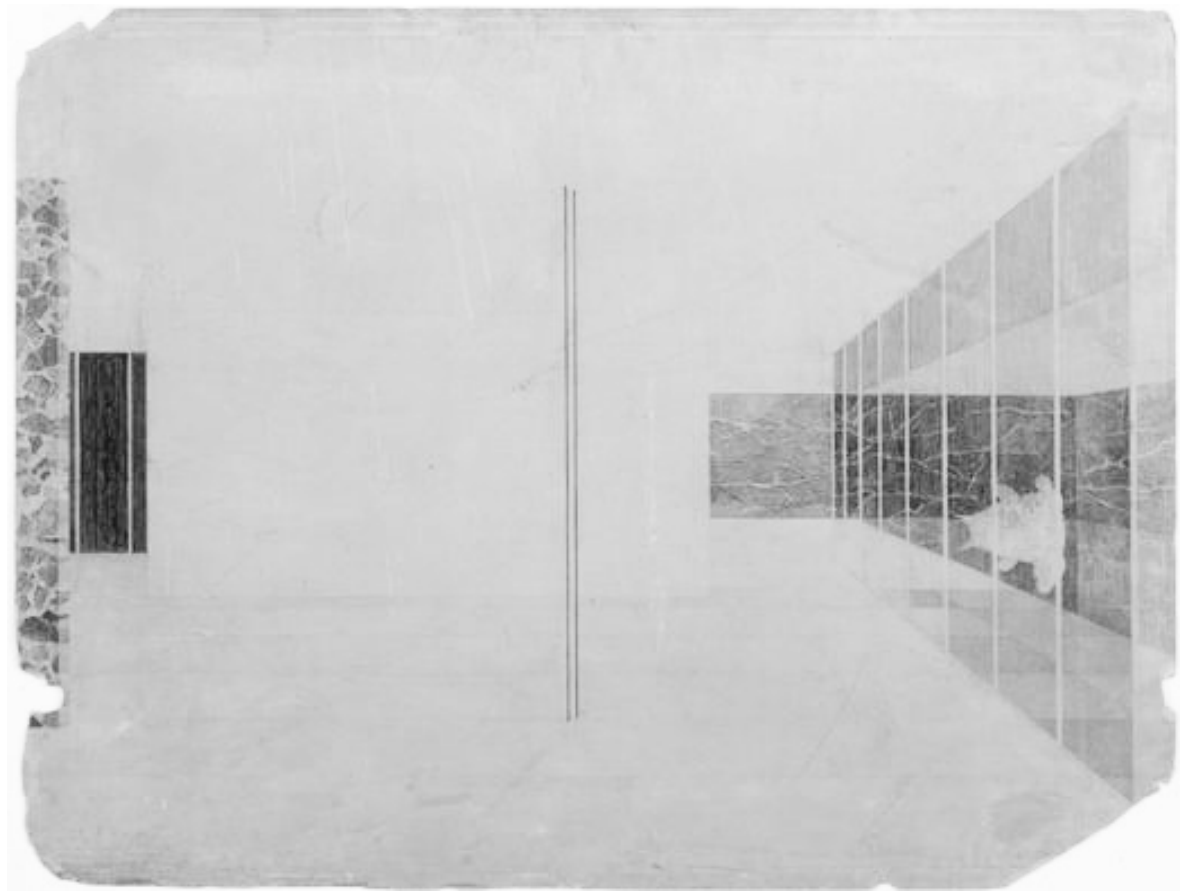

8. Mies van der Rohe, The Barcelona Pavilion,1937-38 
and the Barcelona Pavilion (Kuma, 2008)(Figures 7 \& 8).

Krauss describes Mies' work as 'illusionism' with "every material assuming, chameleon-like, the attributes of something not itself columns dissolving into bars of light, or glass walls becoming opaque and marble ones appearing transparent due to their reflectivity" (Krauss, 1996, p. 134). His designs seemed to resist; resist the 'spectator's grasp,' resist meaning, and resist 'thingliness' itself (Krauss, 1996, p. 134). Krauss extends her discussion into the realm of art and notes that this 'other' that appears within Mies' work is apparent in Renaissance perspectives as well. In fact, the first perspectives by Brunelleschi were created without a drawn sky. Instead, when the viewer looked into the apparatus to view the perspective, they saw the drawing in the foreground upon a layer of silver leaf that then depicted as a mirror image the very sky and clouds that existed above the viewer's heads. This act "operated as the lack in the center of that knowledge, the outside that joins the inside in order to constitute it as an inside" (Krauss, 1996, p. 142). The sky and clouds had no meaning assigned to them - its only purpose was to act against the elements within, against the image of the perspective itself. It is precisely this other that "is a 'remainder' - the thing that cannot be fitted into a system but which, nevertheless, the system needs in order to constitute itself as a system" (Krauss, 1996, p. 141). In this way, Mies' work is that significant other the silver leaf in the perspective, that as Neumeyer claimed "project[s] that significance back at you in a shockingly powerful way" (Baird, 1996). 
Over 70 years after Mies concerned himself with the idea of disappearance, the Japanese firm SANAA still asks a similar question. They are interested in architecture being environment, trying to blur the conditions that separate inside from outside or object from environment, while working with a very minimal palette. Similar to Mies, they play on the idea of what is and isn't present and what can be grasped (in terms of the object) from their work is always difficult to determine. While not giving way to absolutely nothing, in the nihilistic sense, SANAA seemingly accepts the objectified nature of architecture but in so doing attempts to minimize and dissolve it as much as possible. Reflecting on their design for the 2009 Serpentine Pavilion, they claimed that it "[drifted] freely between the trees like smoke. The reflective canopy undulated across the site, expanding the park and sky. Its appearance changes according to the weather, allowing it to melt into its surroundings" (Etherington, 2009). The materiality of this project is how it succeeds, in part, as almost nothing (Figure 9). The reflective surfaces of polished aluminum make it difficult to distinguish from its surroundings and blur it in a sense, despite the concrete ground plane that interrupts the effect. Likewise, for the recently completed Louvre in Lens, France (an outpost of the Parisian museum) SANAA's intent was quite similar. When they visited the site, they were taken by not only the landscape of Lens but also the quality of the diffused, soft natural light that this northern French region received. Instead of creating a loud and spectacular piece like other architects have done for satellite 


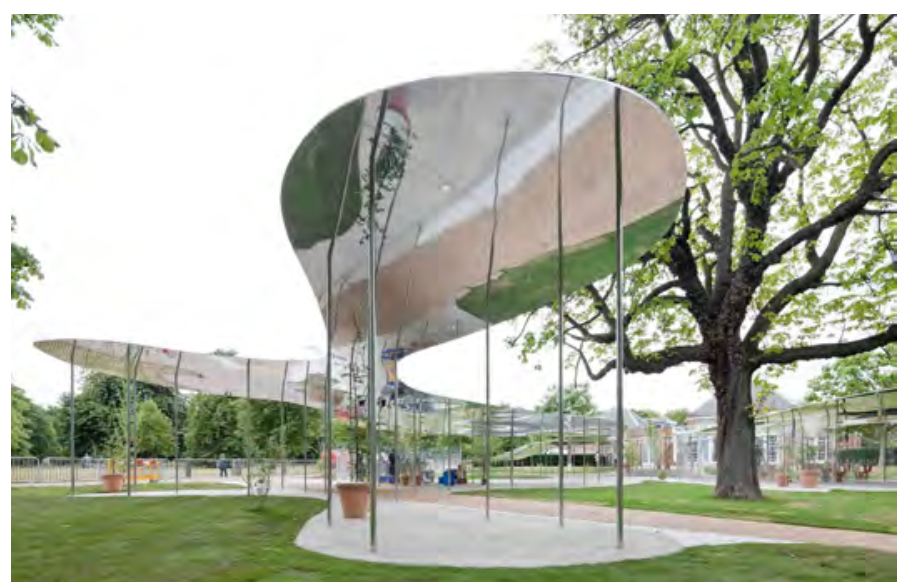

9. SANAA, Serpentine Pavilion, 2009.

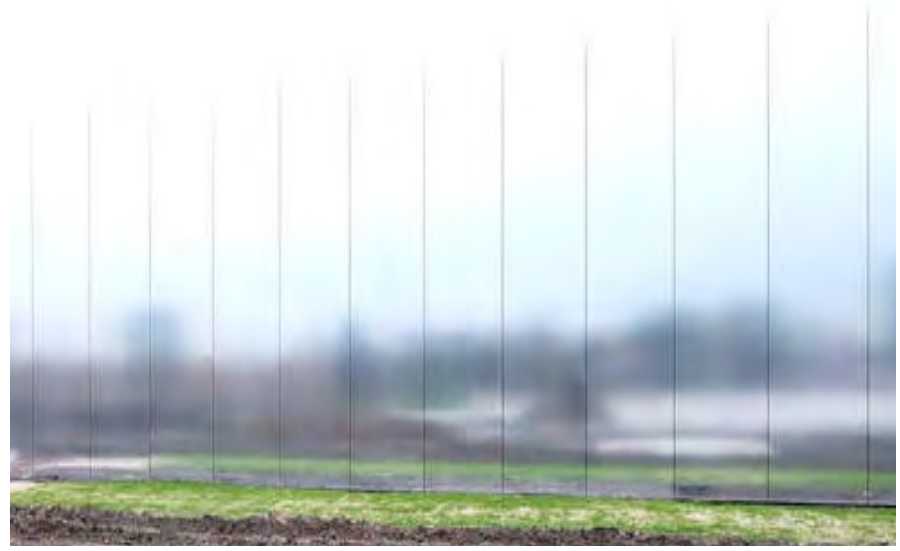

10. SANAA, Louvre, Lens, 2012. 


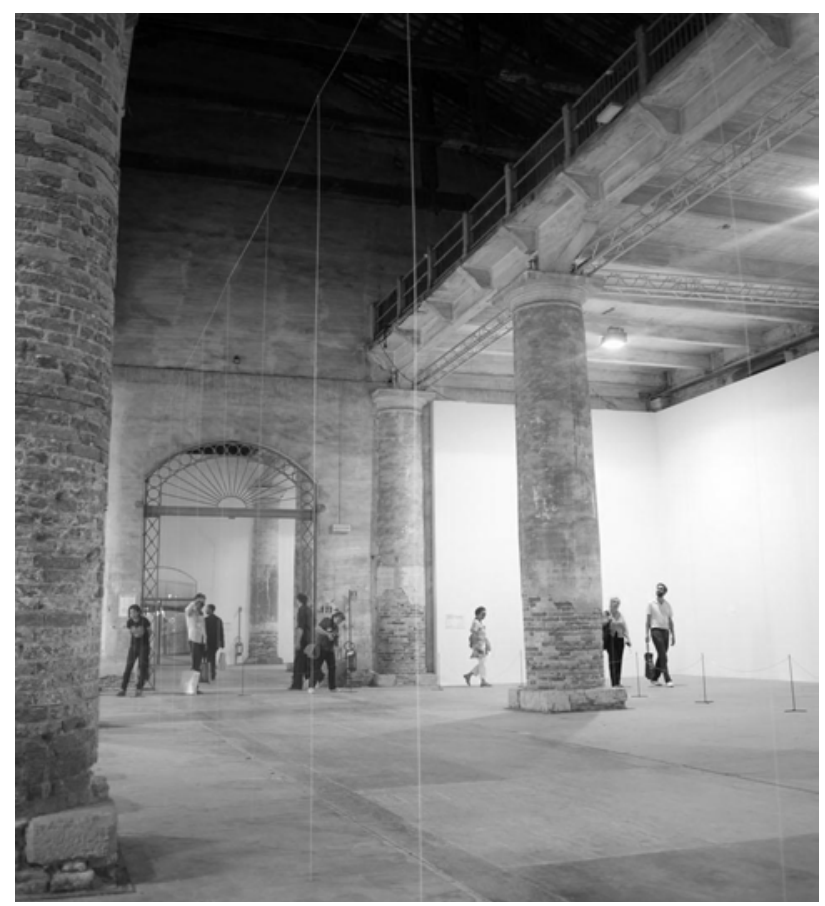

11. Junya Ishigami, Architecture as Air, 2010. 
galleries (such as the Guggenheim Museum in Bilbao and the Centre Pompidou in Metz), they chose to 'melt' the building into its surroundings. Again using aluminum they covered the building both inside and out to create a subdued and fogged reflection of the landscape on the outside and of the artwork on the inside (Figure 10). Unlike a normal gallery, this more northern Louvre does not display art upon its walls - SANAA instead opted to 'erase the wall,' to let them vanish behind the artwork (Wainwright \& Smith, 2012). In this way, their work appears Miesian in its effect though with new ideas about how to achieve a nothingness - an architecture that, in this case, through materiality can start to dissolve into something greater while also playing on what is the foreground and background at any given moment.

A project titled Architecture as Air, shown at the 2010 Venice Biennale of Architecture, explored the idea of nothingness through the use of thousands of minute carbon fibers. Designed by Junya Ishigami, the winner of the Golden Lion for that year and a previous member of the SANAA team, the project goes beyond dematerializing and formally explores how a building can be perceived as nearly nothing, looking specifically at the structural aspects. The work consisted of hand rolled white carbon fibers no wider than a drop of rain that ran from floor-toceiling to suggest space that is only visible close up and very much invisible from afar (Figure 11). Ishigami's work deals with space at an almost atomic level where each single particle of a comprised work is highly considered so that the piece in its entirety becomes an ephemeral 


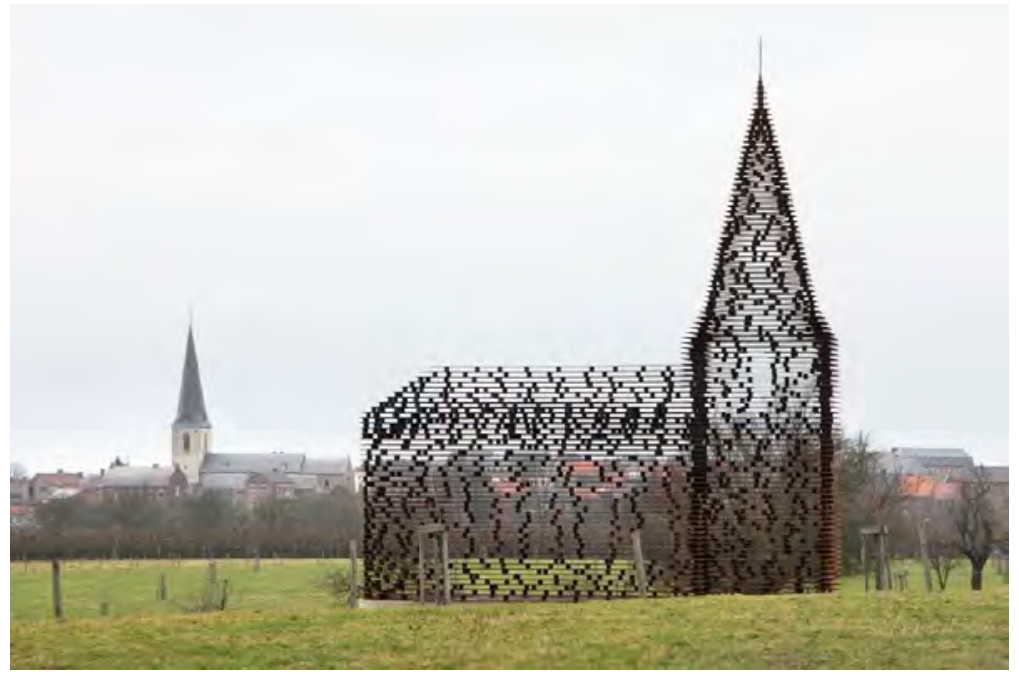

12. Gijs Van Vaerenbergh, Reading Between the Lines, 2011. 
representation of architecture (Bose, 2011). His work breaks down the material into small parts, thus making the form very difficult to read but making it easier to blend into its surroundings - something that both SANAA and Mies continually tried to exact. This is very similar to a recent project by the Belgian firm Gijs Van Vaerenbergh titled Reading Between the Lines. They also explored the idea of evading the object not by the use of reflective materials but again, similar to Ishigami, by spacing out a material that, depending on perspective, is either a very tangible structure or a very dissolved series of lines that blend into the background landscape (Figure 12). The idea, as described by the architects, was that "the church makes the subjective experience of the landscape visible, and vice versa" while also "emphatically transcend[ing] the strictly architectural" (Reading Between the Lines / Gijs Van Vaerenbergh, 2012 \& Gijs Van Vaerenbergh, 2011). Whereas Mies and SANAA play with the qualities of the materials they work with, both Ishigami and Gijs Van Vaerenbergh play further with the movement and spacing of such materials. This play with dematerialization is a move that has been attempted by many architects interested in mitigating the object-ness of their work. It's the level of dematerialization that changes; on one hand it can be completely literal and having to do with the tangibility of the thing itself and on the other having to do with the perspective and form of the material instead. However, through either tactic, the ultimate idea is to blend the project into its surroundings and to evade it being read as a separate object. 


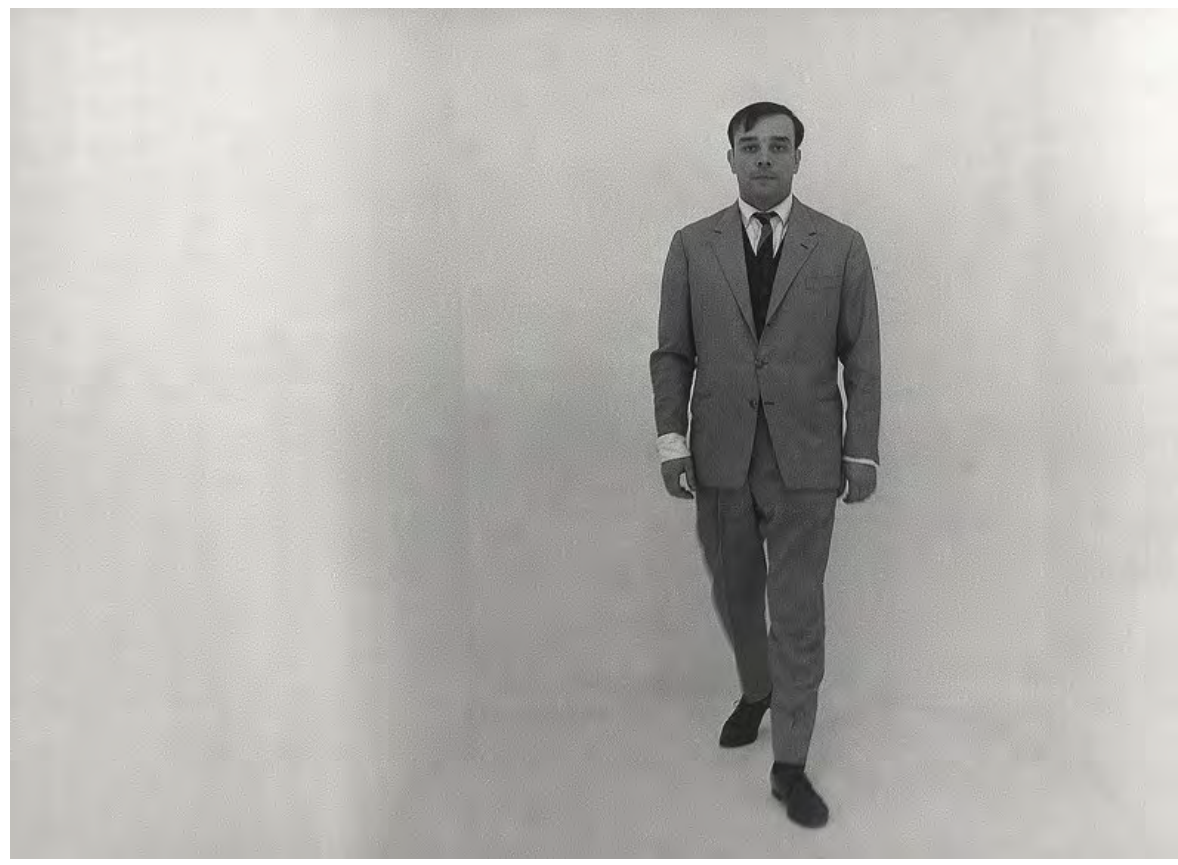

13. Yves Klein, Le Vide (The Void), 1958. 


\section{negation \& the void}

One of the first contemporary pieces of work regarding nothingness and likely one of the most influential is Yves Klein's The Void (1958) and his later work Leap into the Void (1960), both works that most definitely could fit Krauss' description of 'resisting the spectator's grasp' (Figures 13 \& 14). The Void was first shown at the Galerie Iris Clert in Paris during the spring of 1958 and later in 1961 in the Haus Lange Museum in Krefeld, Germany, a building designed by Mies himself. Klein claimed his Void was a room devoted to 'immaterial pictorial sensibility' though he wished it to "go beyond art, beyond sensibility, [and] into Life" (Riout, 2009). The Void was simply an empty room where Klein filled all other rooms in the building (most notably in Haus Lange Museum) with objects. He left this seven square meter room completely empty and painted it white on all surfaces. For Klein this was dematerializing artwork to act as a relief against the other pieces in the museum; it was about finding the purity of art without it becoming clouded with external judgment - much like Mies' attempts to bring architecture down to its most basic form while attempting to dissolve it. Likewise, his Leap into the Void was a piece where he seemed to give himself completely over to the 'other,' an acceptance of the nothingness (through Heideggarian angst). The Void and Leap into the Void were both works that allowed others to choose their own interpretation or to be captivated into a realm 


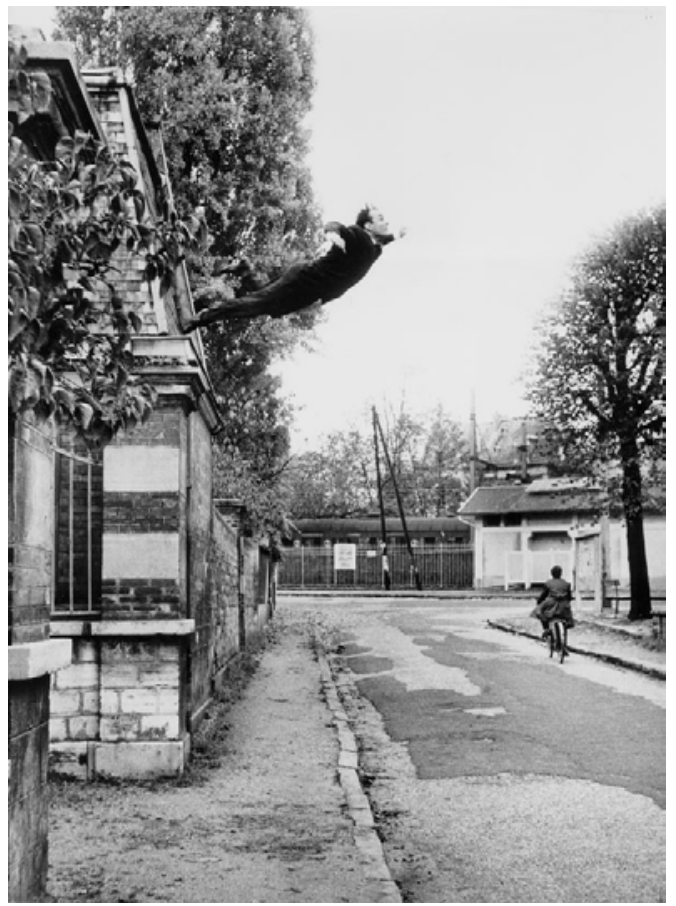

14. Yves Klein, Le Saut dans le Vide (Leap into the Void), 1960. 
I

TACET

I

TACET

III

TACET

15. John Cage, Score for 4'33", 1952. 
beyond rationality and led into deep contemplation over the everything that's within it (Riout, 2009). To this day the empty room Klein created still exists in the Haus Lange Museum though you will not find it on any gallery map - it is only opened for those who ask - a powerful (though seemingly unintended) final statement by Klein himself (Riout, 2009).

John Cage created a similar piece of work in 1952, possibly acting as one of the inspirations for Klein's work less than ten years later. Cage developed a musical score titled 4'33" that was 4 minutes and 33 seconds of uninterrupted silence (Figure 15). In 1948, Cage claimed in an address at Vassar College that he wished to make a piece of music with an ending that would "approach imperceptibility" (De Bievre, 2009 , p. 277). Only four years later did Cage finally create that work - a piece that was influenced mostly by his study of Oriental philosophy and his interest in silence but also, as he described, by seeing the blank canvases of Robert Rauschenberg which he responded to "not as objects, but as [...] airports for shadows and dust... [or] mirrors of the air" (De Bievre, 2009, p. 278). His work was the void of noise - a silence that allowed the existing sounds to become part of its score, like Rauschenberg's canvases allowed it to become part of the 'shadows and dust' of the space.

It is in this framework that Paley Park in New York City by Zion and Breen can be understood. It is, like 4'33", a silence in the dense, uninterrupted fabric of New York City. Consisting of only a handful of 


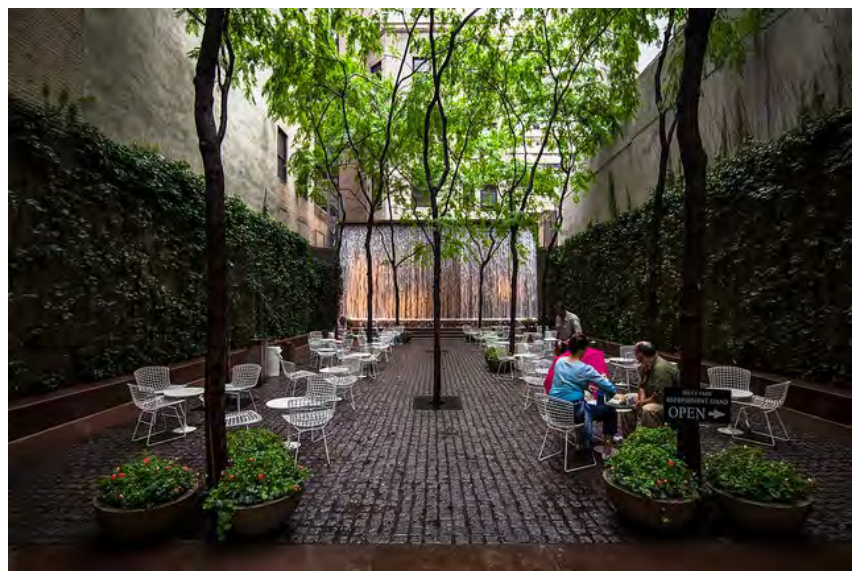

16. Zion + Breen, Paley Park, NYC, 1967. 


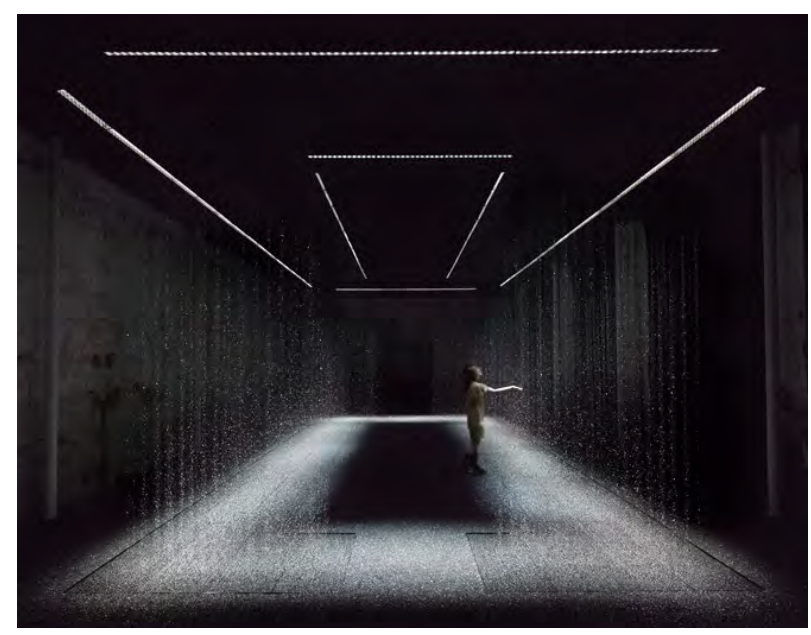

17. DGT, Luce Tempo Luogo, 2011.

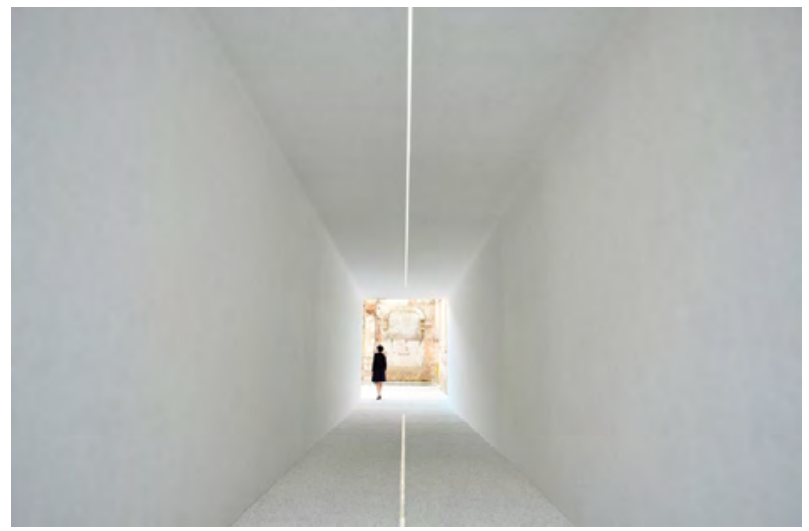

18. DGT, Luce Tempo Luogo, 2011. 


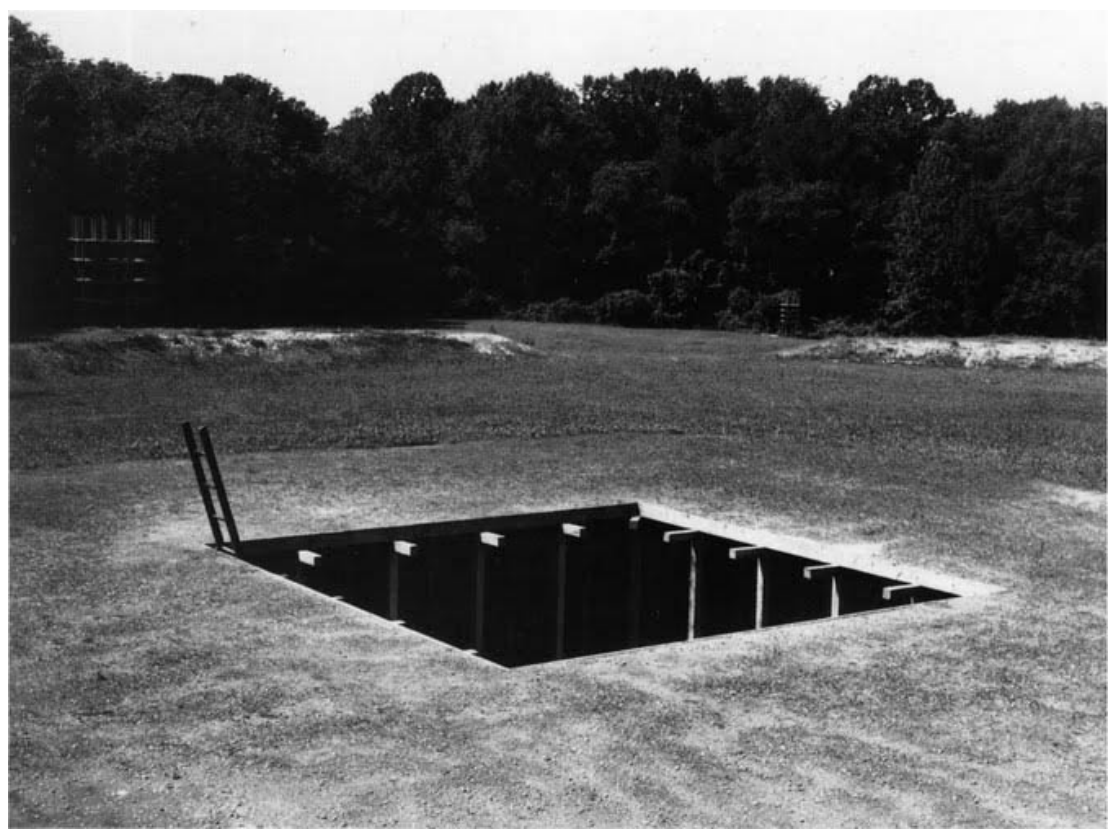

19. Mary Miss, Perimeters, Pavilions, Decoys, 1978. 
trees and a waterfall, the mostly empty space becomes a pause for the urban dweller - a place that escapes the city sounds and chaos to allow people to take a moment and breathe (Figure 16). DGT (Dorell Ghotmeh Tane) Architects teamed up with Toshiba to create a similar project for the Milano Salone 2011. Titled Luce Tempo Luogo (Light Time Place) the project was situated in a context that was over a century old - ruins of one building and an alleyway that led to it. Attempting to create a "unique experience with light ... [that] convey[ed] emotional resonance," tying water to each of the interventions they created (Dorell Ghotmeh Tane, 2011). By lining the void of the alleyway with white they created a tunnel that leads to a water-filled courtyard and then finally into the ruined structure where water drops lit from above frame interior walls (Figure $17 \& 18$ ). The project adds very little to the existing site, though dramatically changes the experience of the site. Another void, a project by Mary Miss entitled Pavilions, Perimeters, Decoys, is an excavated square cut out of a field where the sculpture perhaps should have stood - a void from above but barely perceivable from a distance on the ground (Figure 19). This project attempts to defy perceptibility by becoming a void below the horizon line where DGT highlighted a void in the dense Milan landscape to create an experience with water and light. The void has also recently been, rather fittingly, the subject for memorials - specifically for the World Trade Centre Memorial in New York City and for the Vietnam Memorial in Washington D.C. Each project, like Pavilions, Perimeters and Decoys, is a cut in a landscape, 
a very evident void in contrast to the surrounding context each project sits within. Here, the void is used as a symbol of remembrance and to indicate an absence, a Sartrian nothingness.

\section{featureless: technology as tool}

Diller Scofidio + Renfro, a New York based contemporary architecture firm, produced the Blur Building for the 2002 Swiss National Expo. By using technology and engineering to mask the structure of the building, the architects approached the idea of nothingness from the very ephemeral and fleeting perspective (Figures 20 \& 21). The building, as described by the architects, is an "architecture of atmosphere" where "visual and acoustic references are erased... [with] only an optical 'white-out' and the 'white-noise' of pulsing nozzles" remaining (Diller Scofidio + Renfro, 2012). They claim that this is a project where there is "nothing to see but our dependence on vision itself ... it is an experiment in de-emphasis on an environmental scale" (Diller Scofidio + Renfro, 2012). The building consists of 35,000 high-pressured nozzles within a lightweight tensile structure sitting in Lake Neuchatel where it pumps and filters the water to create the fog (Diller Scofidio + Renfro, 2012). In theory, much like the work of SANAA, it is an attempt at dematerializing an object - making it nearly disappear into the environment and atmosphere within which it exists, hidden and blurred within an engineered cloud of mist and fog. The project uses technology 


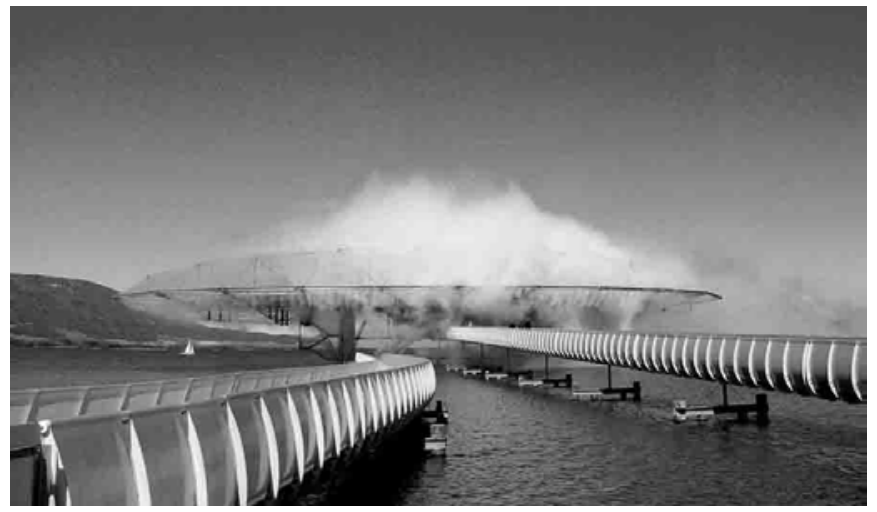

20. Diller Scofidio + Renfro, Blur Building, 2002.

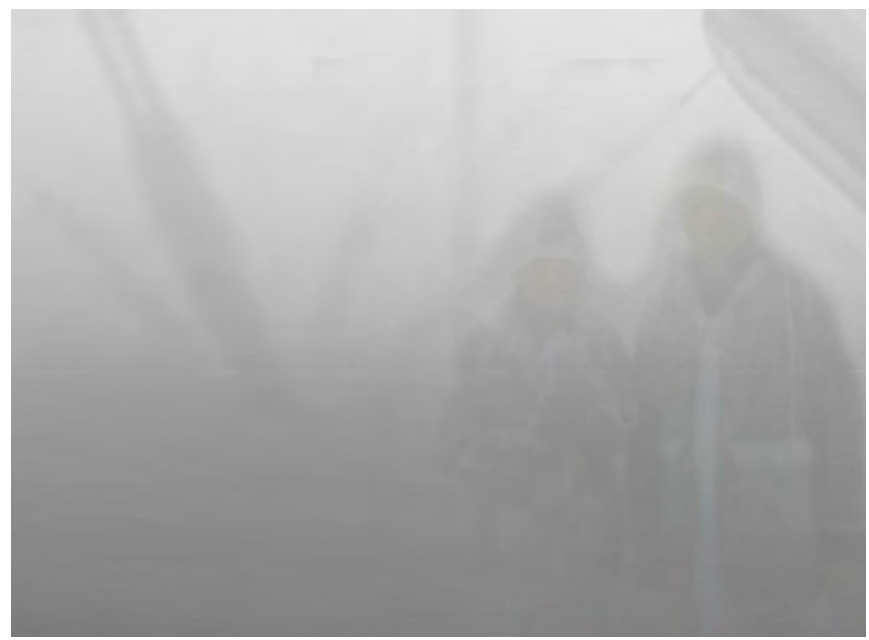

21. Diller Scofidio + Renfro, Blur Building Interior, 2002. 
as well as environmental engineering to develop the modes through which the building can be made to appear as almost nothing at all. Similarly, at the 2010 Venice Biennale of Architecture, German engineering firm Transsolar and Japanese architect Tetsuo Kondo teamed up to create Cloudscape - a climate engineered cloud that floated within the Corderie. This ultimately left that space with a foggy atmosphere, a blurred condition in an empty space (with the exception of Tetsuo's helical ramp that wrapped the interior columns) and practically nothing else (Figures $22 \& 23$ ). Like the Blur Building, this project used engineering and technology to create an atmospheric space that, other than the millions of water particles floating in the air, was an empty space where something was created out of nothing - it made air visible. The project was entirely fleeting - with the flick of a switch the pressure nozzles that expelled tiny particles of mist could be turned off and the cloud would ultimately disappear. The helical ramp wound up from the floor into the cloud so visitors could experience the total immateriality of the cloud itself and also the differing air conditions (temperature and humidity) that changed as they climbed the ramp toward the ceiling of the room (Simo, 2010). At the same Biennale, a project by Janet Cardiff and George Bures Miller titled 40 Part Motet was a work that filled yet another empty room with sound. The only obvious objects in the room were numerous speakers through which the sound was being emitted. Unlike Cloudscapes, this installation made sound a material - it was a series of speakers that each represents a single 


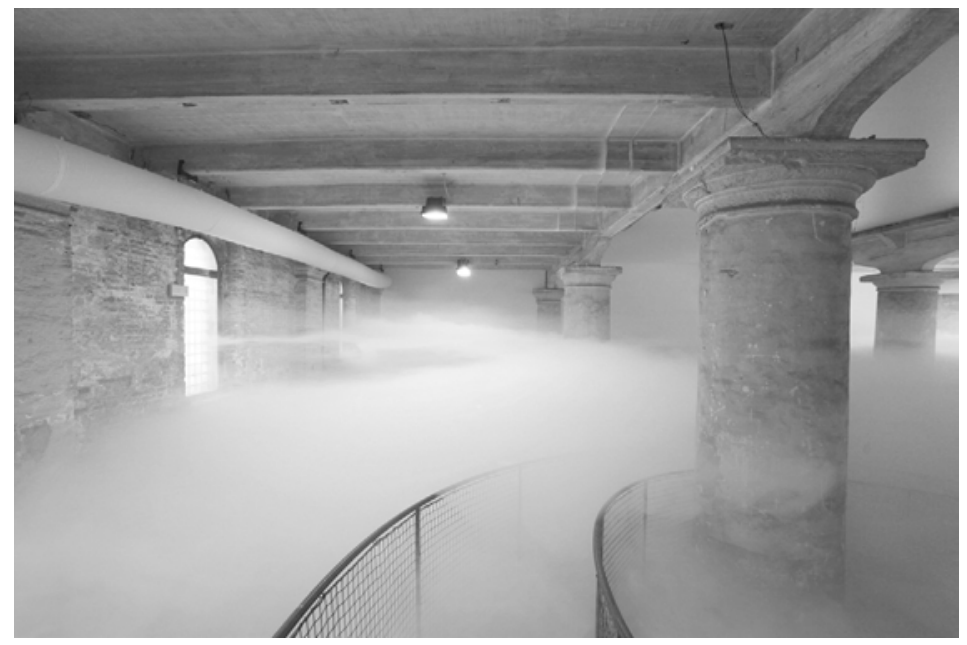

22. Transsolar + Tetsuo Kondo, Cloudscapes, 2010.

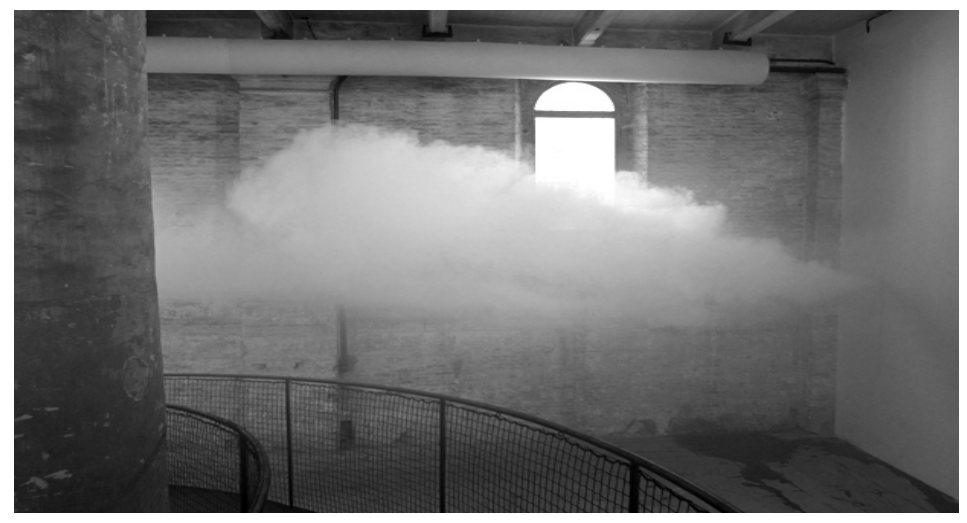

23. Transsolar + Tetsuo Kondo, Cloudscapes, 2010. 
choir singer (the idea was to show how a choir experiences singing a piece of music standing together versus hearing it in the audience as a collection of voices). From various points around the room the music was experienced differently - different voices were clearer or louder than others and you could hear the various baritones or sopranos that made up the piece of music, each heard as individual voices. It was an ephemeral project - its sounds were different from any point within the room, the sounds became the space itself.

From Klein's Void to Diller Scofidio + Renfro's Blur Building, several methods to achieve a nothingness have evolved. These, combined with Kuma's division of the Anti-Object, serve as a foundation of ideas in search of a nothingness in architecture. Some of these methods include: dissolving, diminishing, dematerializing, fleeting, breaking down, minimizing, removing, erasing, reversing, blurring, distilling, camouflaging, unraveling. Designs of a nothingness can ultimately develop from each of these acts - inspired by the very definitions of these words and what they mean in regard to space. Yet, as always, as these ideas enter the world as (un)built form, they will shift and change, defined by each individual that experiences their existence. It is this act that brings them to life. 

experiments 

To use the idea of nothing-ness as a device to attempt to remove the object-ness of architecture (or to distill it as much as possible) would allow architecture to come into a new relationship with its surroundings - be that a landscape, an urban context, a room, or beyond - and also with those that ultimately experience it. Through the nothingness, a new perspective on architecture can be achieved - one that will see architecture become a meaningful and thoughtful aspect of human life rather than the banal, the superfluous, the ostentatious architecture seemingly existing everywhere today. These spaces are intended to create pause, a moment of contemplation amidst the chaotic system that is our current society.

The following series of experiments explore methods by which to achieve an architecture of nothingness. Each experiment is set up to achieve a particular outcome, as defined by previous attempts at achieving nothingness through the numerous case studies. However, beyond this, experiments are conducted that attempt to achieve a nothingness through modes previously untried. As with any experiment, there are a series of controls and variables that must be set in order for the experiment to be in any way successful (whether achieving the desired outcome or not). First, it must be understood that these experiments are not nihilistic - they are not an attempt to discover, create 
or elucidate upon nothing (absolute nothing). They are experiments that are conducted with the understanding of using nothingness - in the sense of Heideggarian angst or in the same line of thought as the Buddhist stages of purification - as a device that will ultimately reveal a substance of greater meaning. Second, each experiment is limited by the context within which it exists. This context is defined at the outset and remains as the major limiting factor through which the experiment is conducted - if it at all can be considered a limit. Lastly, each experiment remains an important step in understanding how to create an architecture of nothingness, like a stage of Buddhist purification, and becomes a step further into understanding. It should be noted that these experiments are not set up to find a definitive answer since this is an impossible and useless task. They use nothingness as the substrate through which to understand a new architecture of thoughtfulness and reveal meaning. There is a dichotomy here between the object as a meaningless thing and the idea of creating meaning out of nothing - a reversal of what is normally considered the real, the thoughtful (those tangible things of the world) into a realm of nothingness (what is normally considered the banal, the useless). This parallels the ideas of Buddhist thought, as well as the ideas of Watts - it is about focusing on the background, on the space that defines and brings meaning to the world. 




\section{almost nothing - the act of exposing}

This initial attempt was an installation intended to discover nothingness. Using the existing context of the gallery space, a series of gallery labels were created to showcase 'invisible' elements that were already present within that space. Completed in conjunction with a seminar that explored the curatorial position in architecture, the piece had to narrate a particular aspect of the nothingness. As such, invisible elements became the focus of the work. Artists such as Yves Klein and John Cage were inspirations for the installation. The following is the text included in the description of the installation:

All things, and we with them, sink into indifference. But not in the sense that everything simply disappears. Rather, in the very drawing away from us as such, things turn toward us. This drawing away of everything in its totality, which in angst is happening all around us, haunts us. There is nothing to hold on to.

The only thing that remains and comes over us--in this drawing away of everything--is this nothingness.

Martin Heidegger 
According to Martin Heidegger, it is the experience of nothingness that brings meaning to being, to existence or to life. Nothingness is the most powerful tool for understanding. This idea is also highly regarded within the Buddhist tradition - that contemplating nothingness can in fact bring you enlightenment. To achieve this enlightenment one must achieve seven steps - a path of nothingness or emptiness itself. This installation reveals a nothingness - the invisible elements of our lives allowing those elements to be brought to mind and to be contemplated. The space of the installation is what informed the invisible content to be displayed. Labels and titles were created to denote the presence of seven invisible elements (paralleling the path to nothingness) and essentially forcing them to become the installation itself - to be what is being exhibited - while remaining entirely invisible. Each label was strategically placed to further emphasize the content and to aid in bringing attention to a particular invisible element. 


\section{on nothingness}

$$
\begin{aligned}
& 1 \text { - air } \\
& 2 \text { - coordinates } \\
& 3 \text { - noise } \\
& 4 \text { - pressure } \\
& 5 \text { - altitude } \\
& 6 \text { - gravity } \\
& 7 \text { - frequency }
\end{aligned}
$$

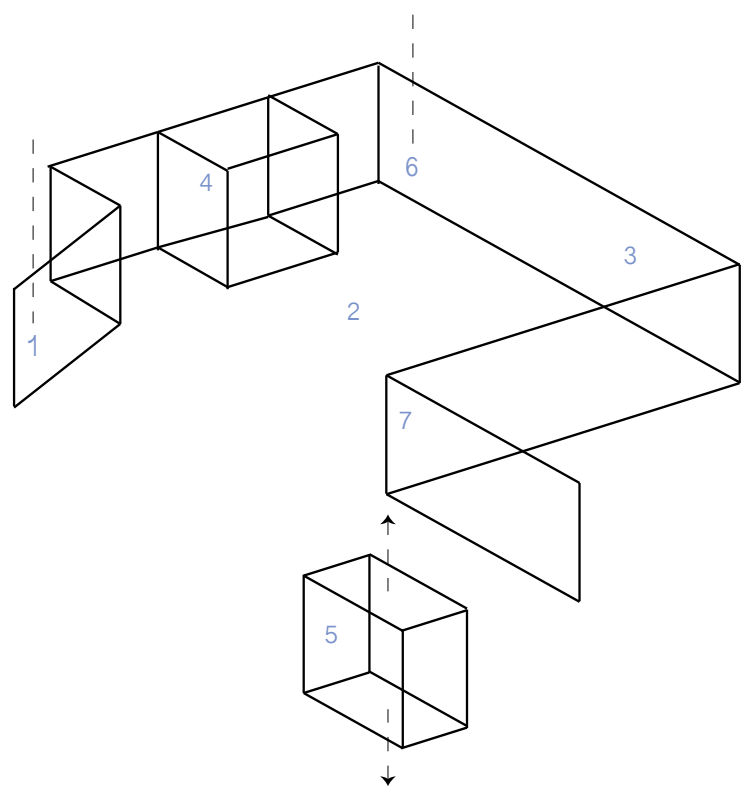

24. Map of installation, Architecture Building, Ryerson University. 

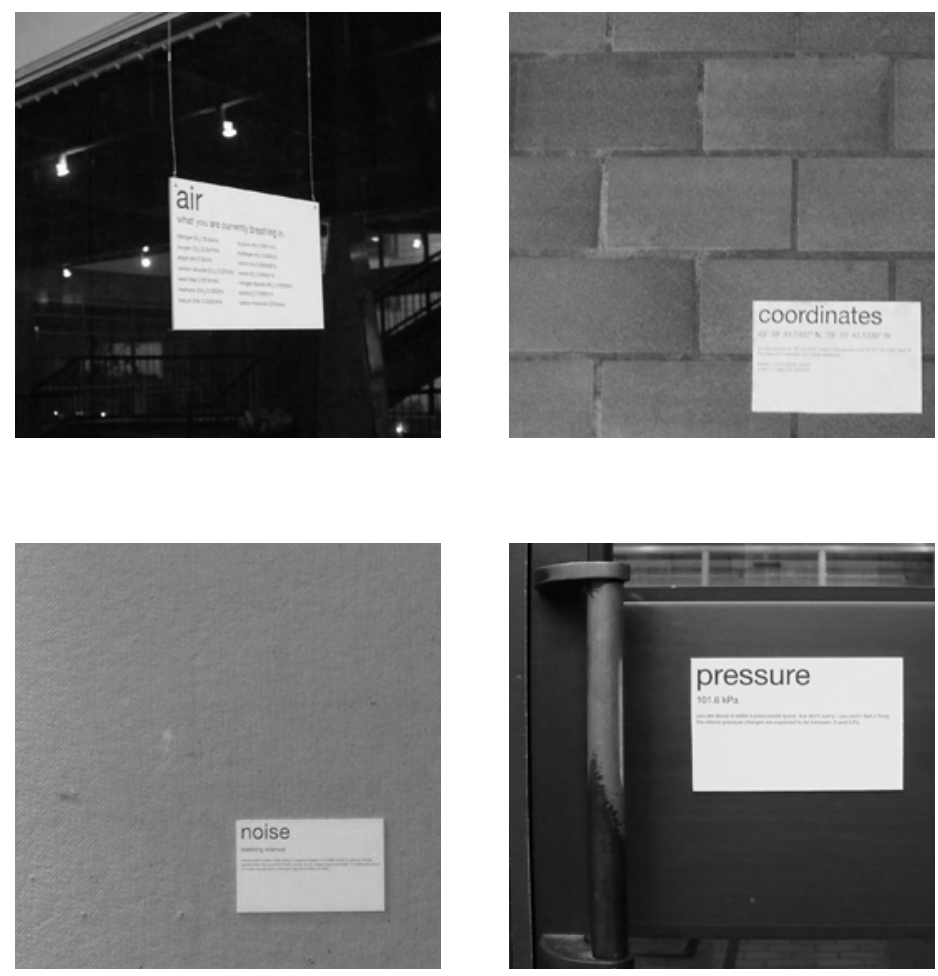

25. On Nothingness, installation, 2012. 

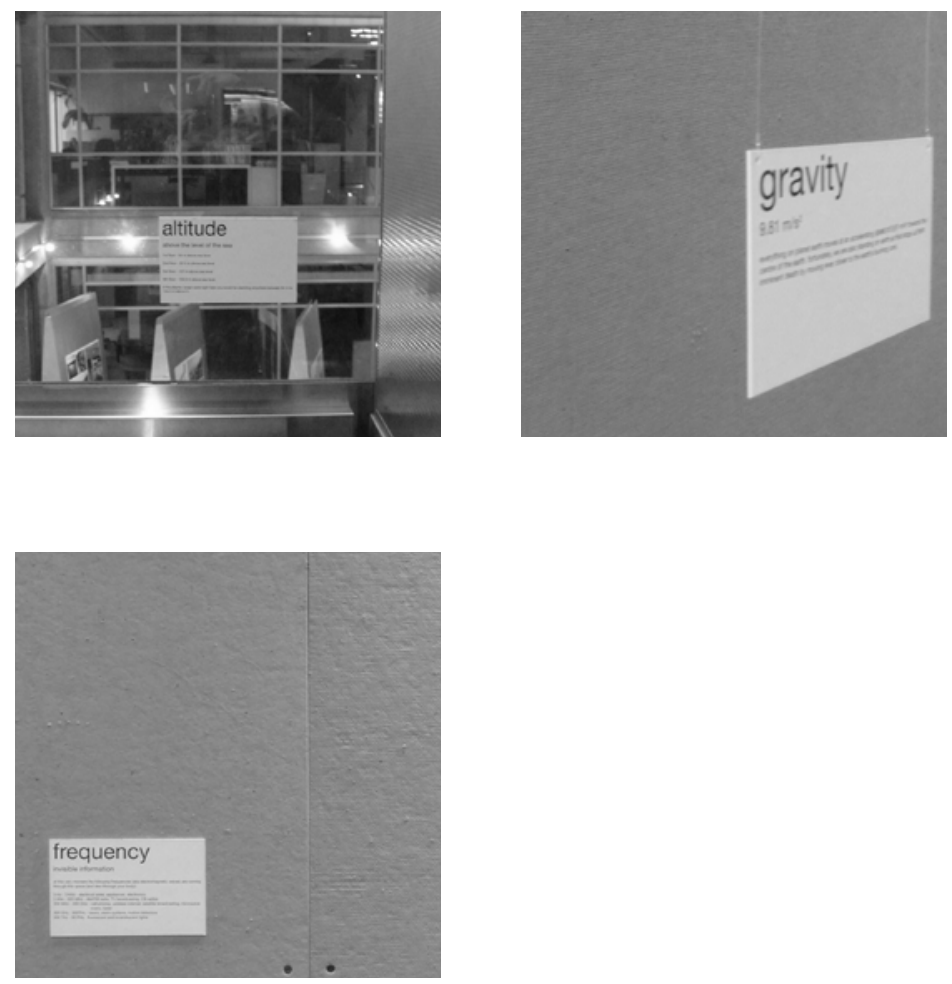



\section{2 less - the act of erasing}

By looking at the strategic removal of particular elements in an environment, these experiments may also be an act of revealing. Focusing particularly on the spatial epitome of consumerist culture, at spaces that seem to exist purely for advertisement or consuming purposes, several locations were chosen in an attempt to eliminate from them this particular consumerist quality and to focus on the spatial quality of the space. The three locations chosen are Times Square in New York City, Dundas Square in Toronto, and Piccadilly Circus in London. These spaces are currently defined by the presence of advertisements - they are recognized based on the advertisements that fill them, the promotional activities that set up within their open spaces, and with their rather strategic locations within each city. By eliminating this consumerist purpose, the spaces become somewhat emptied, void of their consumerist meaning and instead replaced with what the space may have been before it as well as what it could have been outside of a consumerist culture. 

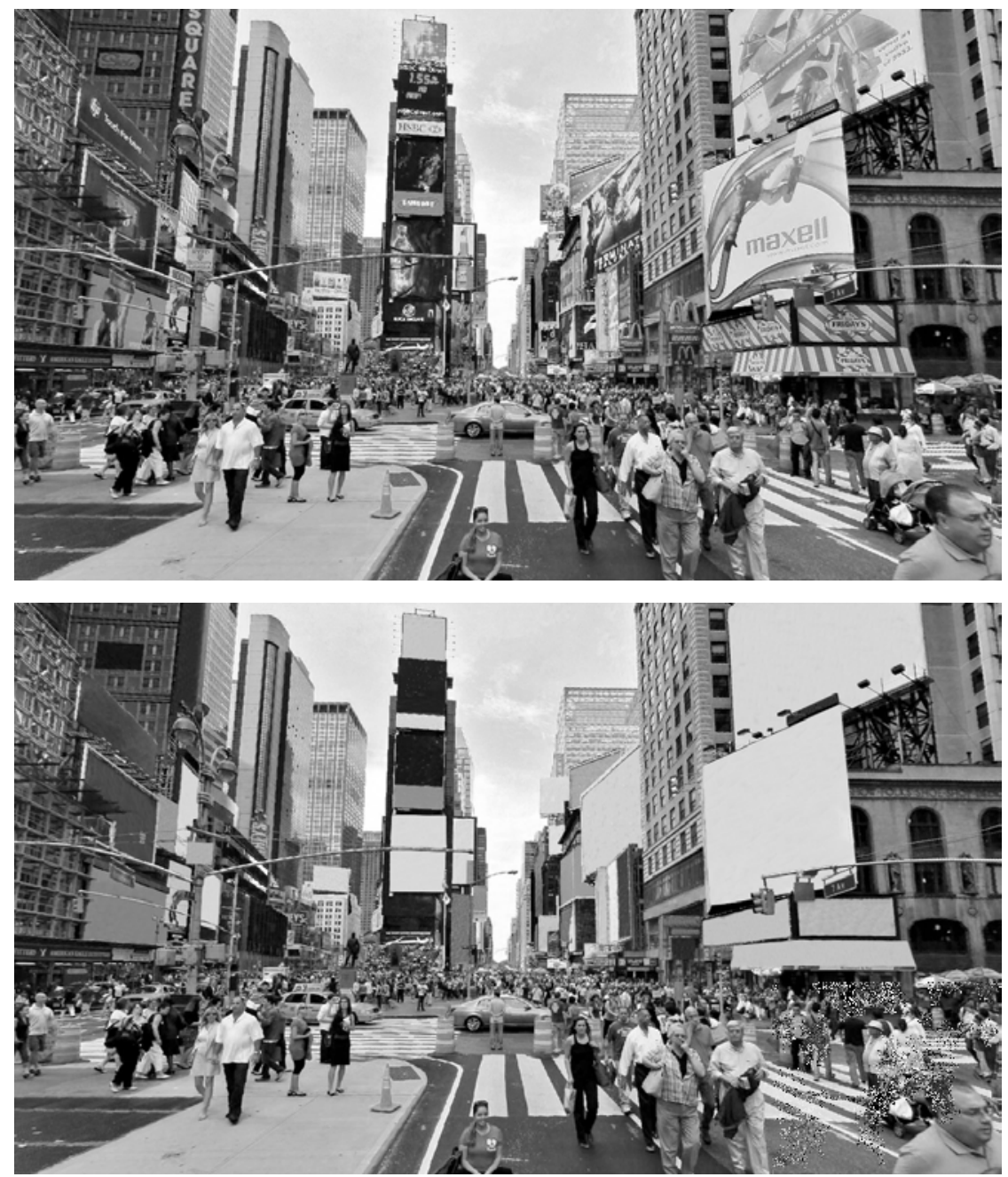

26. Times Square, New York City. 

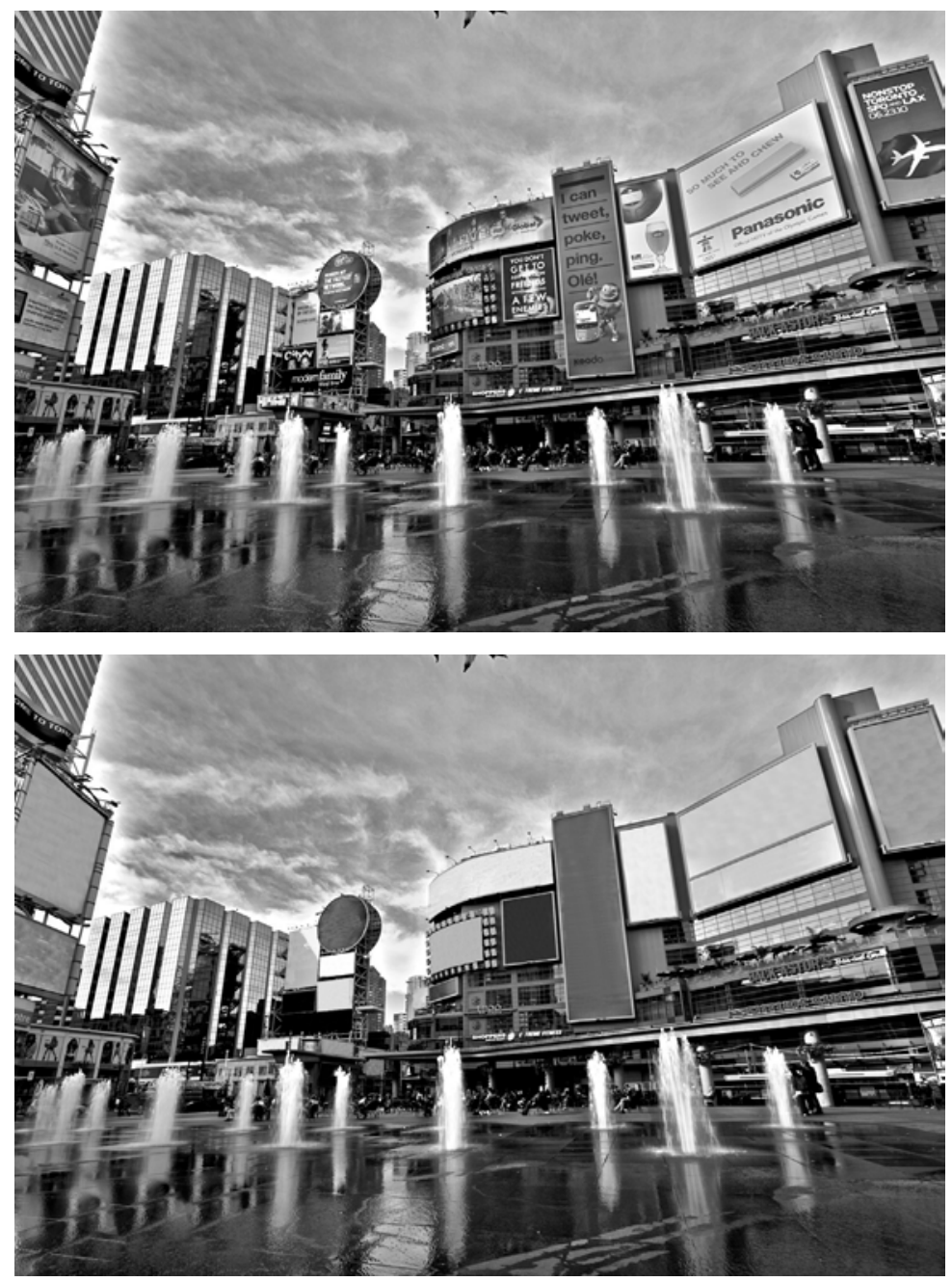

27. Dundas Square, Toronto. 

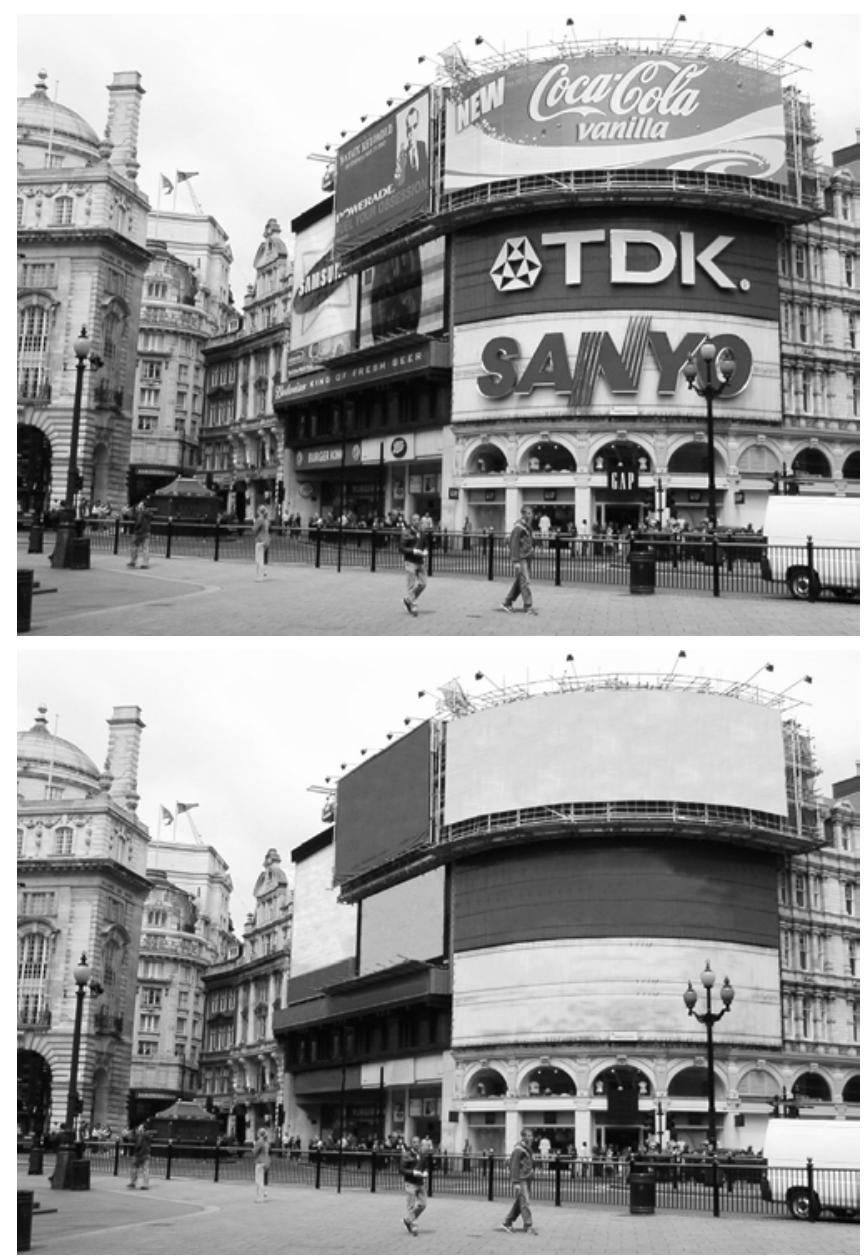

28. Piccadilly Circus, London. 




\section{3 perception - the act of observing}

This experiment explores perception and observation by creating an unconventional observatory that seeks to reveal the skies and nothing else. The observatory serves no other purpose but for observing the sky turning the background into a foreground. As such, the observatory itself cannot be observed. The structure itself will not be seen as the focus will be on the openings that feature particular angles toward the sky. These angles are determined by both the sun and moon - the observatory can be used in either the day or the night. This experiment is very much in line with both the ideas surrounding the void, including the Perimeters, Pavilions, Decoys project by Mary Miss and also in the vein of representation that Mies is known for; evading the idea that this is an object at all. The representation allows it to be seen as not the object known as the observatory but instead as the space that offers what an observatory is programmed for. As such, the observatory can be placed within either a rural or an urban condition - as long as the building itself (if it can be indeed referred to as a building) is masked or hidden within the existing context of a site. 

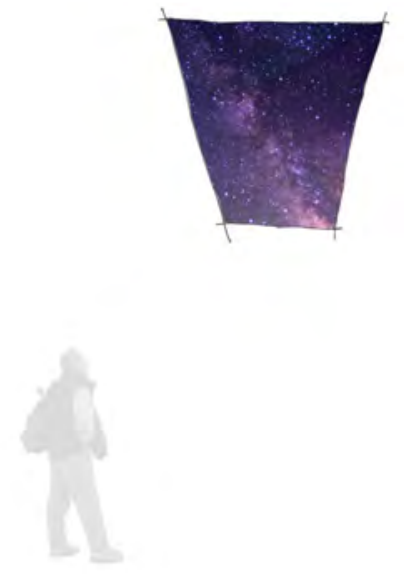

29. Interior view of observatory at night. 


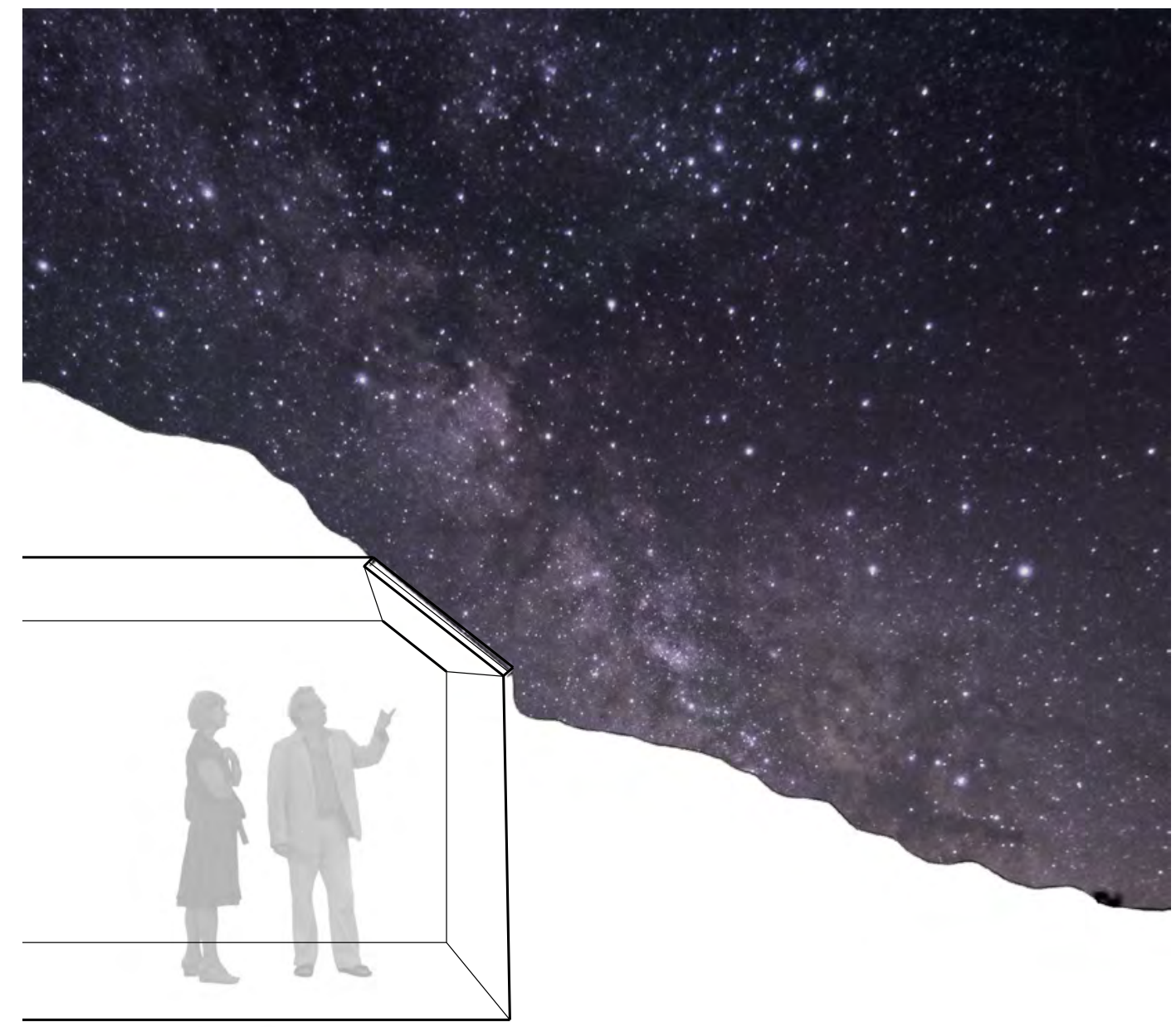

30. Section through observatory space. 


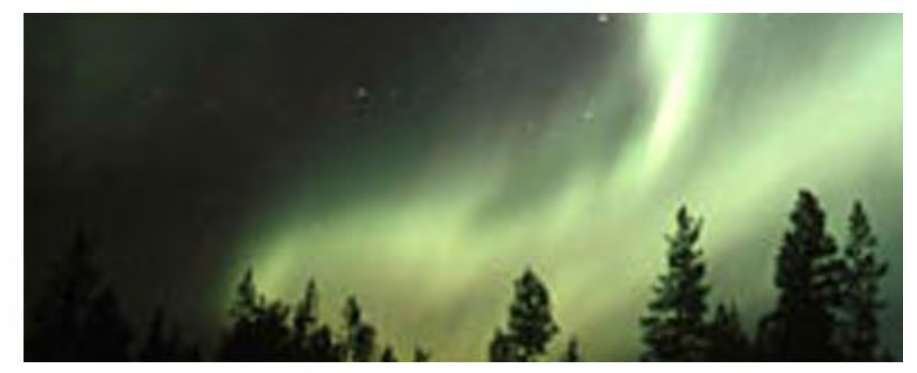




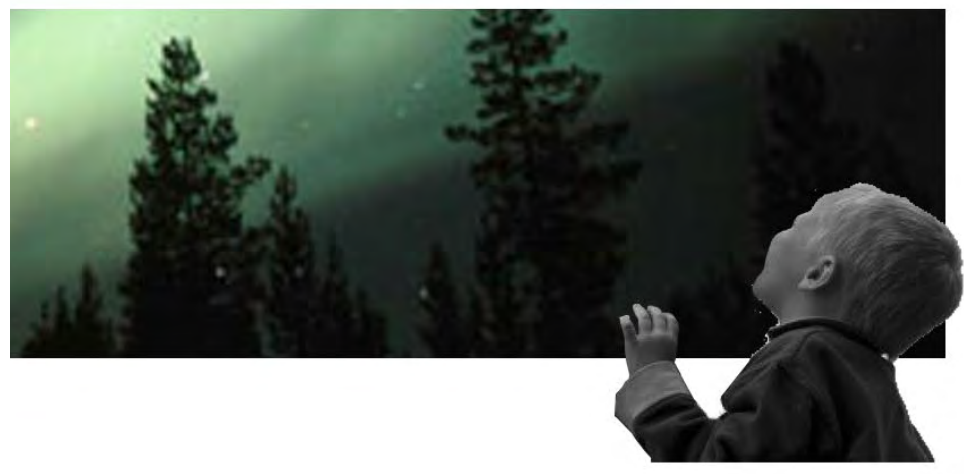

31. Window looking to the north. 



\section{4 restraint - the act of revealing}

The final experiment took the ideas generated from the previous experiments and attempted to apply them to a real site - along the Queen Street West shopping corridor. In his 1903 essay, "The Metropolis and Mental Life," Georg Simmel claimed that the urban dweller is essentially bound in a psychological condition brought on by "the intensification of emotional life due to the swift and continuous shift of external and internal stimuli" (Simmel, 1903, p. 11). Rather than acting in a more emotional manner to, for example, a dying homeless man on the side of the street or to a beautiful piece of classical music being performed in a subway station, the "metropolitan type reacts primarily in a rational manner" where the mind is "moved to a sphere of mental activity which is least sensitive and which is furthest removed from the depths of the personality" (Simmel, 1903, p. 12). Yet, in becoming numb to the stimuli of a city, in an effort to survive and not be overcome, the urban dweller leaves behind the "resistance ... to being leveled, swallowed up in the social-technological mechanism" (Simmel, 1903, p. 11). The same can be said in regards to today's dominant consumer culture - one where either the objects of such a culture or the propaganda that goes along with it consistently overwhelms us or where Sudjic's objects of suffocation, Eco's fake realities and the endless forms of unconscious architecture all play into this intensification, each adding to the deluge of stuff that makes up our lives. The twenty-first 
century urban dweller also possesses a numbness in regards to the 'intensification' of their surroundings - and they have to. Cities are so packed with stimuli that one cannot possibly react to all of them. Is it possible to remove the mind from this state, this psychological condition that Simmel refers to, and create something (or nothing) as a Heideggarian withdrawal that reveals meaning?

The design was initiated by a list of terms that defined the space that was to be created, inspired by both the case studies and Kuma's work in Anti-Object (Figure 32). From the list, a design was developed to become a pause amongst a consumerist strip in the city. The site, near Queen Street West and Peter Street in downtown Toronto, lies right in the heart of many major retailers and popular chain restaurants - essentially a very consumerist neighborhood similar to an outdoor mall (Figures 33, 34, 36-40). Amongst this densely packed shopping experience lies a newly created void. The site was destroyed by fire in October 2012, causing the demolition of the existing building (which at the time contained a clothing retailer and tattoo parlor). Left behind in the rubble and ash was a deep void in this shopping fabric and it is for this reason that this site acts as the fourth experiment - an instrument for revealing, for pulling away in order to reveal. 
CRITERIA:

ephemeral

boundless

fleeting.

timeless

spectacle -less

reserved

restrained

meaningful

subtle

dependent (outside forms)

revealing.

modest

quiet

opportunistic

reflection (prschoophys.)

simularmn

temporal

transformative

32. List of terms.

111 


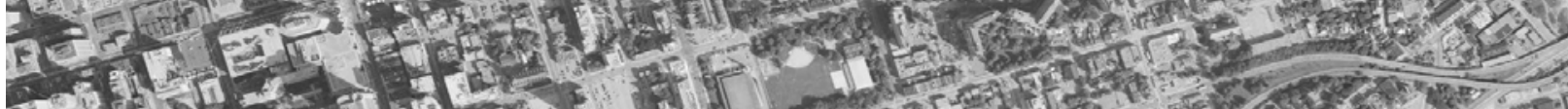

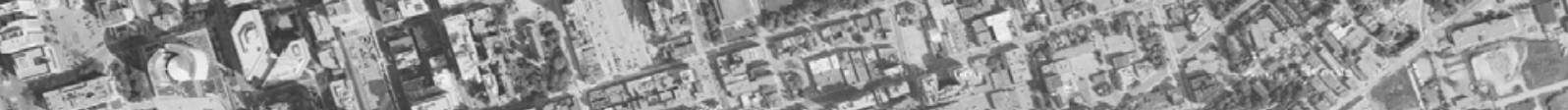

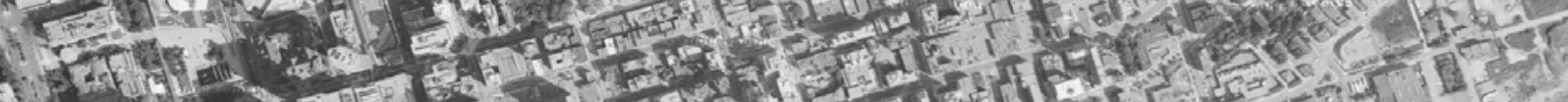

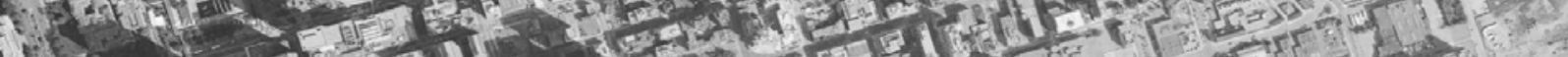

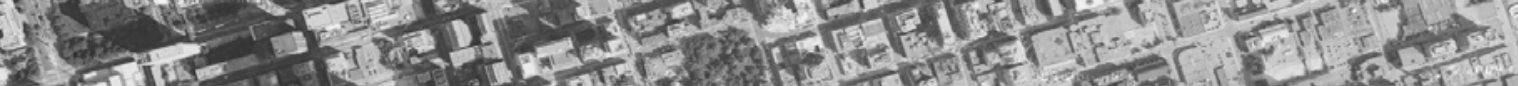

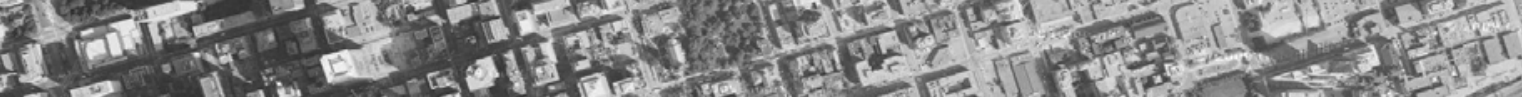

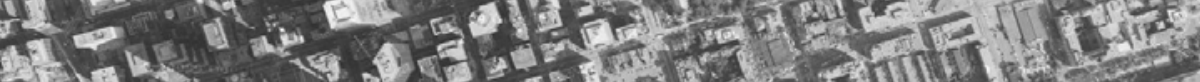

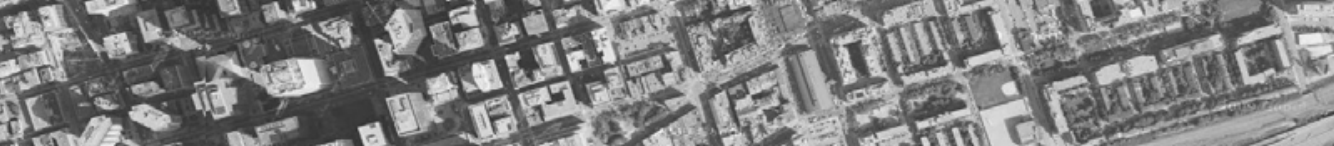

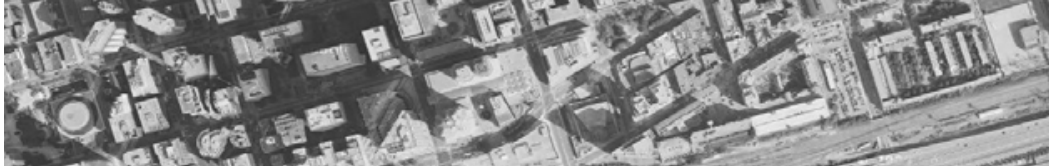
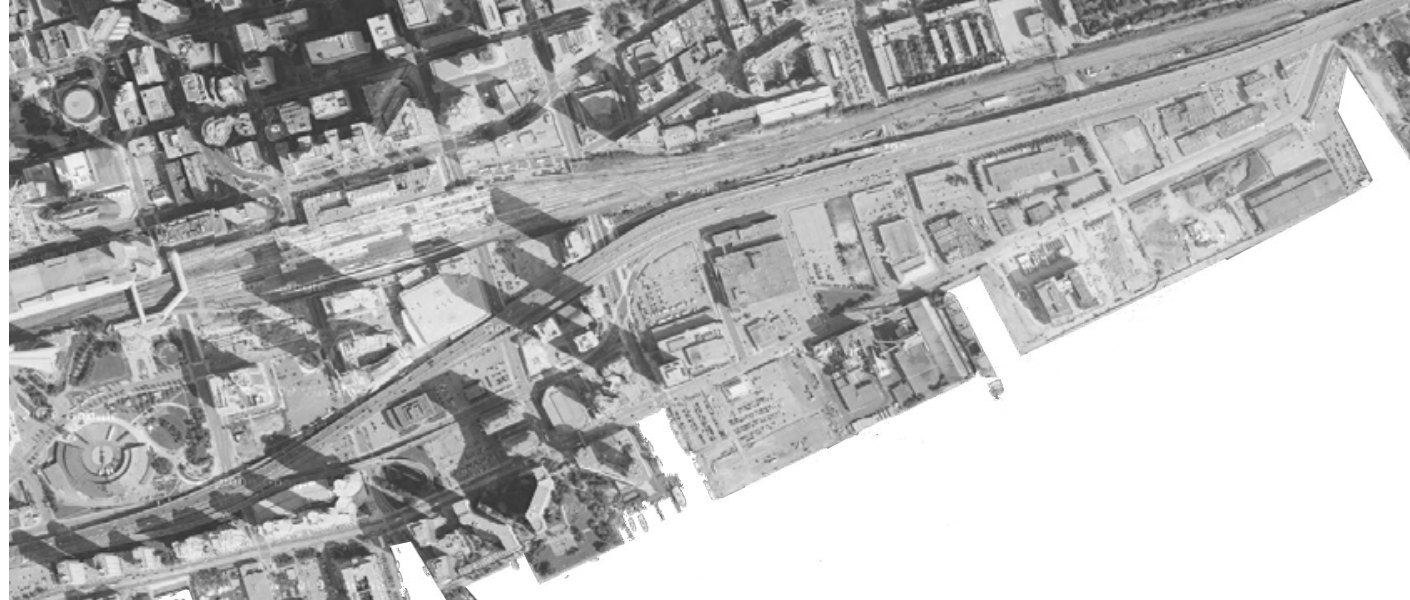

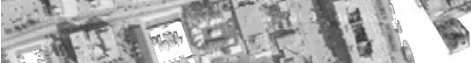

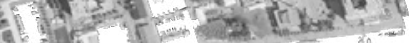

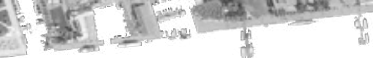

33. Context map - City of Toronto, downtown 


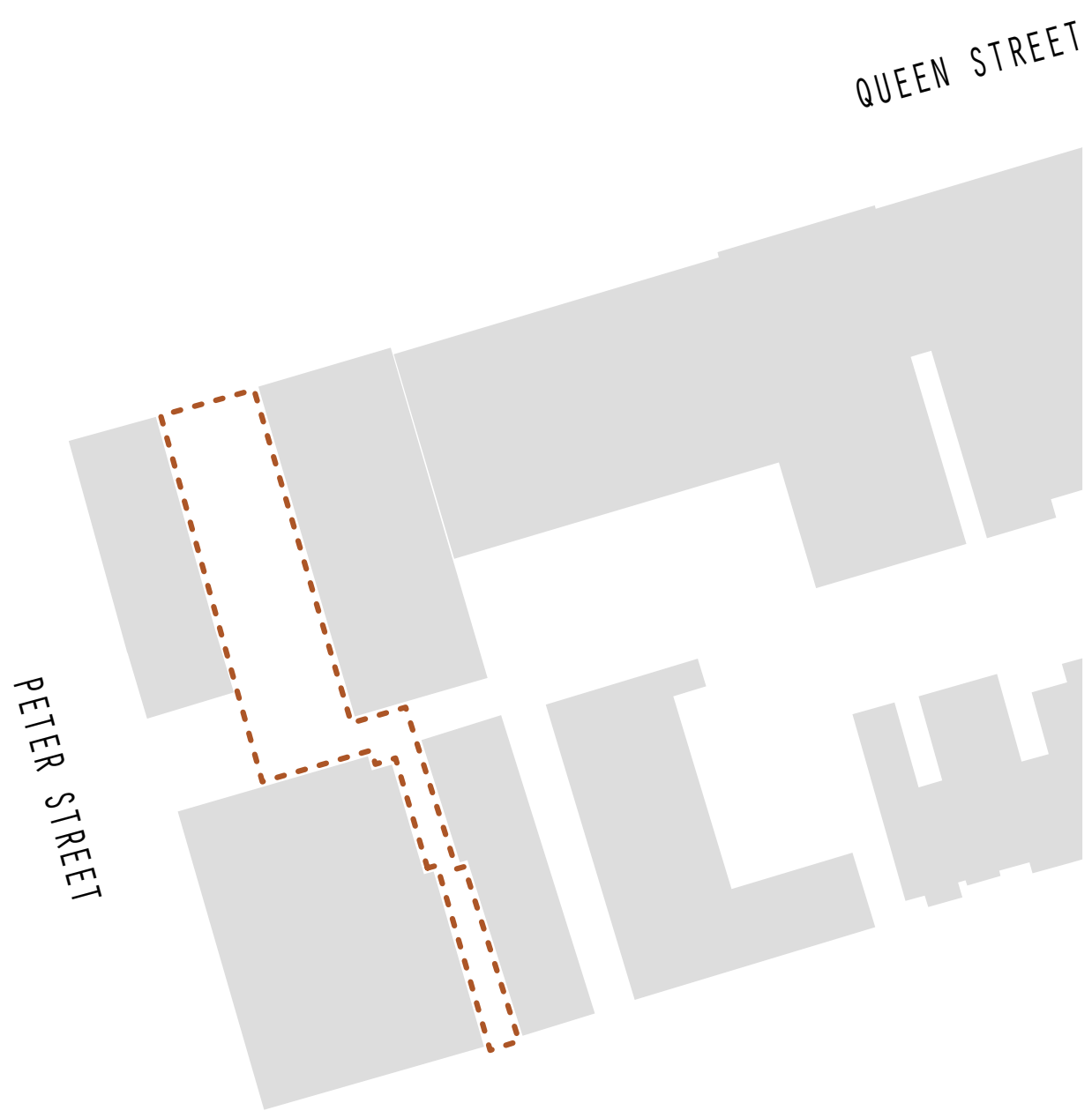

114 


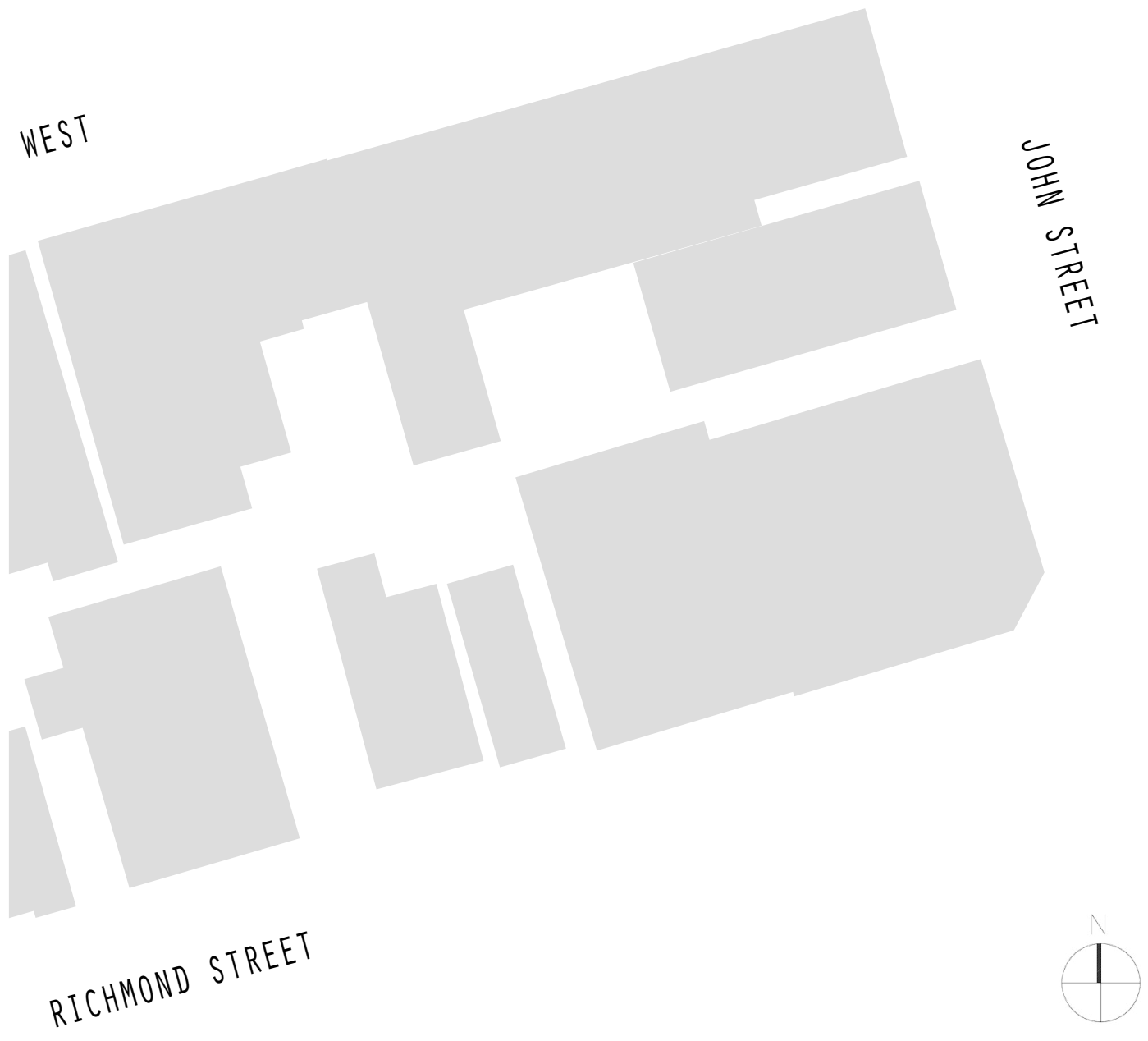

34. Site map. 
There are three major interventions on the site: (1) a path that stretches from Queen Street West to Richmond Street West, (2) a focus on the planes that bound the site itself, and lastly, (3) an (anti)object that defines the main entry to the site along the Queen Street West façade (Figure 35). Along the first intervention (1) through the alleyway, the design is focused around light and movement. The second intervention (2) alters the walls that bound the site through reflection, blurring and skewing perspective through the use of water and aluminum. The third intervention (3) along the north facing façade is both an object and not an object - a screen that defines the built portion of the site. In addition to these three major interventions, the site is bounded by reflective aluminum edging, which layers the site and, with the planes of water, is representational of the Buddhist line of thinking where the self is removed from the world through a series of stages of purification. Each boundary, in this way, acts as a similar sort of threshold as each visitor is removed from the condition of the street to the condition of the site (Figure 41). 


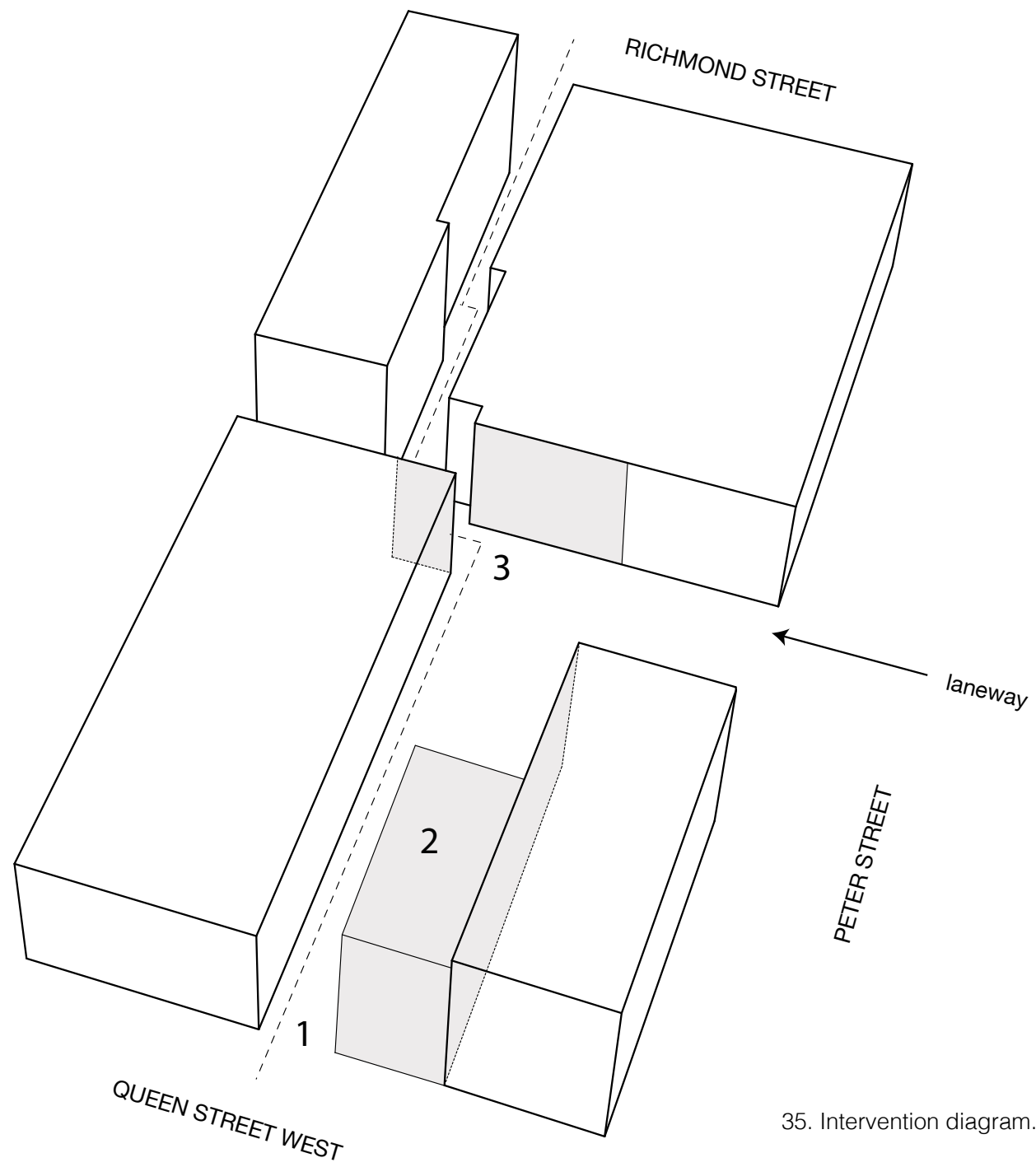



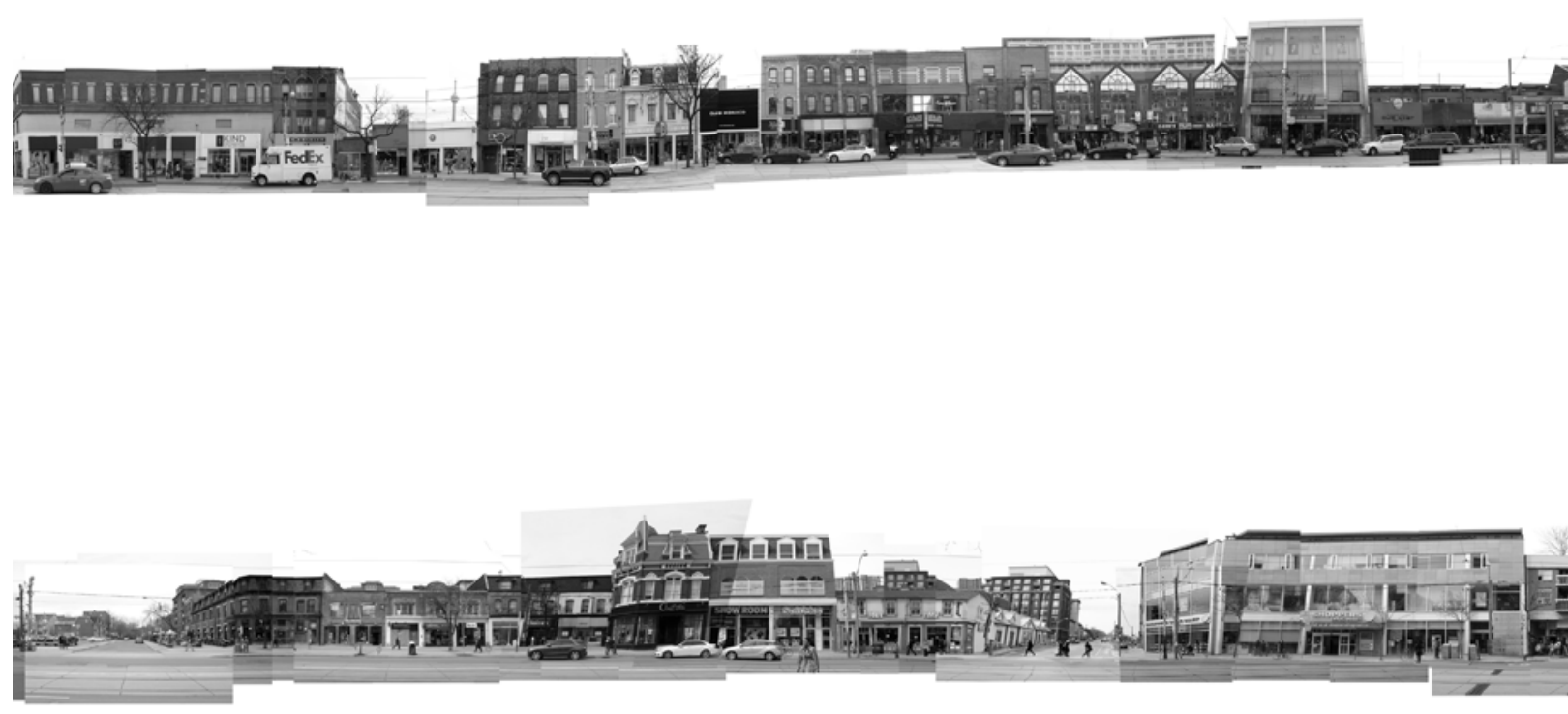

36. Context of Queen Street W. (from John to Spadina) South Elevation (above), North Elevation (below). 


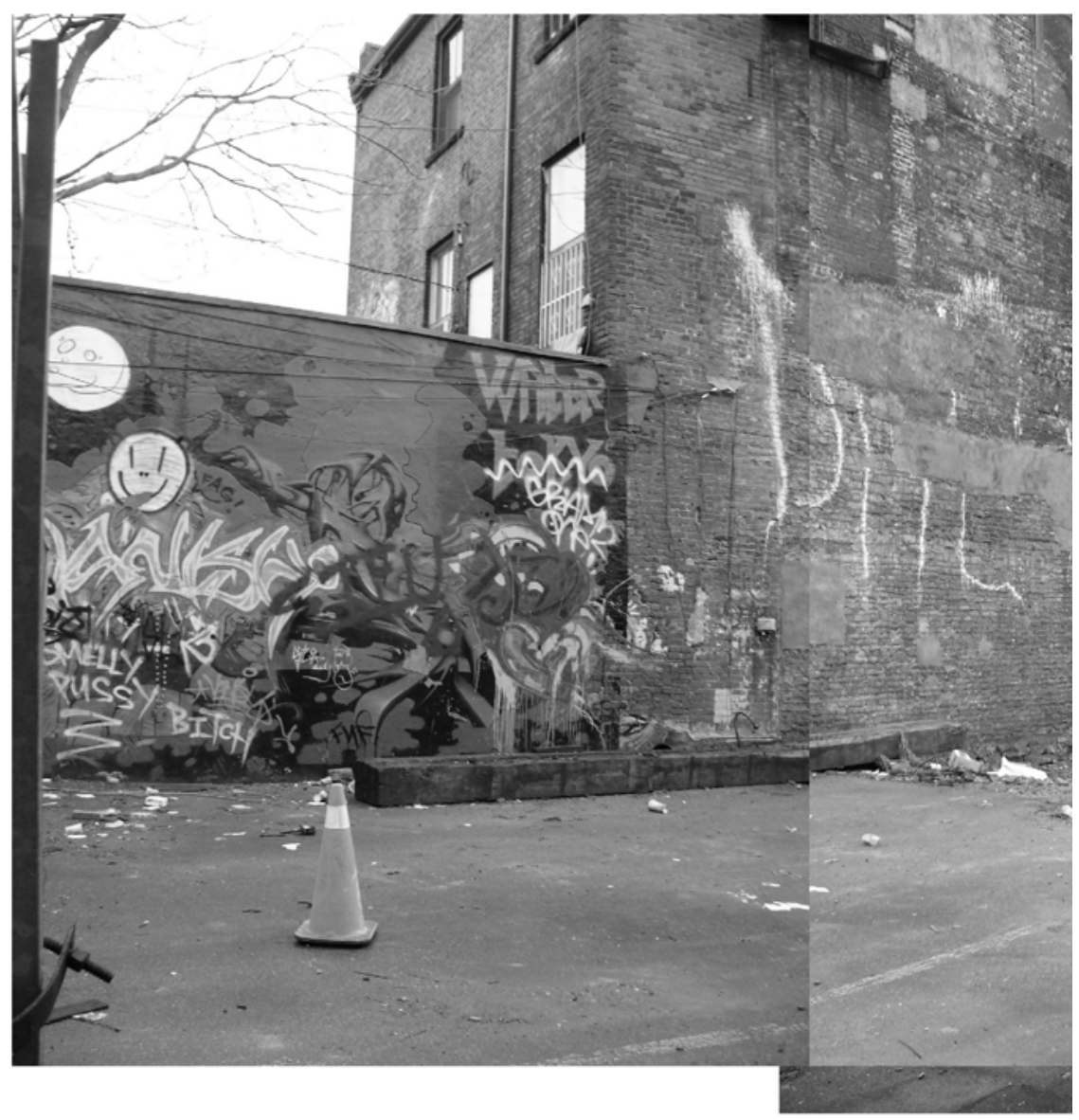

37. View of existing site looking North. 


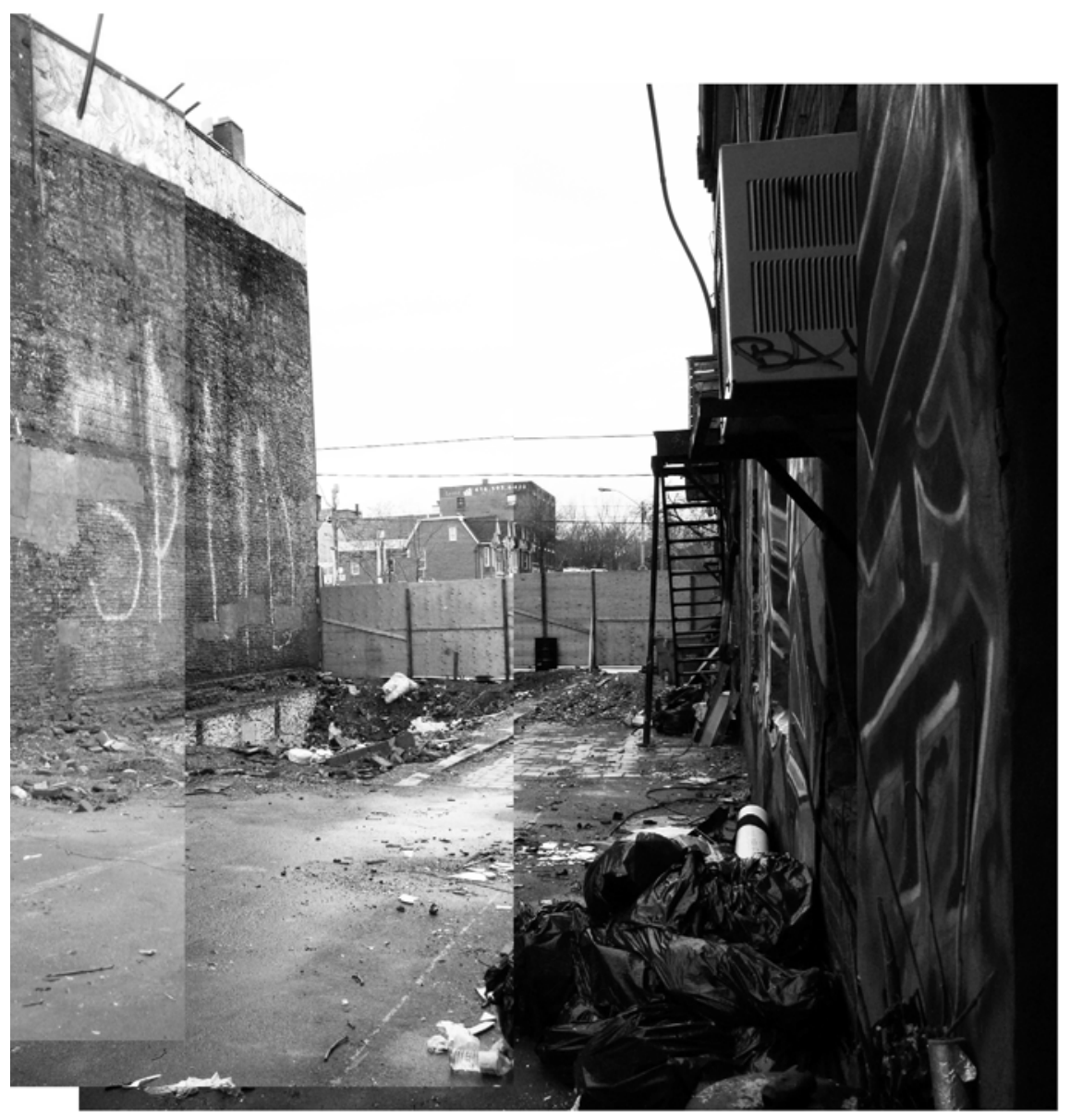




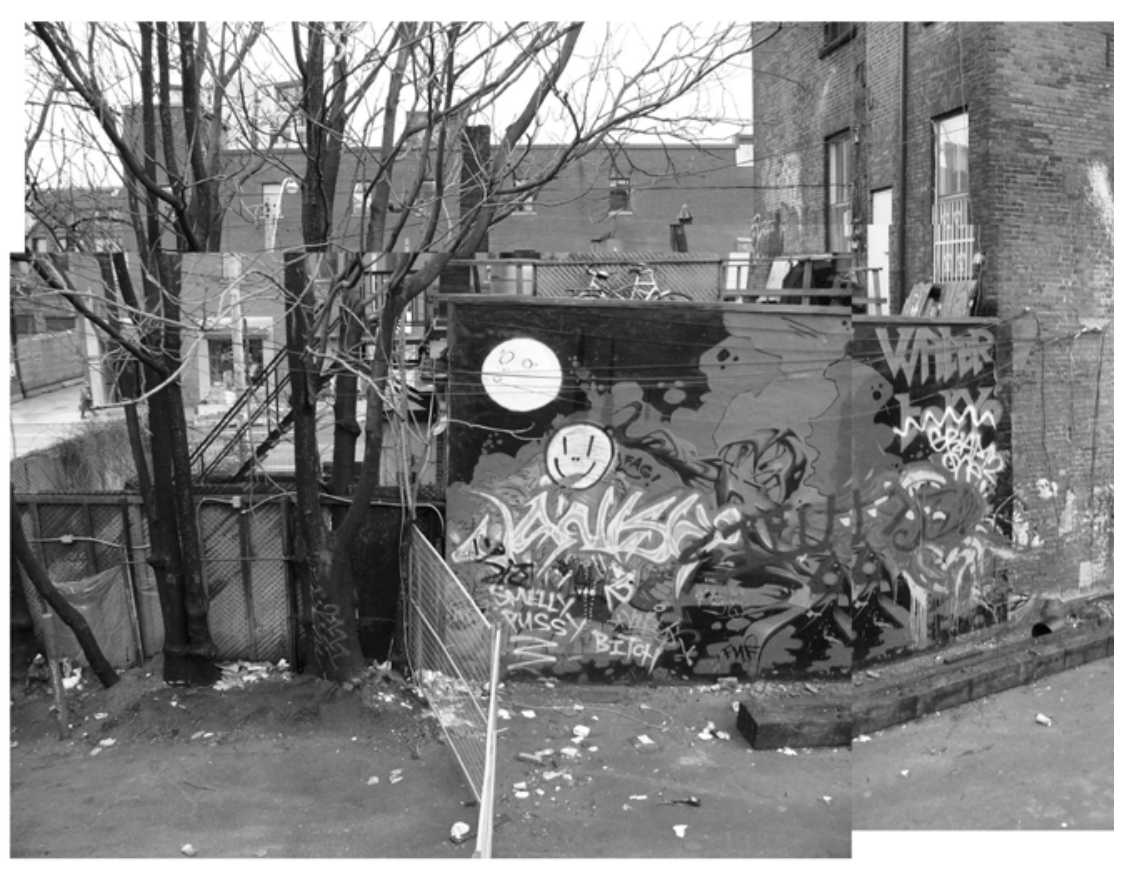

38. View of existing from above looking North. 


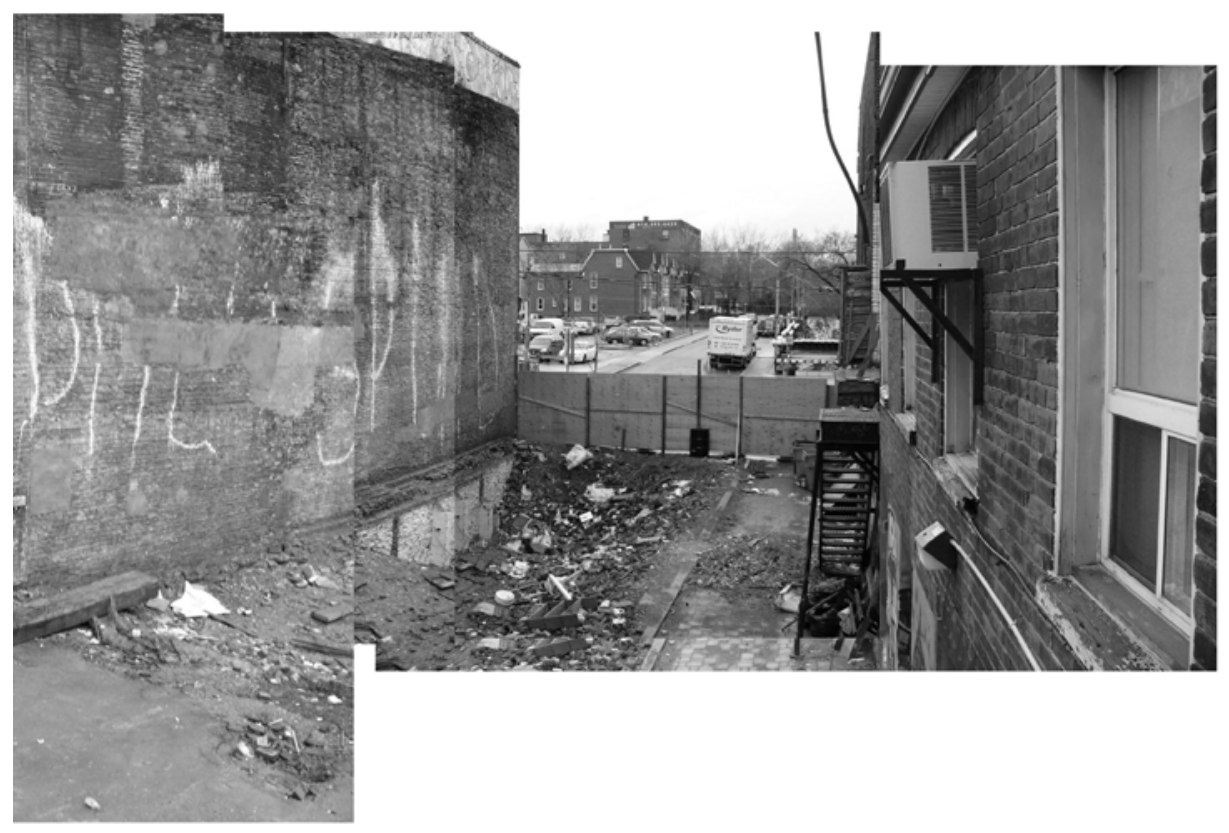




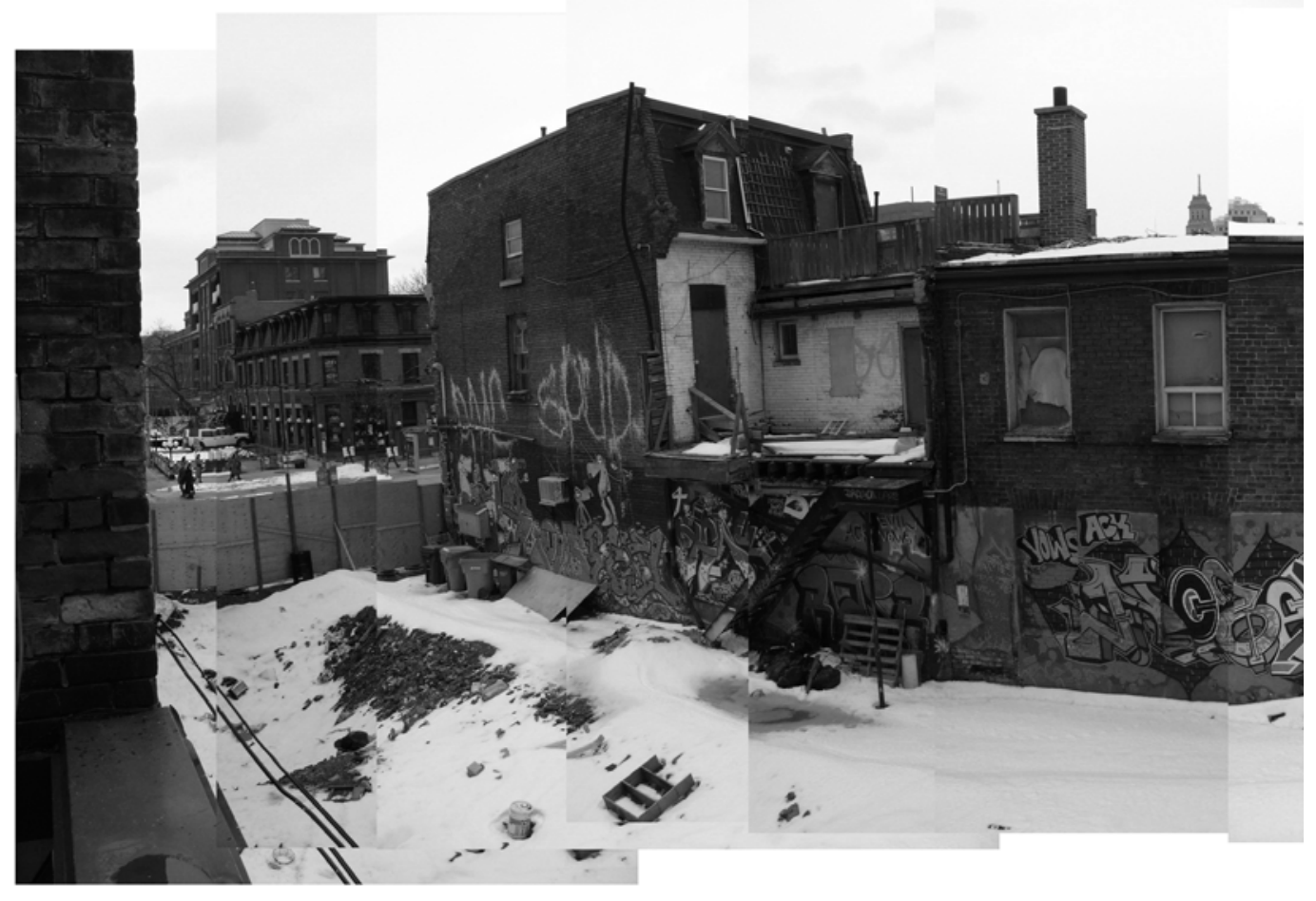

39. View of existing site looking East. 


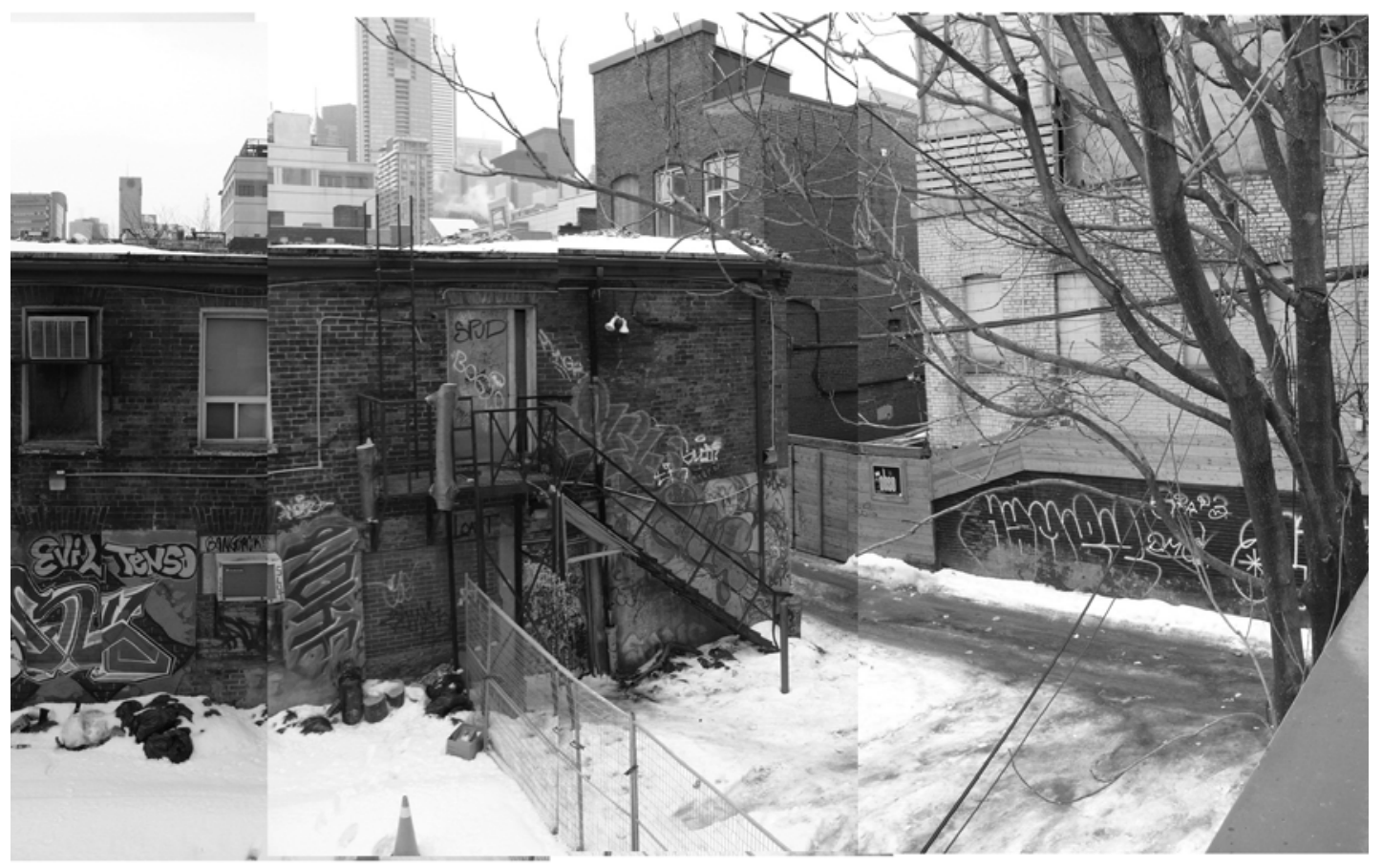




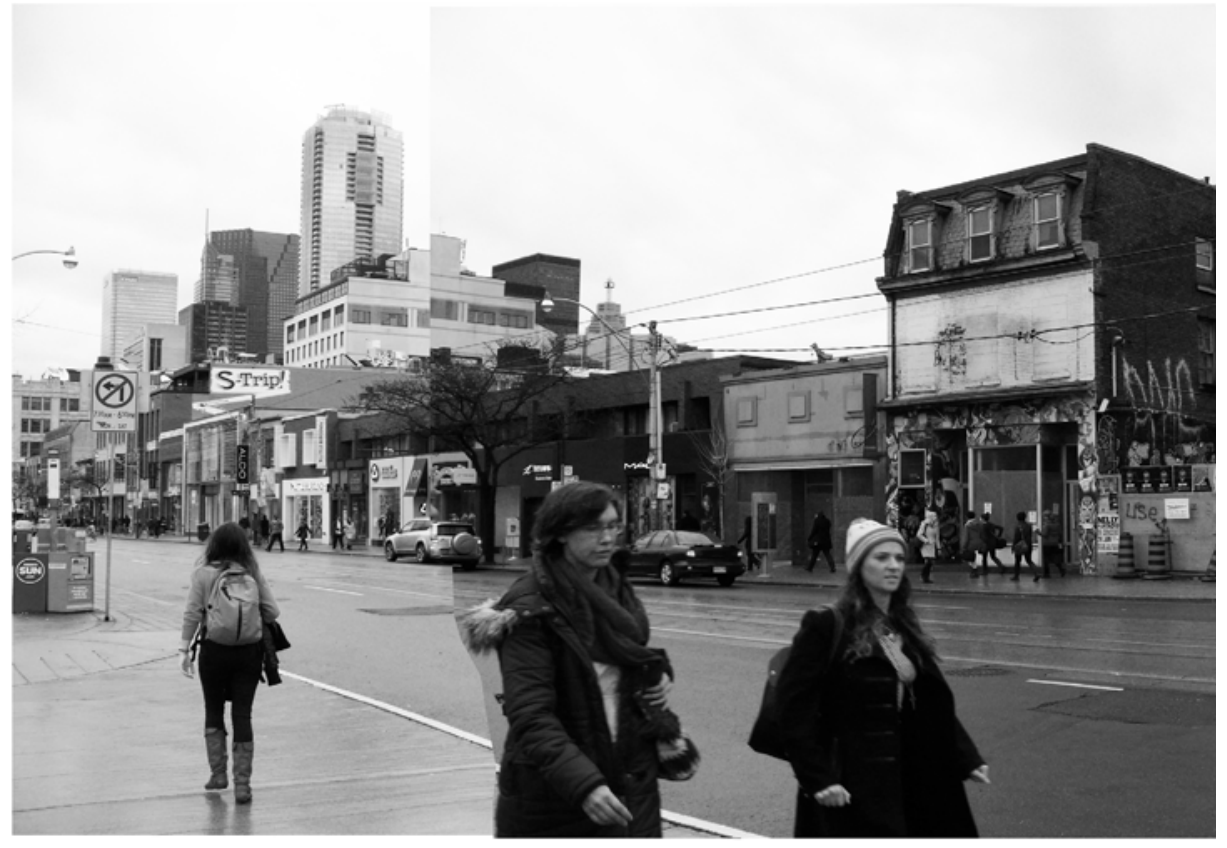

40. View of existing site looking South. 


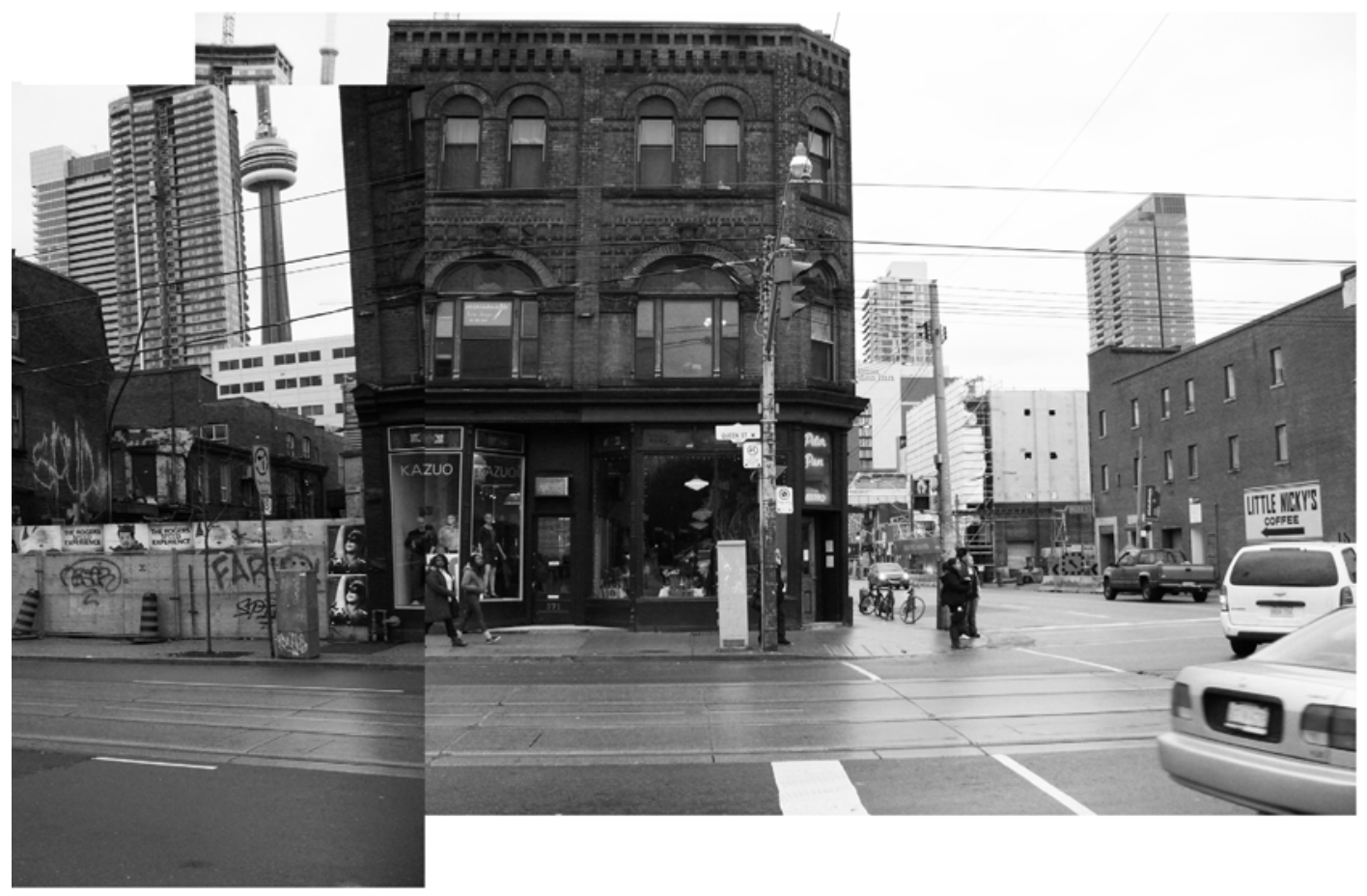




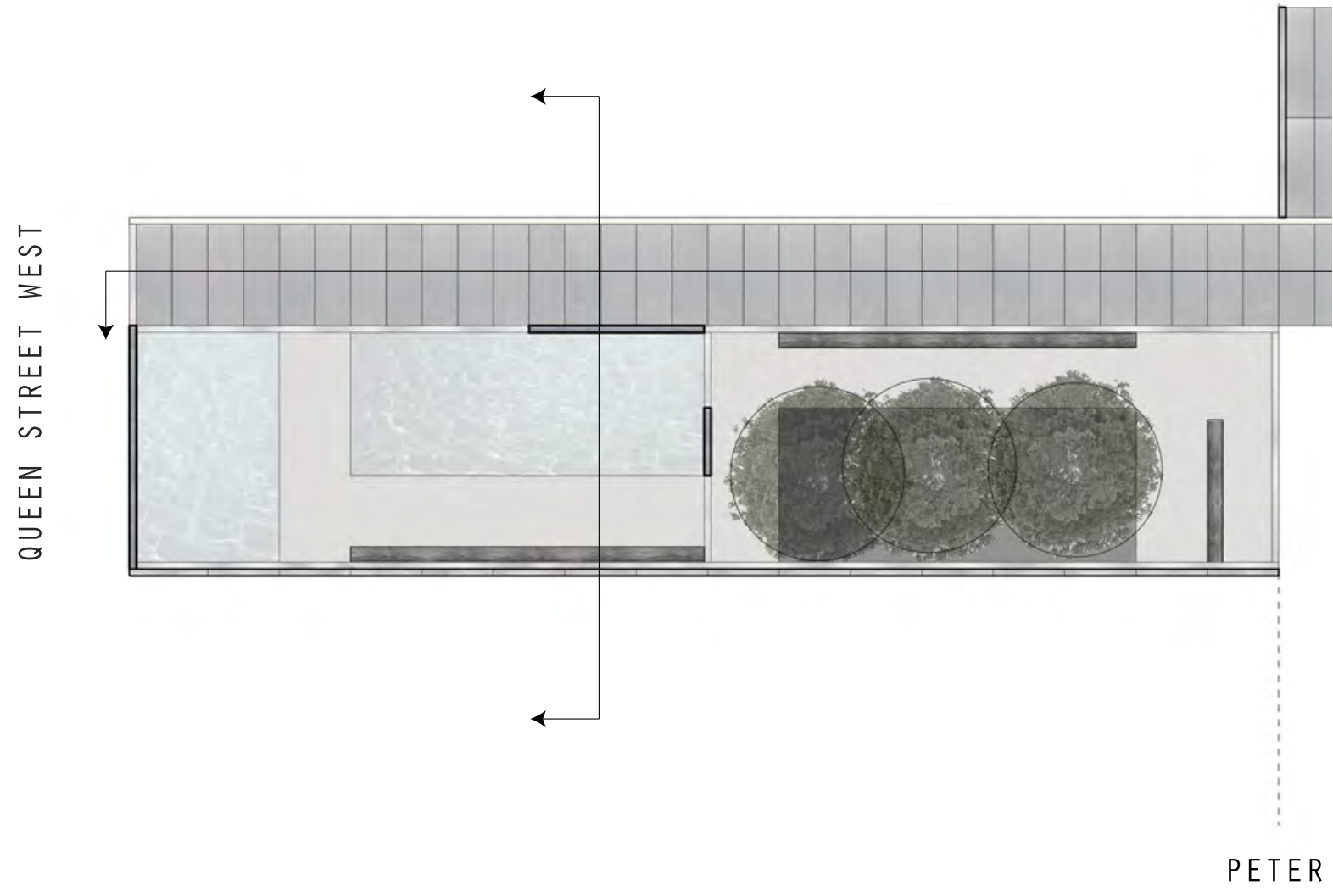




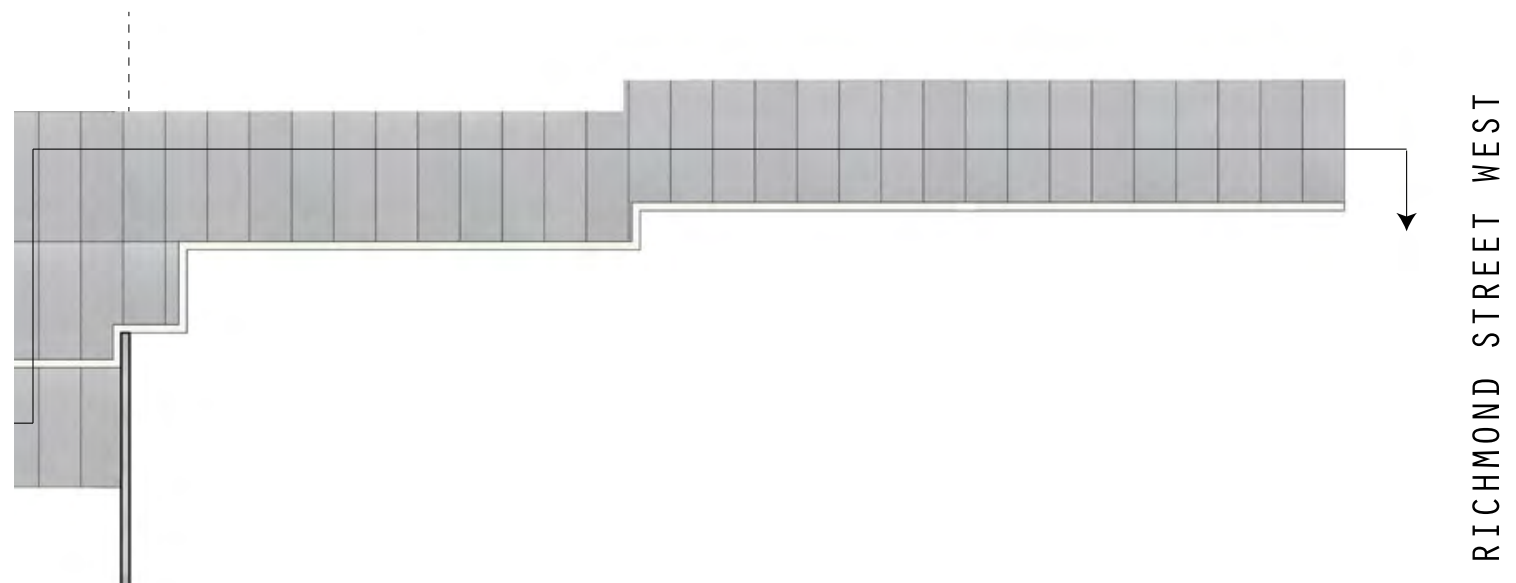

STREET

41. Site Plan. 


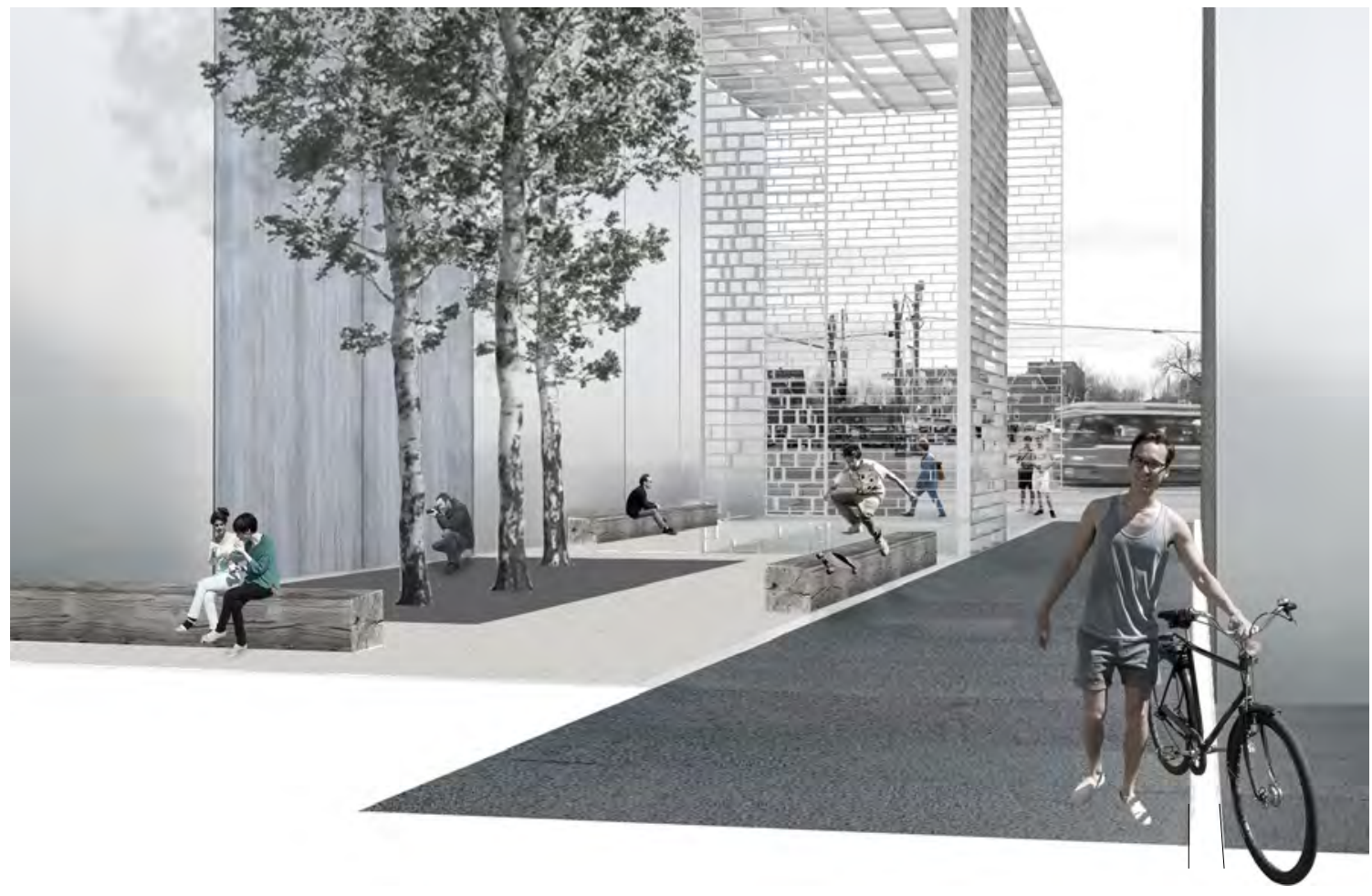

42. Looking North to Queen Street West. 
Instead of defining the materials used as concrete or glass, they are defined in a similar manner as the terms that first defined the design as water/ice/fog, sound/silence, light/darkness, temperature, color, etc. However, the tangible materials (including aluminum, sandblasted glass, flamed black granite, crushed obsidian and limestone screening) act as the material infrastructure to support these ephemeral experiences. The sandblasted glass carries the light that defines the first intervention; the aluminum carries the reflective properties of light, shadow and water through the site. Limiting the color palette in the site, the aluminum and water pull colour from the surroundings as it changes throughout the day, the week, the year. If an added element did not possess this reflectivity, the condition became that the element would be mostly comprised of either black or white in regards to color - black being the absence or complete absorption of light and white being the presence of all colors or zero absorption of light. For example, the ground condition beneath the waterwall is made up of black crushed obsidian in contrast to the much lighter limestone screening elsewhere on the site.

With this experiment, the idea was to create a pause amongst the chaos that exists in an urban condition. This pause was to be minimally designed in the sense of minimal elements that were to be considered an object while maintaining the space as void and creating the experience of nothingness. With the level of reflectivity and the elimination of city sounds - the site pulls the visitor from meaninglessness into meaningfulness, from unconsciousness to consciousness. 


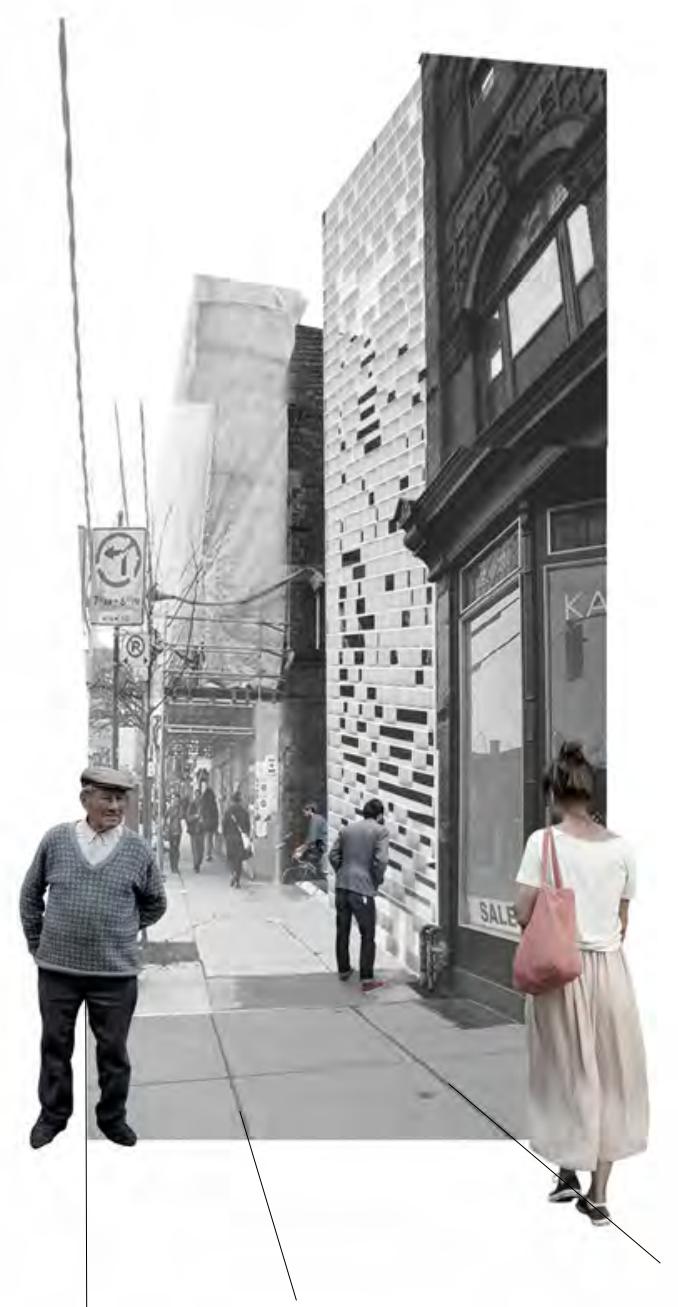

43. Looking East along Queen Street West. 


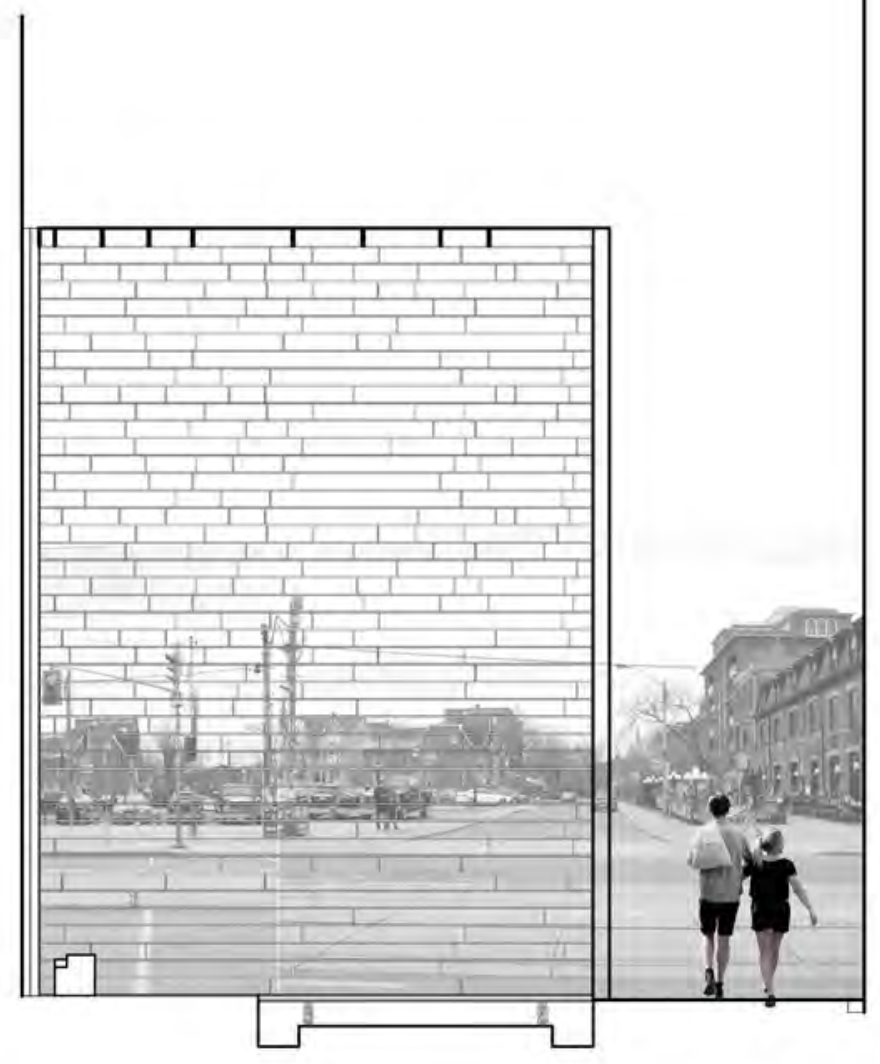

44. Transverse section looking North. 


\section{light detail}

This detail acts to wash a brick wall on the site with soft light. In addition, it is a line that follows the path through the site - beginning with the main entrance/exit point to Queen Street West and ending with a secondary entrance/exit point at Richmond Street West.

The element of the light detail extends throughout the site and is combined with the level of reflectivity from the aluminum and the water.

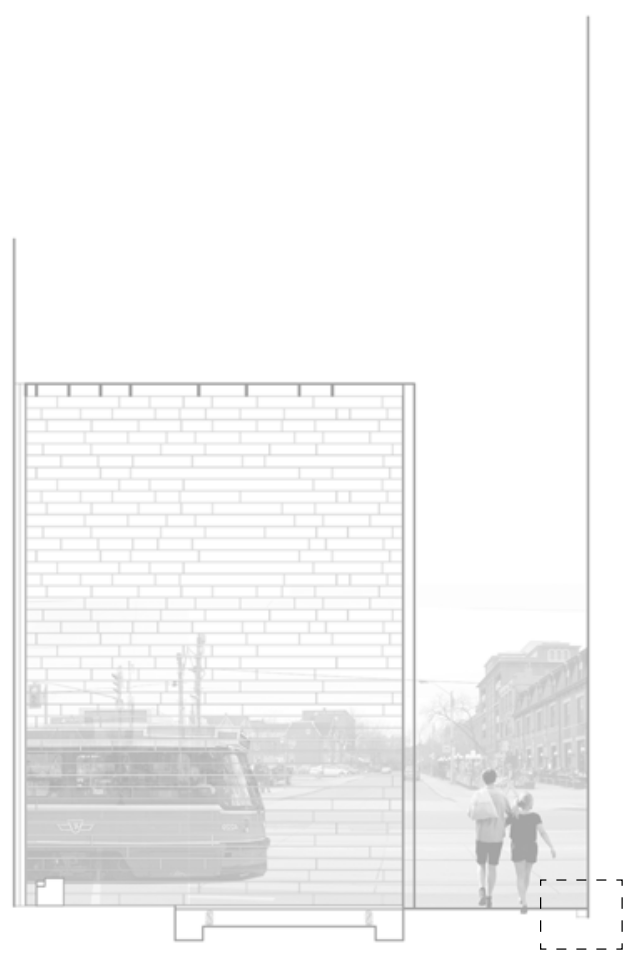




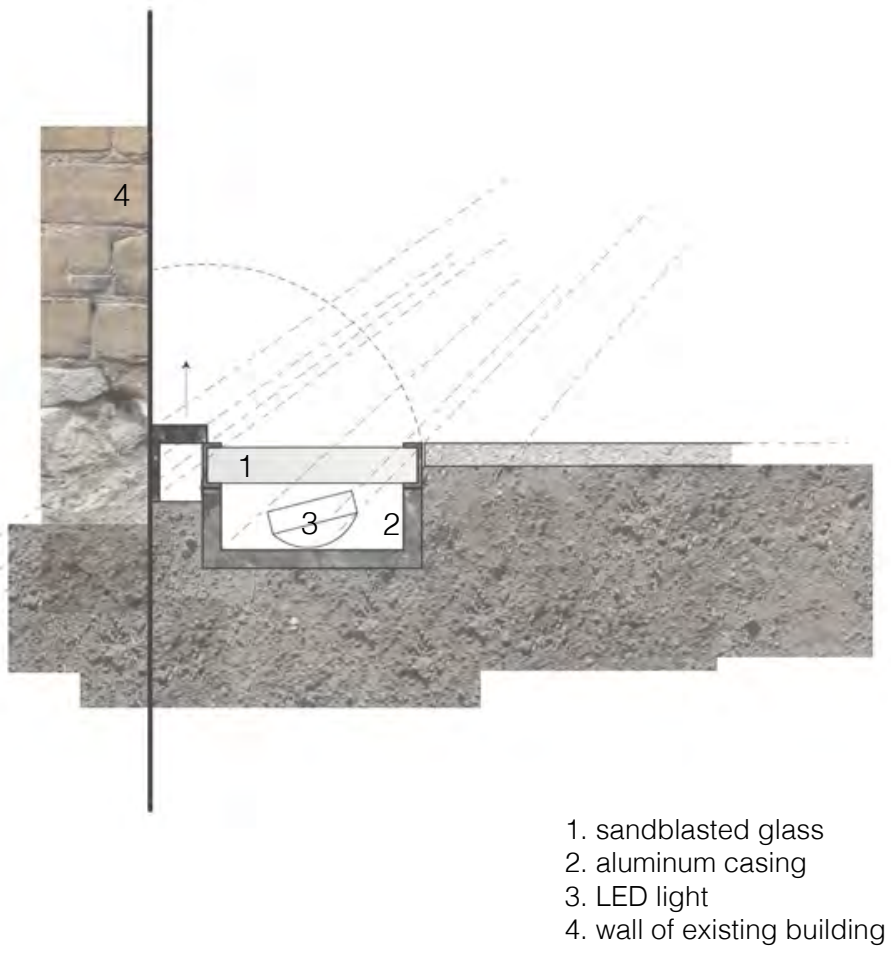

45. Light detail. 


\section{bench detail}

This detail continues the light detail through to the seating within the site softly illuminating both the aluminum edging that lines the south part of the site as well as the aluminum panels that extend along the length of the west side of the site.

The two details represent the bench that sits within the latticed structure next to the horizontal water feature in the northern part of the site (shown to the left) and the bench, with the light inverted, along the southern portion facing the waterwall.

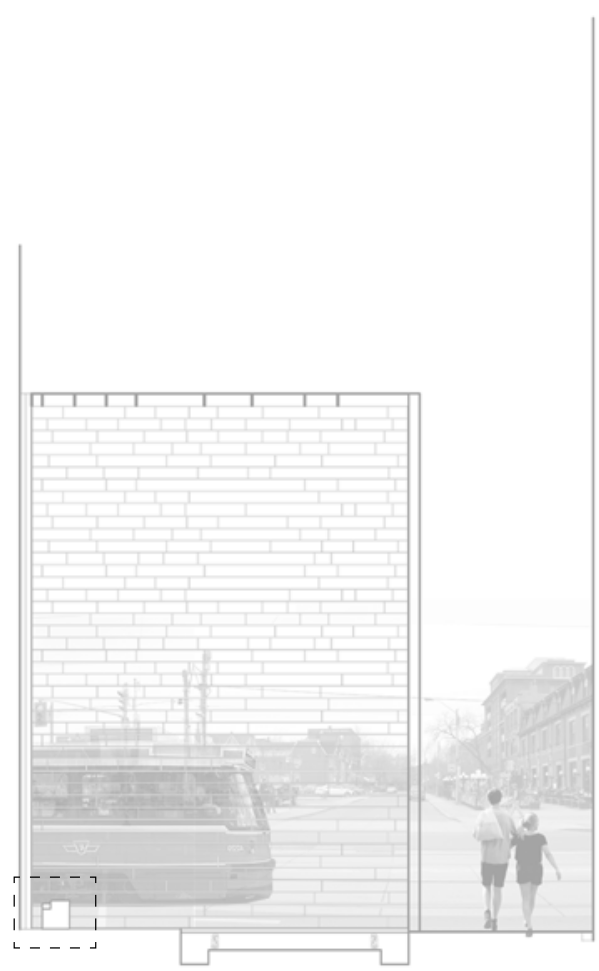



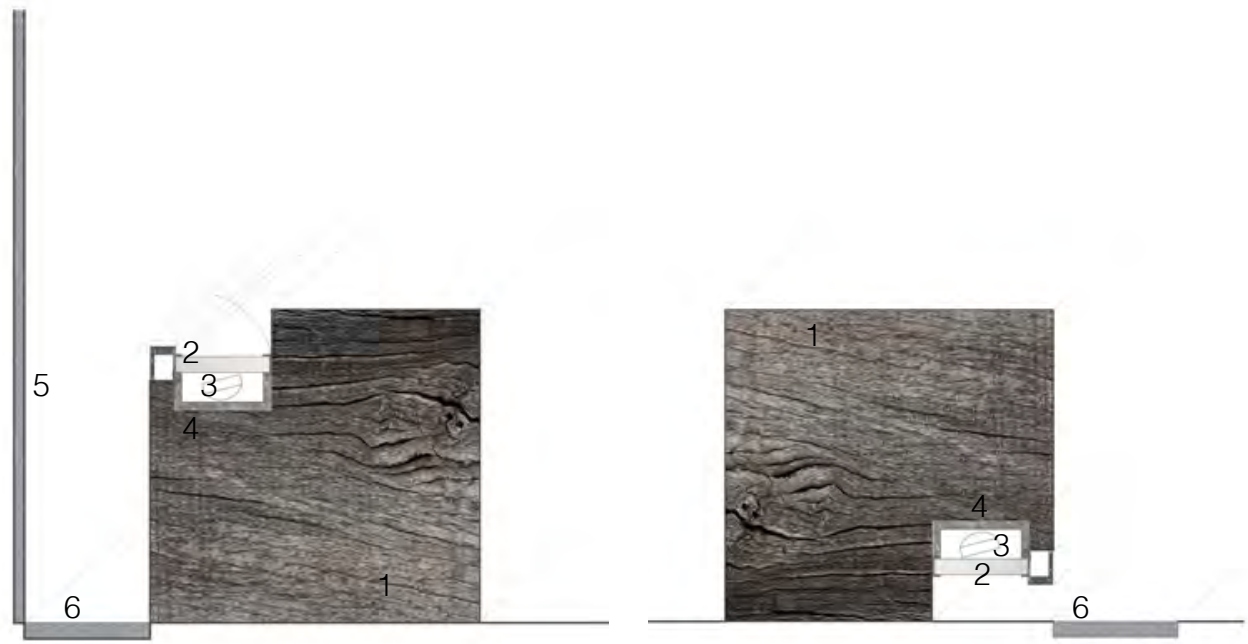

1. reclaimed wood bench

2. sandblasted glass

3. LED light

4. aluminum casing

5. aluminum panel

6. aluminum edging

46. Bench detail. 


\section{water detail}

This detail, focused upon two horizontal planes on the north part of the site, consists of a stainless steel panel that sits upon industrial spings - connecting it with the vibrations of the ground below. When a streetcar or a truck passes by the site, the steel panel will vibrate creating geometric patterns on the surface of the water.

Additionally, an LED light washes this surface with water at night further creating a more reflective and interesting pattern.

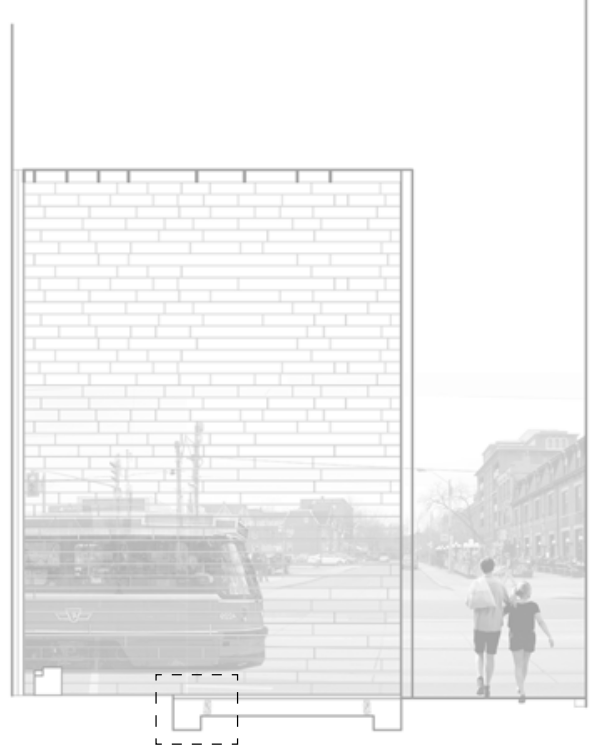




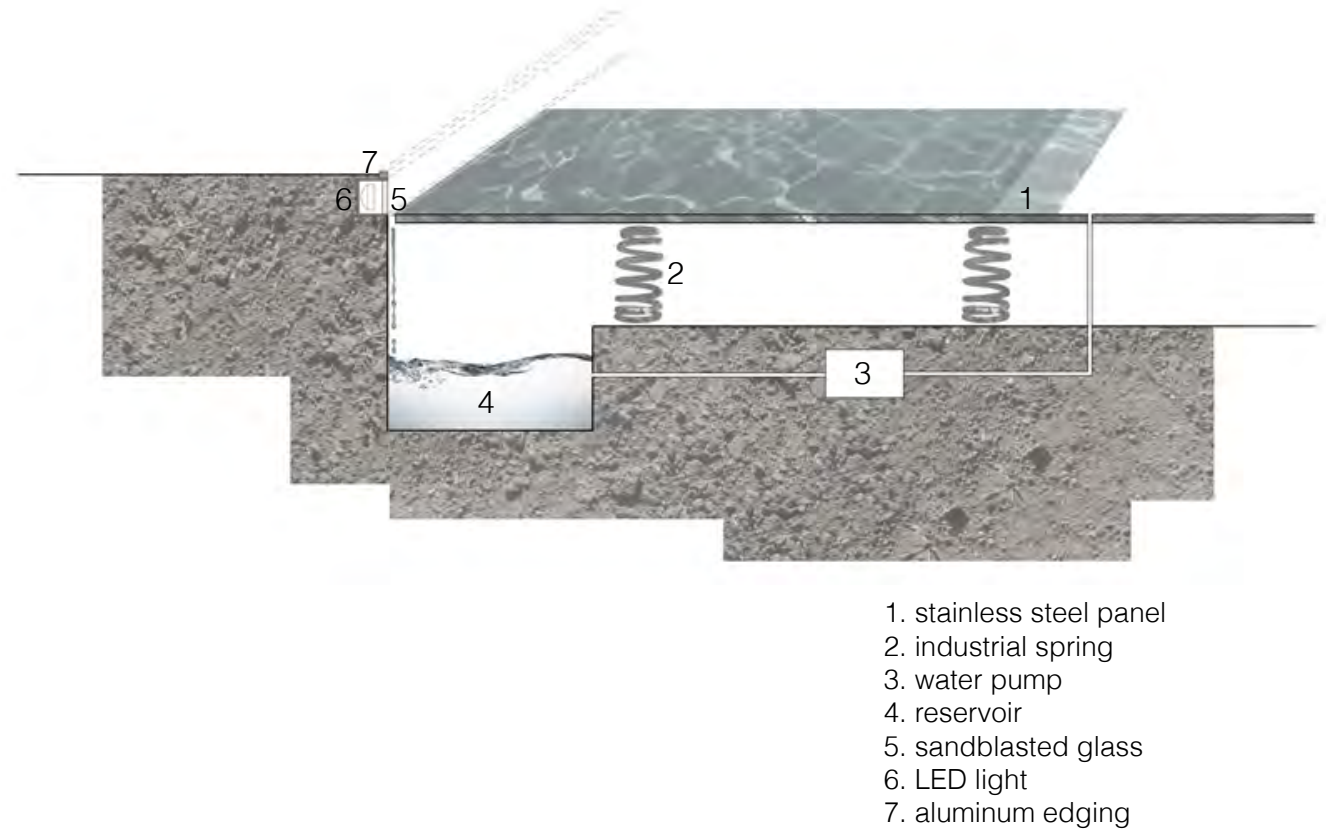

47. Water detail. 


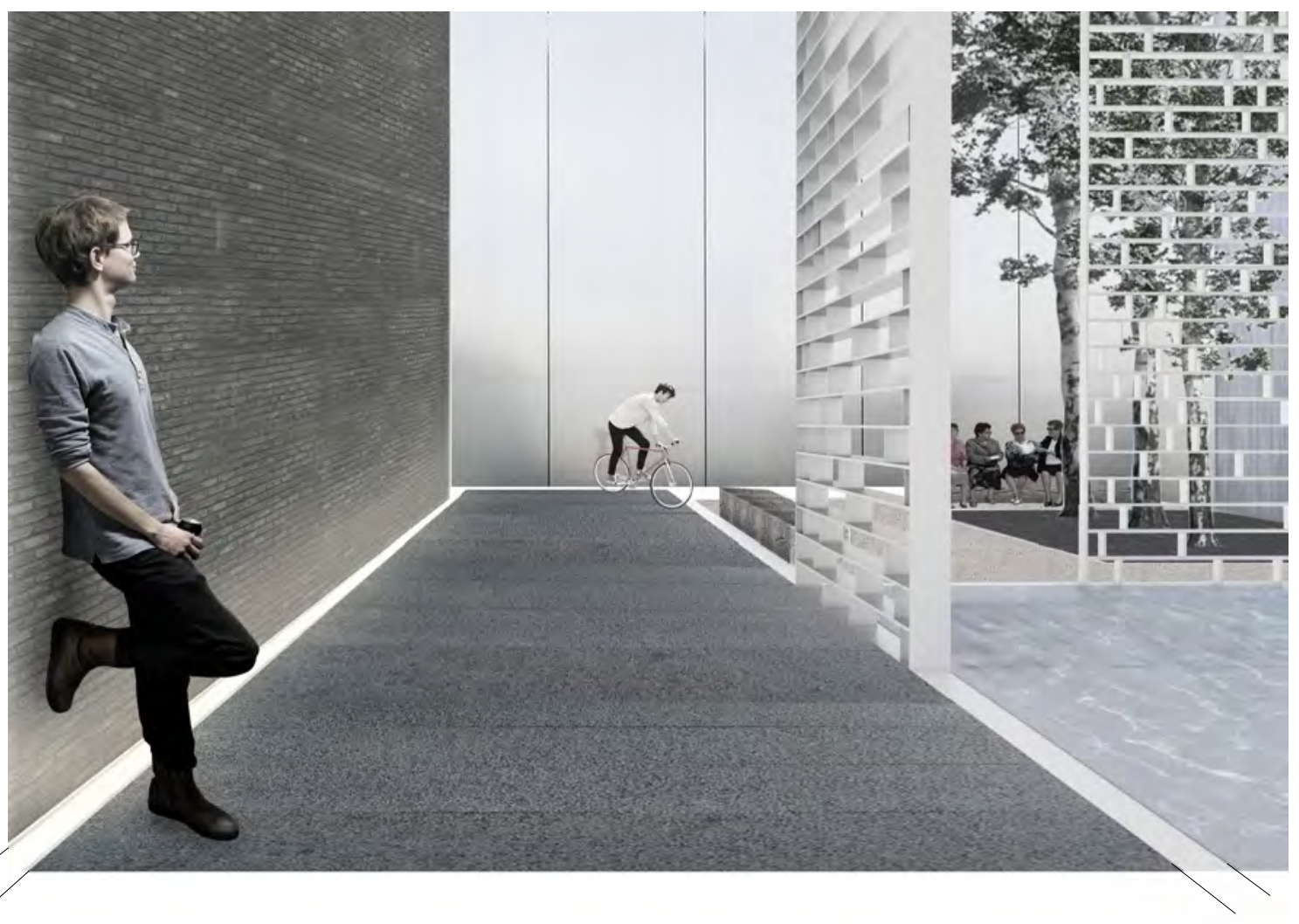

48. Looking South through the site. 


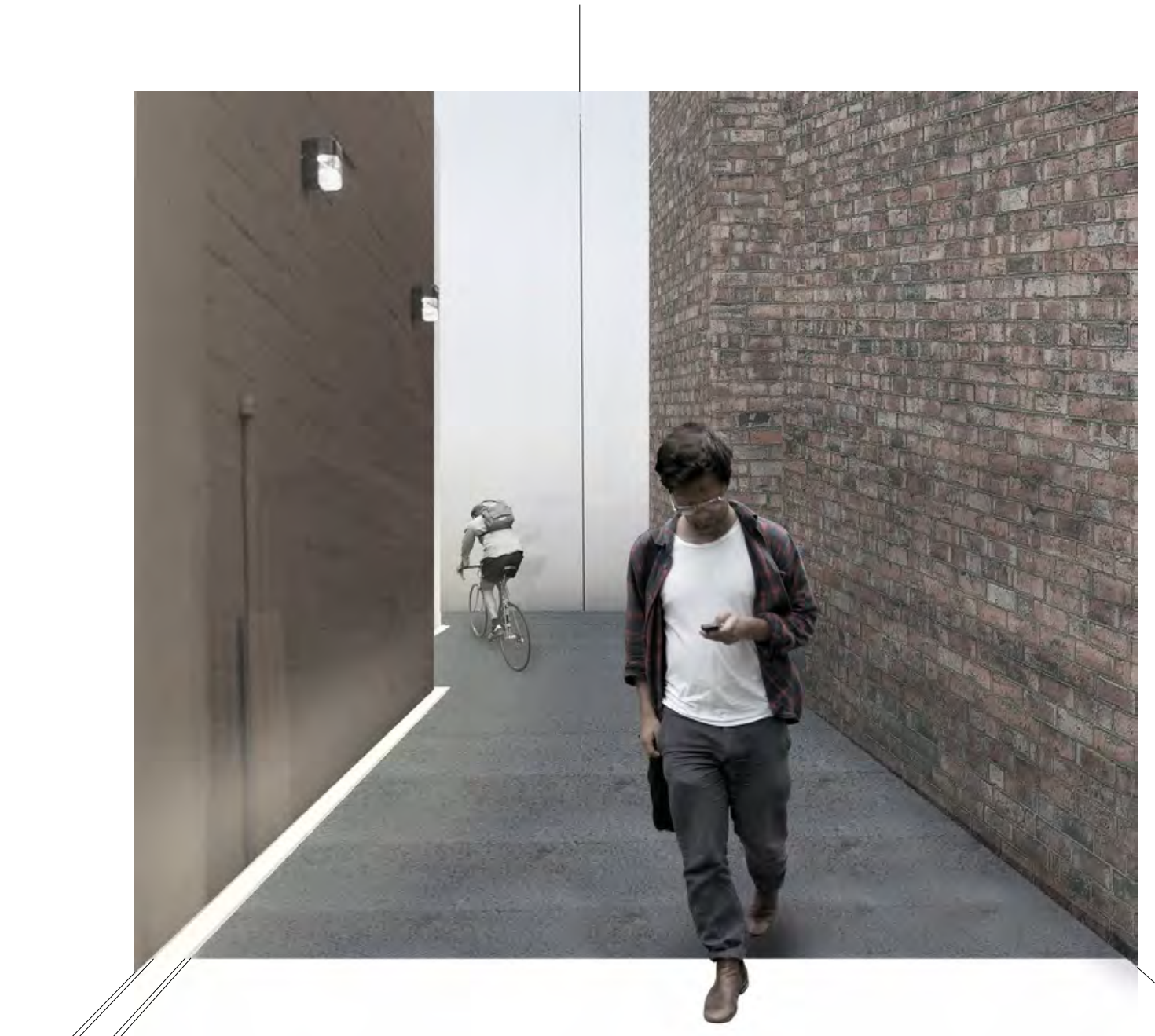

49. Looking North through alleyway to Richmond Street West. 

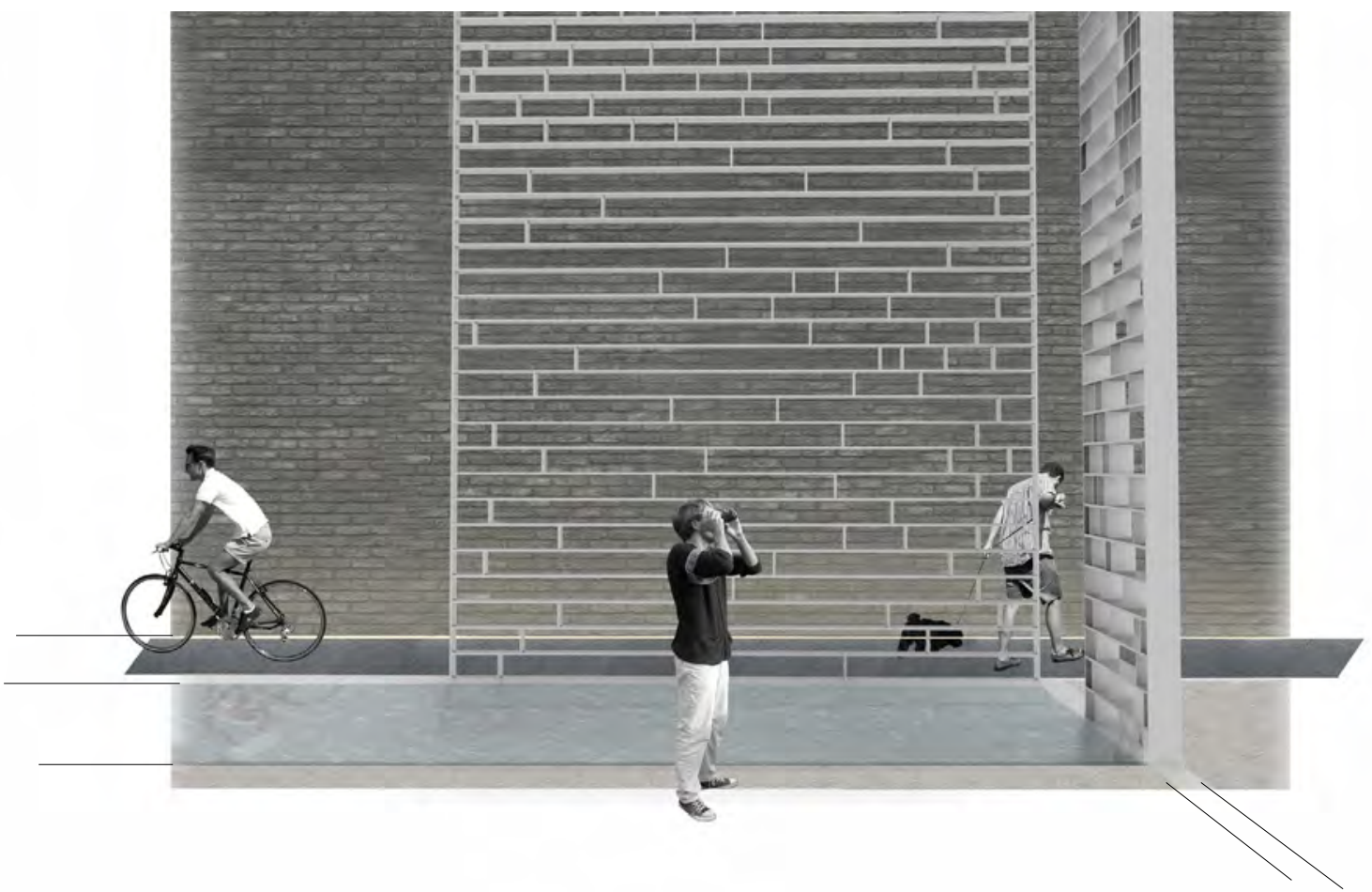

50. Looking East through site. 


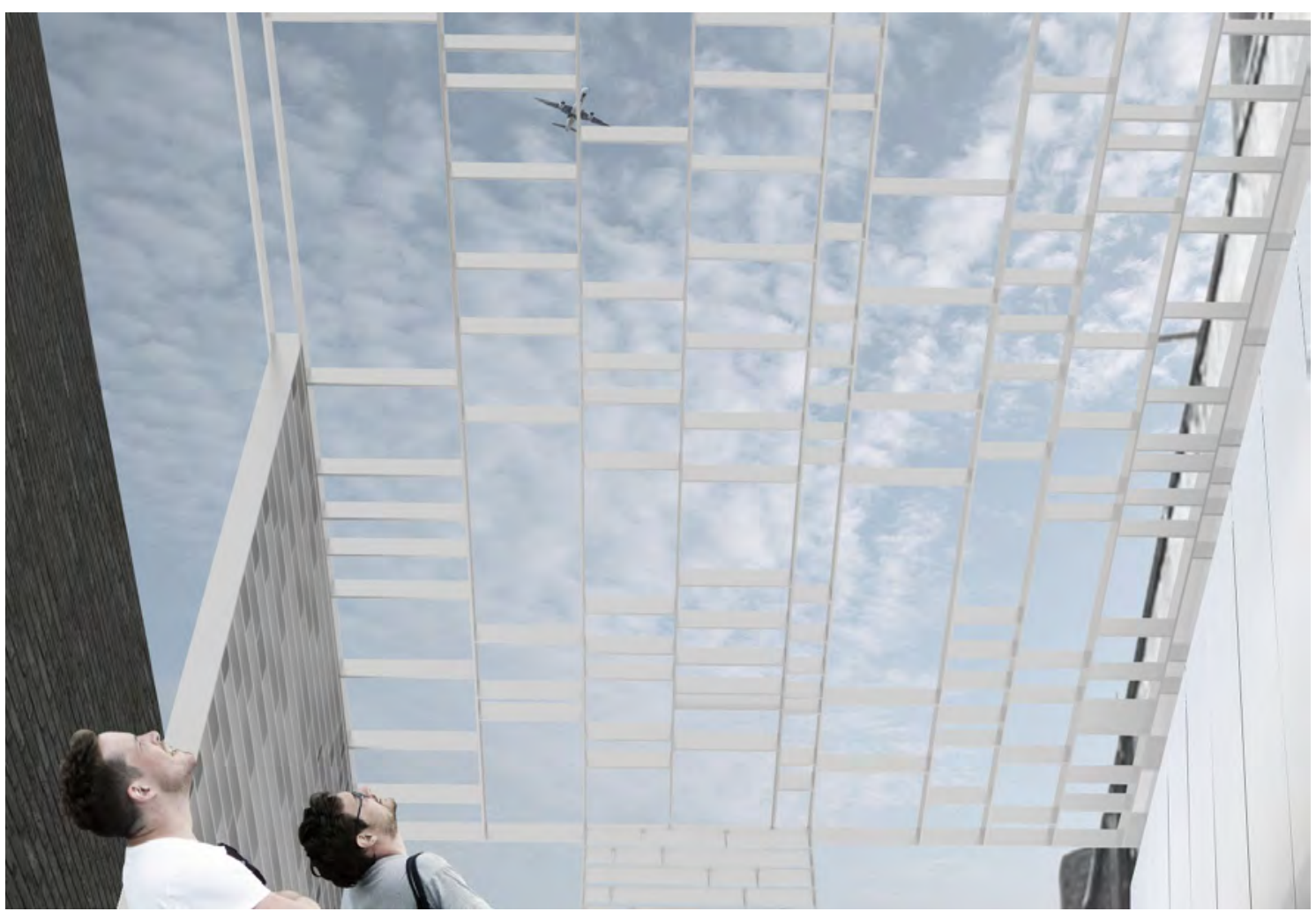

51. Looking up. 

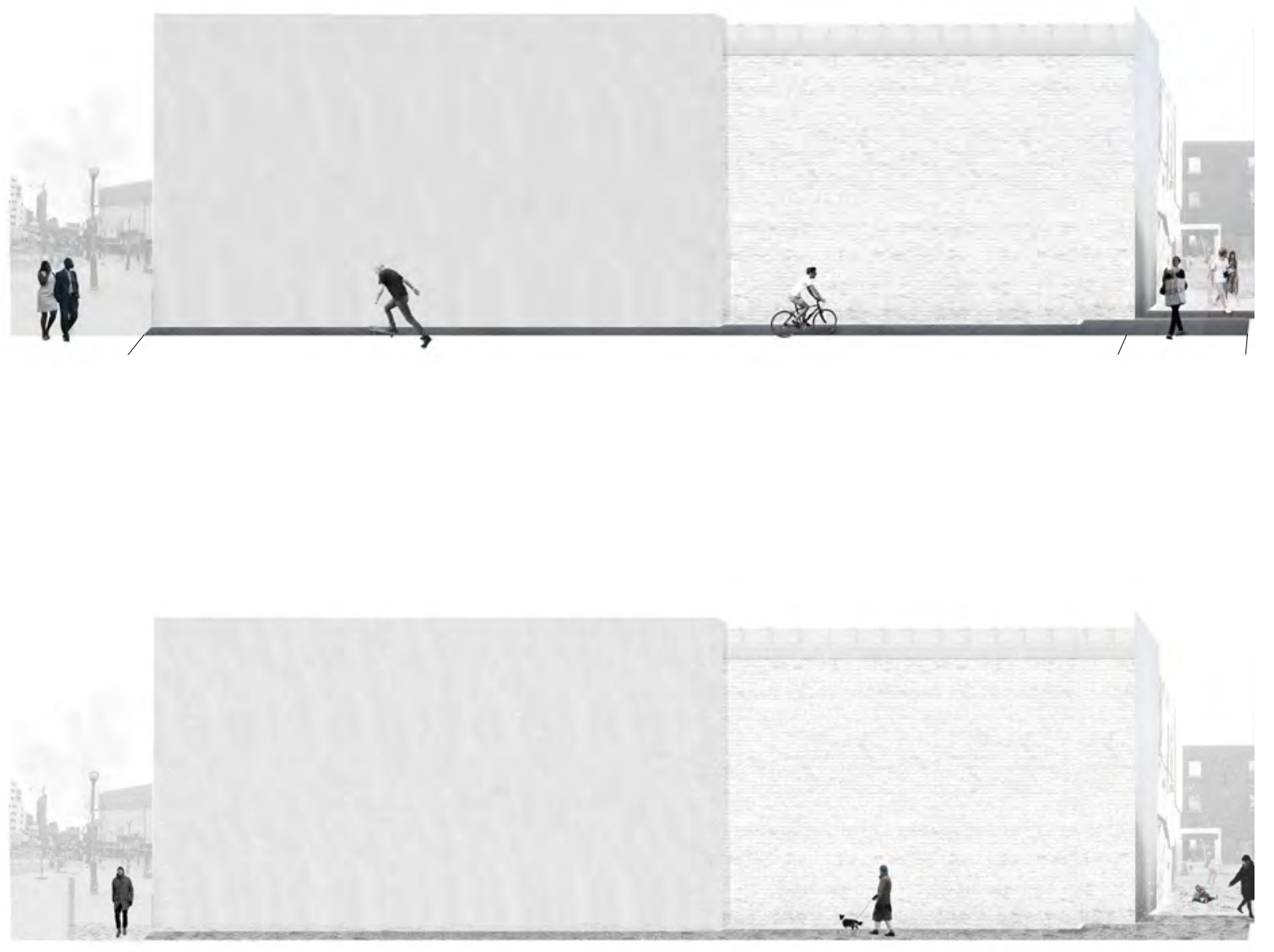


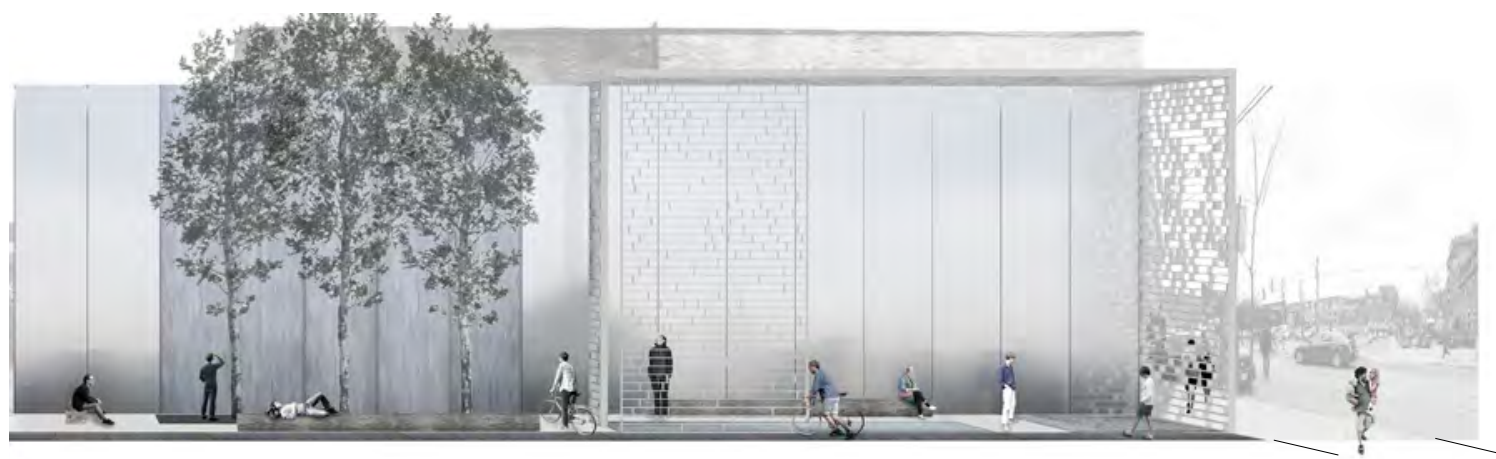

52. Sectional view looking West: summer.

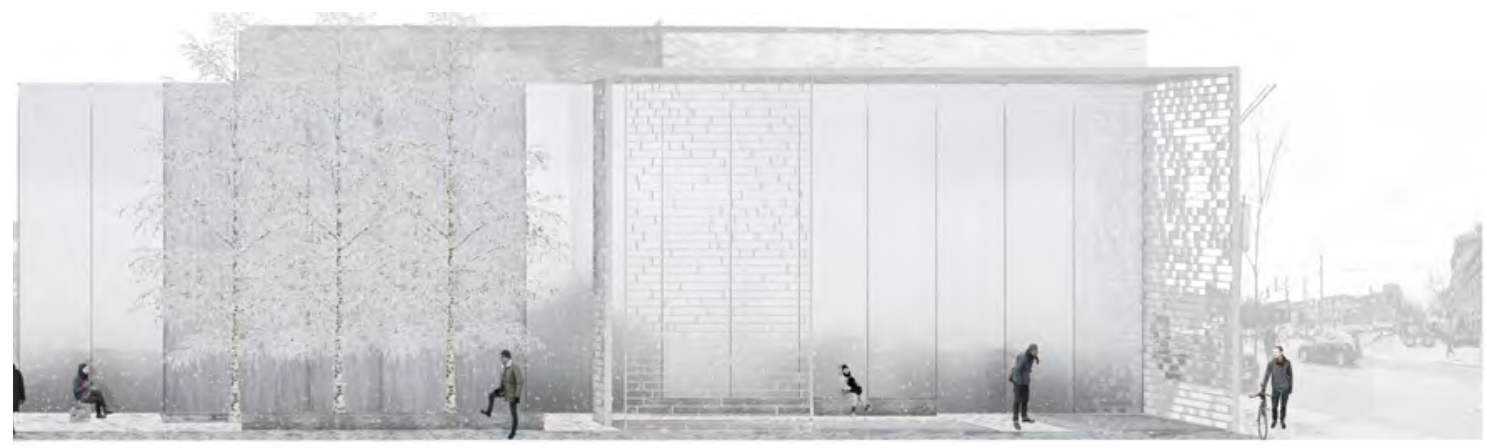

53. Sectional view looking West: winter. 


\section{daylight}

Since the site is bounded on three sides by walls of existing buildings, the amount of daylight reaching the site was an important consideration. Here, for both the summer and winter solstice, are light conditions on the site throughout the day.

As the sun sets, the site illuminates with soft light washed upon the east wall of the neighboring building as well upon the reflecting surfaces of aluminum along the west and south parts of the site.

\section{summer}

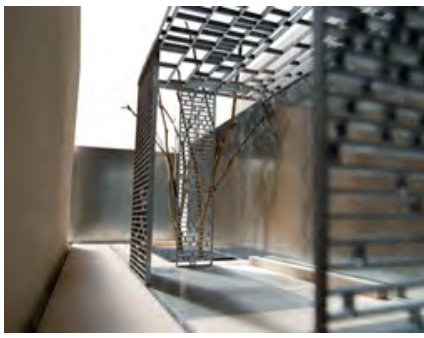

morning

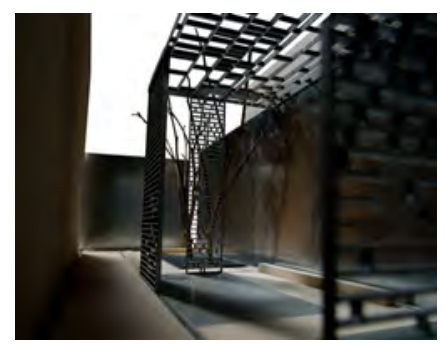

morning 


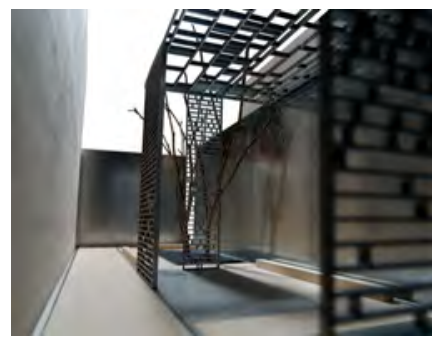

afternoon

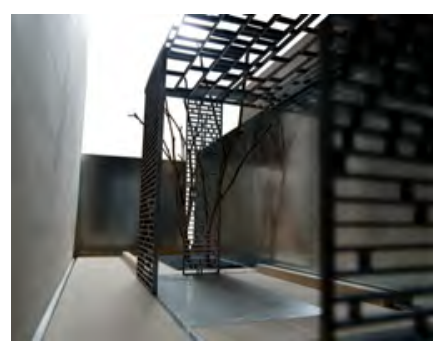

afternoon

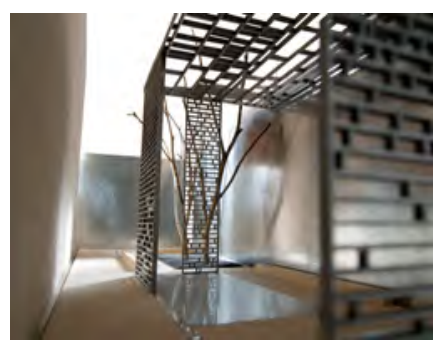

evening

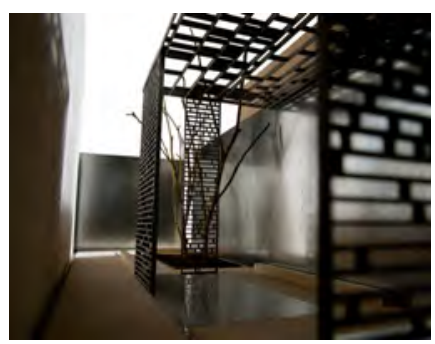

evening

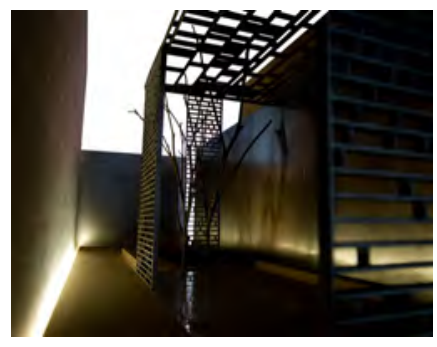

night

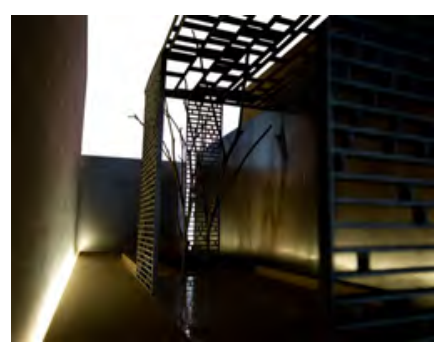

night

54. Daylight study with model. 


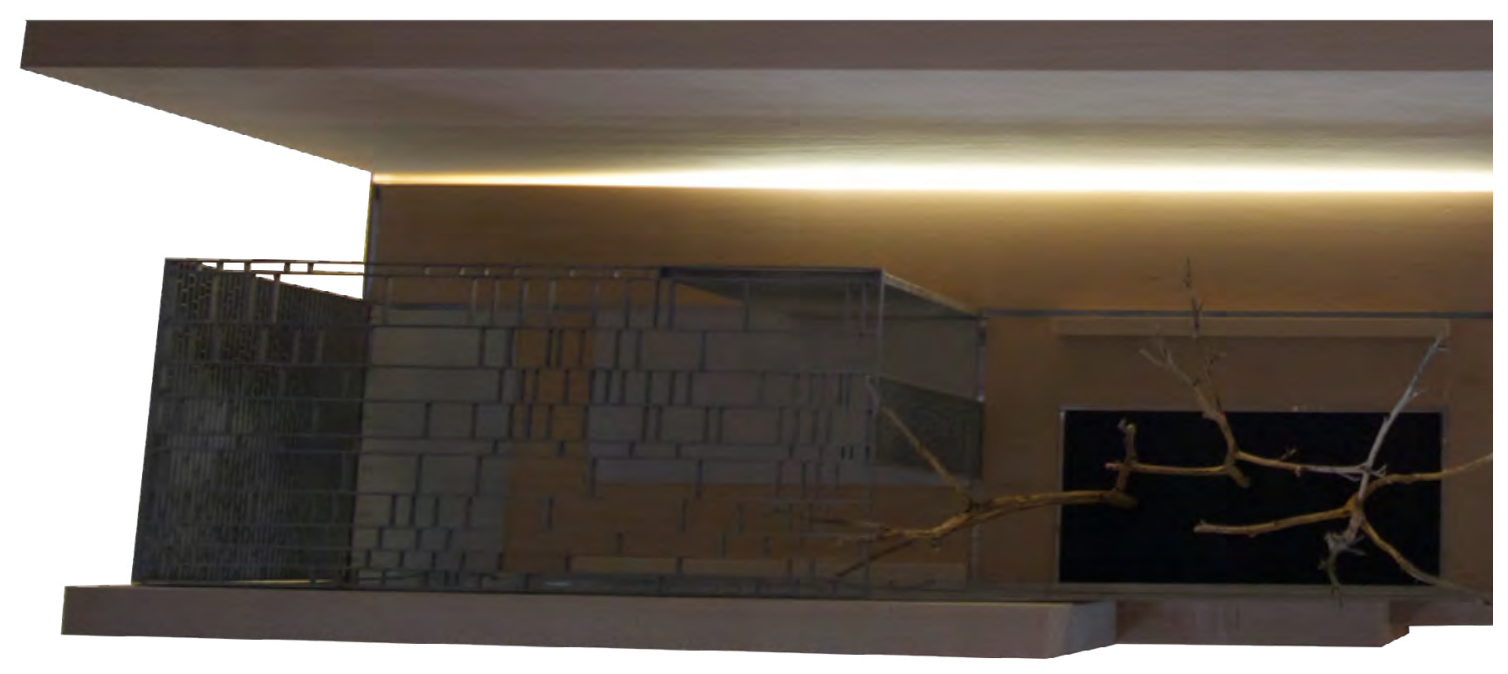




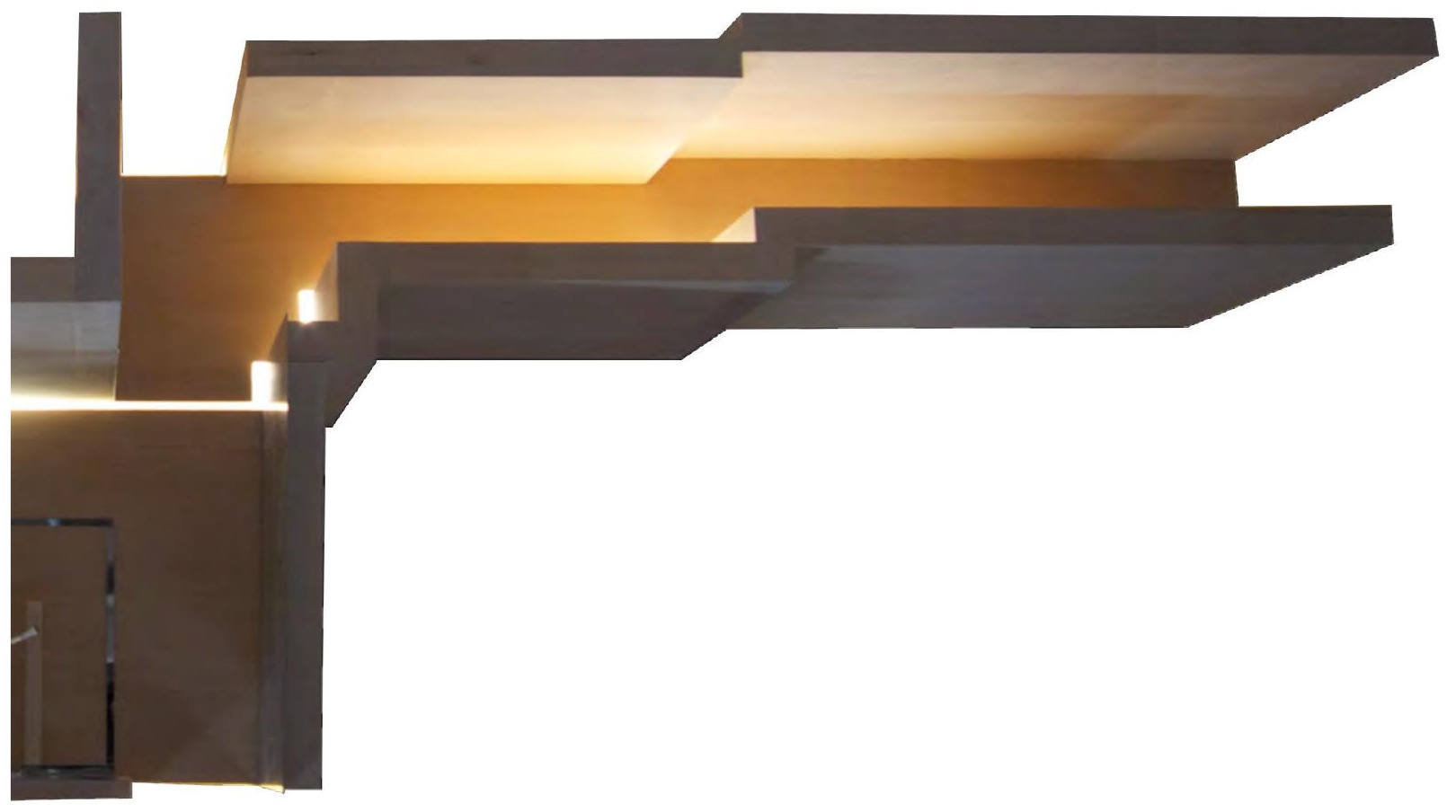

55. 1:50 scale model of site and intervention. 



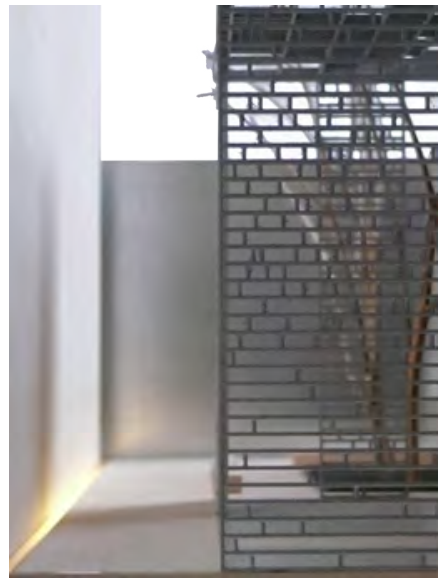

Looking South through lattice.

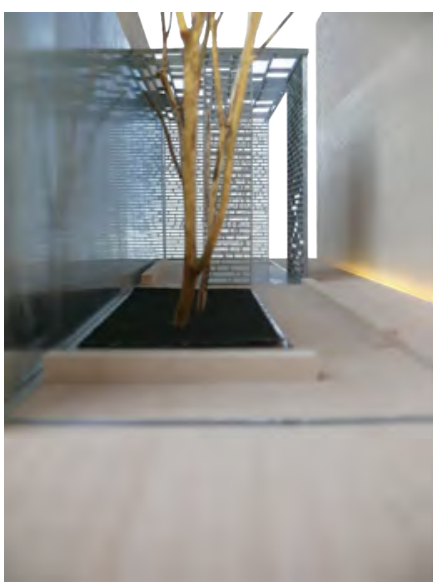

Looking North.

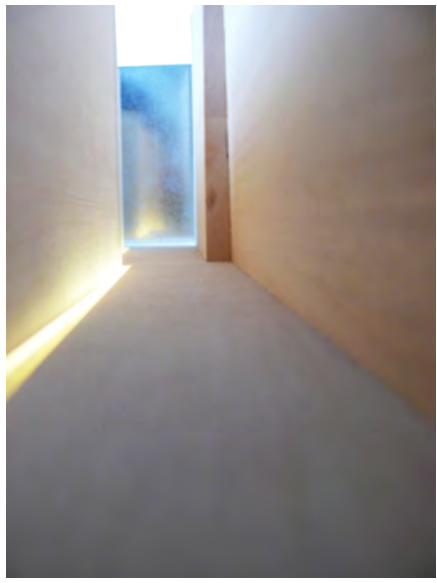

Looking North through alley.

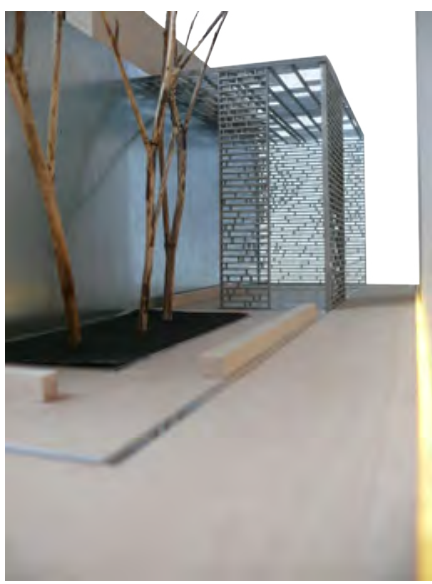

Looking Northwest.

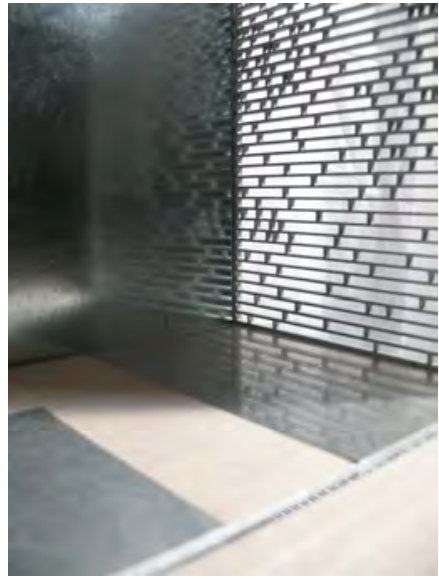

Quality of reflectivity.

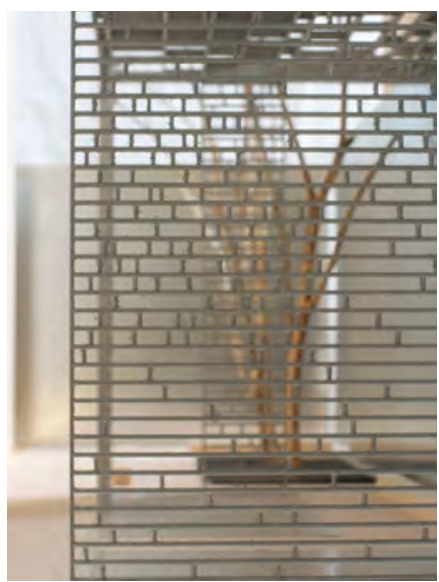

Effect of lattice pattern.

57. 1:50 scale model - views through the site. 


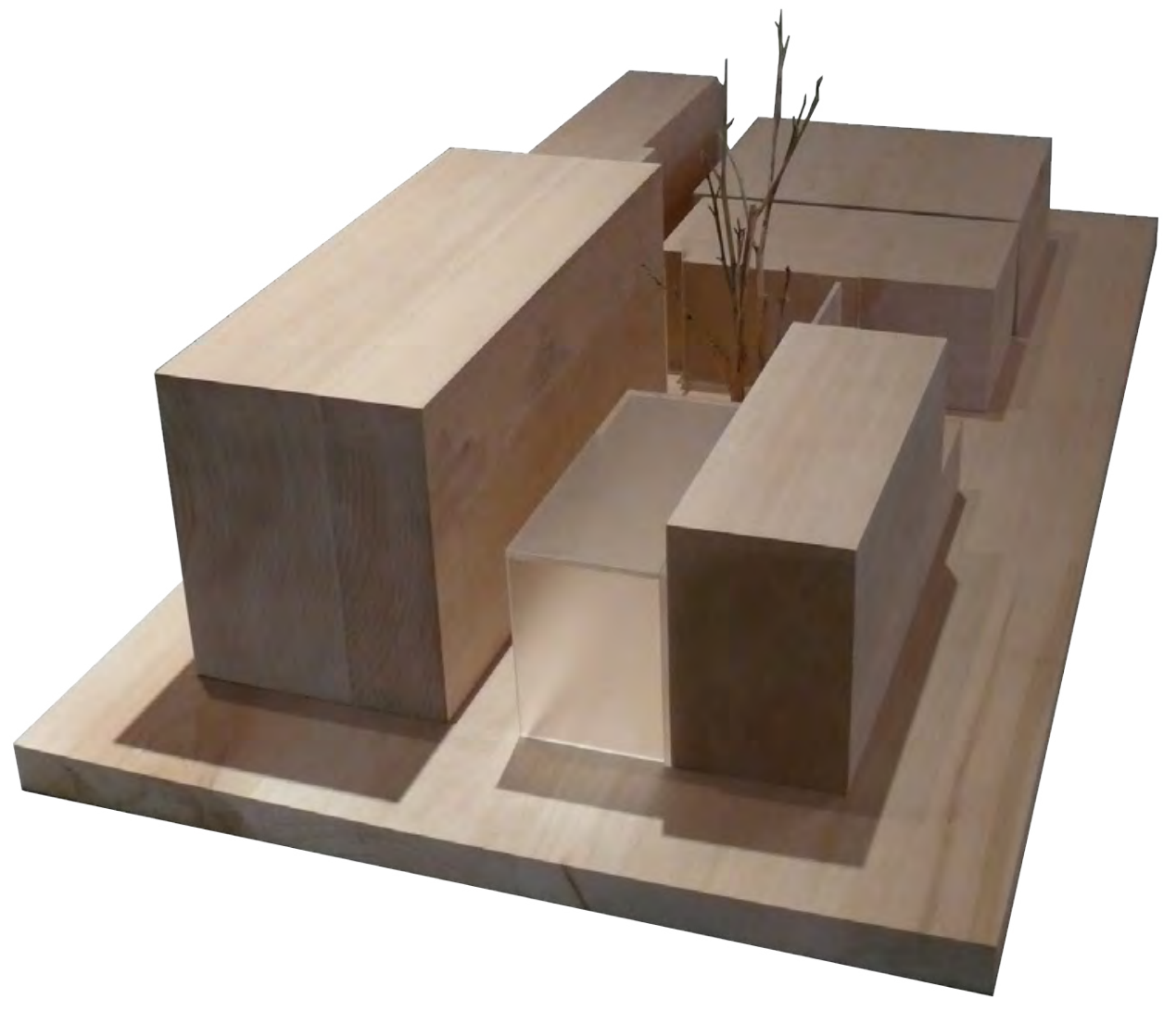

58. 1:100 scale massing model. 


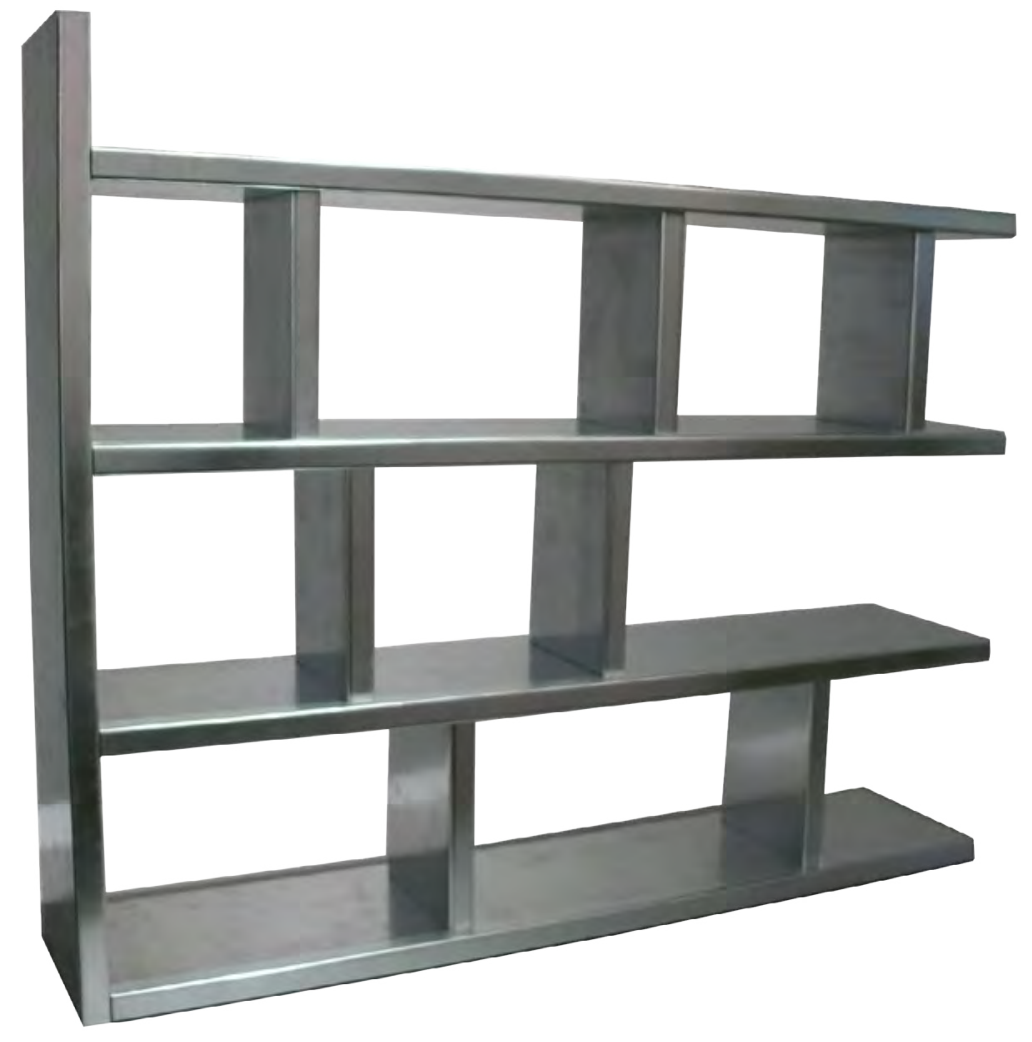

59. 1:1 scale model - detail of lattice pattern. 

conclusions 

The real conclusion here is not to completely dissolve architecture into absolutely nothing (to nihilism at its most extreme), but rather to attempt to dissolve architecture as a method of making it more meaningful. To use the idea of nothingness as a device to attempt to remove the objectlike nature of architecture (or to distill it as much as possible) can bring architecture into a new relationship with its surroundings - be that a landscape, an urban context, or with humans themselves. To remove the objectness of architecture does not necessarily mean objectless, it is rather a different understanding of the object altogether. As the avantgarde firm Superstudio once claimed, "By the destruction of objects, we mean the destruction of their attributes of 'status' and the connotations imposed by those in power, so that we live with objects (reduced to the condition of neutral and disposable elements) and not for objects" (Superstudio, 2007, p. 198).

Nothingness is a technique to produce architecture in a thoughtful and meaningful manner rather than produce the architectural garbage, the unconscious architecture, the visible entropy that Kuntsler and others continually refer to. The idea is that architecture becomes almost nothing - not in a statement of anti-architecture, not on a nihilistic basis, but rather as a kind of disappearance, an informal silence, a way to state that architecture should be meaningful and should have a stronger 
relationship to the context within which it sits. This is, essentially, a kind of rejection of the current culture of architecture as it currently stands. It is a refusal to add any more banal objects to a world already cluttered with them. Instead, this is an architecture of disappearance, of nothing-ness, of Heidegger's angst and of Kuma's anti-object - this is an architecture of meaning.

The nothingness shown here is really the device that distills an idea down to its barest form as a method to show what's most important, substantial or meaningful through something that can at first seem completely valueless (an empty room for example). As seen through several installations, pieces of art, as well as many examples of architecture it is an attempt to remove the object-ness from an idea, like Klein's 'immaterial pictorial sensibility' - which may not necessarily mean to erase but just to distill, to edit a relationship between those who perceive the exhibit and those who have created the perception - to communicate an idea in a powerful and impactful manner. If architects (and many others involved in the realm of design) were to consider this idea of nothingness we would be making work that is in light of a new perspective. It is an architectural angst where the outcome is design that is stripped of the banal, of the surface meanings and, due to the heightened understanding of its creators, it is work that becomes thoughtful and enlightened. This is not necessarily a new avant-garde but instead it is an architectural attempt at purity. It is an architecture 
of removal - not literal or physical removal but removed from the banal, from the fragmented and brought back into the world with meaning. This is an architecture that should not necessarily have to be explained with words, but rather understood as something that is felt, that is integral; it is apparent and inseparable. This architectural nothingness is not nothing - it is the pause in the chaotic life of consumption, the still point in a turning world, and the fearless leap into the void. 



\section{bibliography}

Allen, S. (1999) Infrastructural Urbanism. In S. Allen, Points and Lines: Diagrams and Projects for the City (pp. 46-57). New York: Princeton Architectural Press.

Badiou, A. (2001). Does Man Exist? In A. Badiou (Ed.), Ethics: An Essay on the Understanding of Evil (pp. 4-17). London: Verso.

Baird, G. (1996). "Looking for "The Public" in Mies van der Rohe's Concept for the Toronto-Dominion Centre." In D. Mertins (Ed.) The Presence of Mies. (pp.159-177). New York: Princeton Architectural Press.

Baudrillard, J. (1993). "Paroxysm: The Perfect Crime." In Study for the Secret Meetings, June 9-11, 1993 at the Venice Biennale. AFAA (Association Française d'Action Artistique) Paris: AFAA.

Baudrillard, J. (2002). Singular Objects of Architecture. Minneapolis: University of Minnesota Press.

Bogost, I. (2012). Alien Phenomenology or What it's Like to be a Thing. Minneapolis, University of Minnesota Press.

Bonardel, F. (2009). "The Path of Emptiness." In M. Copeland (Ed.) Voids: A Retrospective. (pp. 175-186). Zurich: JRP-Ringier.

Bose, S. (3 August 2011). "Architecture as Air: Chateau La Coste." domus.

$<$ http://www. domusweb.it/en/architecture/architecture-as-air-chateau-lacoste-> 
Comay, R. (1996). "Almost Nothing: Heidegger and Mies." In D. Mertins (Ed.), The Presence of Mies. (pp. 179-189). New York, NY: Princeton Architectural Press.

Critchley, S. (6 July 2009). "Being and Time, Part 5: Anxiety" The Guardian.

< http://www.guardian.co.uk/commentisfree/belief/2009/jul/06/ heidegger-philosophy-being >

Dallmayr, F. (1992). "Nothingness and 'Suuyataa: A Comparison of Heidegger and Nishitani." Philosophy East and West. (42)1. (37-48).

De Bievre, G. (2009). "A Full Void." In M. Copeland (Ed.) Voids: A Retrospective. (pp. 277-281). Zurich: JRP-Ringier.

Diller Scofidio + Renfro (2012). Blur Building. < http://www.dsrny.com>

Dorell.Ghotmeh.Tane. (2011). Toshiba milano salone / "luce tempo luogo". <http://www.dgtarchitects.com/project/detail/it05/en>

Eco, U. (1990). Travels in Hyperreality. New York: Mariner Books.

Eliot, T.S. (2003) "Four Quartets." In D. Damrosch (Ed.) The Longman Anthology of British Literature (2 ed., Vol. 2C, Pp. 2370-2374). New York: Longman.

Etherington, R. (13 July 2009). "Serpentine Gallery Pavilion by SANAA" dezeen.< http://www.dezeen.com/2009/07/13/serpentine-galleypavilion-by-sanaa-3/> 
Frampton, K. (1982). "The Status of Man and the Status of his Objects: A Reading of The Human Condition, " Modern Architecture and the Critical Present (special issue of Architectural Design). No.7/8 (p.6-19).

Frampton, K. (1983). "Towards a Critical Regionalism: Six Points for an Architecture of Resistance." In H. Foster (Ed). The Anti-Aesthetic: Essays on Post-Modern Culture. (pp. 16-30). Port Townsend, WA: Bay Press.

Gijs Van Vaerenbergh (2011). Reading between the lines. Retrieved from http://gijsvanvaerenbergh.com/z-out/

Illich, I. (1977). Disabling Professions. London: M. Boyers.

Hays, K.M. (1996). "Odysseus and the Oarsmen, or, Mies's Abstraction Once Again." In D. Mertins (Ed.) The Presence of Mies. (pp. 235-247). New York: Princeton Architectural Press.

Hays, K. M. (2010). Architecture's Desire: Reading the Late AvantGarde. Cambridge, MA. MIT Press.

Heidegger, M. (1996). Being and Time. J. Stambaugh (trans.) Albany, NY: State University of New York Press. Originally published 1953.

Holt, J. (1994). "Nothing Ventured: A Bold Leap into the Ontological World". Harper's Magazine. vol.289 (1734). November 1994, p. $74-$ 83,86 .

Huxtable, A.L. (1997). The Unreal America: Architecture and Illusion. (New York: The New Press). 
Kieren, S. and J. Timberlake. (2007). Future Worlds: Urgent Reflections on the Design of Practice.< http://kierantimberlake.com/research/future worlds_1.html\#>

Kuntsler J. H. (2001). The City in Mind: Notes on the Urban Condition. New York: The Free Press.

Krauss, R. (1996). "The Grid, The /Cloud/, and the Detail." In D. Mertins (Ed.) The Presence of Mies. (pp. 133-147). New York: Princeton Architectural Press.

Krauss, R. (1979). "Sculpture in the Expanded Field." October. 8. (30-44).

Kraut, R. (2009). "The Examined Life." In S. Ahbel-Rappe \& R. Kamtekar (Eds.), A Companion to Socrates. Oxford, UK: Wiley-Blackwell.

Kuma, K. (2008). Anti-Object: The Dissolution and Disintegration of Architecture. London: AA Publications.

Kunstler, J. H. (2004). James Howard Kunstler: The Ghastly Tragedy of the Suburbs. TED Talk. Lecture conducted Monterey, California. $<$ http://www.ted.com/talks/james_howard_kunstler_dissects_suburbia. $\mathrm{html}>$

Lang, P. \& Menking, W. (2003). "Only Architecture will be our Lives." In Superstudio: Life Without Objects (pp 20-21). Milan: Skira.

Lippard, L. (2009). "Making Nothing out of Something." In M. Copeland (Ed.) Voids: A Retrospective. (pp. 228-230). Zurich: JRP-Ringier. 
Miessen, M. (2011). The Nightmare of Participation . USC School of Architecture Lecture Series. Lecture conducted from USC School of Architecture. <http://www.youtube.com/watch?v=VHKaQlasSfY>

Miessen, M. (Ed.). (2010). The Nightmare of Participation: Crossbench Practice as a Mode of Criticality. New York: Sternberg.

Miessen, M. \& Basar, S. (Eds.). (2006). Did Someone Say Participate? An Atlas of Spatial Practice. Cambridge, MA: MIT Press.

Merriam-Webster's Collegiate Dictionary (11 $11^{\text {th }}$ ed.). (2004). Springfield, MA: Merriam-Webster.

Myers, T. (2004). Lebbeus Woods: Experimental Architecture.

Pittsburgh: Carnegie Museum of Art, the Heinz Architectural Center.

Nanarama, M. S. (1993). The Seven Stages of Purification \& The Insight Knowledges. Kandy, Sri Lanka: Buddhist Publication Society.

Natalini, A. (2005). "Superstudio In Middelburg: Avant-Garde and Resistance." In V. Byvanck (ed). Superstudio: The Middelburg Lectures. Middelberg: De Vleeshal and Zeeuws Museum.

Ouroussoff, Nicolai. "An Architect Unshackled by Limits of the Real World." New York Times 24/08/2008.

Oxford English Dictionary - Compact Edition (15 th ed.) (1971). Glasgow: Oxford University Press. 
"Reading Between the Lines / Gijs Van Vaerenbergh" (27 Nov 2012). ArchDaily. <http://www.archdaily.com/298693>

Riout, D. (2009). "Exasperations 1958." In M. Copeland (Ed.) Voids: A Retrospective. (pp. 37-46). Zurich: JRP-Ringier.

Saunders, W.S. (2005). Commodification and Spectacle in Architecture: A Harvard Design Magazine Reader. Minneapolis: University of Minnesota Press.

Simmel, G. (2002). "The Metropolis and Mental Life." (1903). In G. Bridge \& S. Watson (Eds.), The Blackwell City Reader. Oxford and Malden, MA: Wiley Blackwell.

Simo, R. (2 September 2010). "Transsolar + Tetsuo Kondo Architects: Cloudscapes, at Venice Biennale." Designboom. $<$ http://www. designboom.com/architecture/transsolar-tetsuo-kondoarchitects-cloudscapes-at-venice-biennale/>

Speaks, M. (2006). "Intelligence After Theory." Perspecta 38: 103-107.

Sudjic, D. (2008). The Language of Things. London: Penguin Group.

Superstudio (2007). "Microevent/Microenvironment." In W. W. Braham \& J. A. Hale (Eds.) Rethinking Technology (pp.195-202). New York: Routledge.

Tafuri, M. (1976). Architecture and Utopia. Cambridge, MA: MIT Press.

Till, J. (2009). Architecture Depends. Cambridge, MA: MIT Press. 
Wainwright, O. \& E. Smith. (5 December 2012). "Louvre-Lens Art Gallery." Video. The Guardian.

<http://www.guardian.co.uk/artanddesign/video/2012/dec/05/louvrelens-art-gallery-video>

Wainwright. O. (February 18, 2013) "Baubles on Pedestals." Fulcrum. 67. (1-2).

Watts, A. (2004). The State of Nothing. [Recorded by Alan Watts]. On Out of Your Mind [Audiobook/CD]. Colorado: Sounds True Multimedia Publishing.

Watts, A. (1994). "Mahayana Buddhism." In A. Watts Eastern Wisdom, Modern Life: Collected Talks 1960-1969. (pp.13-21). San Francisco, CA: New World Library.

Watts, A. (1994). "Zen Bones." In A. Watts Eastern Wisdom, Modern Life: Collected Talks 1960-1969. (pp.151-165). San Francisco, CA: New World Library.

Watts, A. (1994). "What is Reality." In A. Watts Eastern Wisdom, Modern Life: Collected Talks 1960-1969. (pp.227-243). San Francisco, CA: New World Library.

Watts, A. (1974) Nothingness. Berkeley, California: Celestial Arts. 
